Seasonal Climatic Variations Influence Efficacy of Predatory Mites used for Control of Western Flower Thrips in Greenhouse Ornamental Crops

$$
\text { by }
$$

Laura Christine Hewitt

\author{
A Thesis \\ presented to \\ The University of Guelph
In partial fulfillment of requirements
for the degree of
Master of Science
in
Environmental Biology

Guelph, Ontario, Canada

(C) Laura Christine Hewitt, January 2013 


\section{ABSTRACT \\ THE IMPACT OF SEASONAL CLIMATIC VARIATIONS ON EFFICACY OF PREDATORY MITES USED FOR CONTROL OF WESTERN FLOWER THRIPS IN GREENHOUSE ORNAMENTAL CROPS}

Laura Christine Hewitt

University of Guelph, 2013
Advisors:

Dr. C.D. Scott-Dupree

Dr. J.L. Shipp

This research investigated seasonal climate changes within greenhouses and the impacts they have on efficacy of the predatory mites Amblyseius swirskii and Neoseiulus cucumeris. Controlled environment chamber, greenhouse small-cage, and commercial greenhouse trials were conducted to determine which biological control agent is more efficacious for control of the pest western flower thrips (WFT), (Frankliniella occidentalis) on ornamental crops.

When observed under laboratory conditions, predation and oviposition were increased at higher temperatures. Photoperiod and light intensity also have an impact on predatory mites. Predation rates for both mite species were greater when subjected to short day light conditions ( $8 \mathrm{~h}$ light, $11 \mathrm{~W} / \mathrm{m}^{2}$ ). Climates typical of summer (higher temperature and light intensity, long day length) were most favourable in terms of predation and oviposition for $A$. swirskii. Neoseiulus cucumeris laid more eggs under short day as opposed to long day settings.

In summer and winter greenhouse small cage trials, the performance of $N$. cucumeris and $A$. swirskii significantly reduced WFT numbers on potted chrysanthemum plants. However, in summer, A. swirskii provided significantly better thrips control than $N$. cucumeris. The number of adult mites recovered from plants was similar for both mite treatments in winter, while $A$. swirskii were present in higher numbers throughout the summer trials. Results from leaf damage assessments indicate that $A$. swirskii is more effective for control of heavy WFT feeding damage in both summer and winter. Results from commercial greenhouse trials yielded similar trends as those found in the summer and winter small cage trials. 


\section{ACKNOWLEDGEMENTS}

I would first like to thank my advisory committee Drs. Cynthia Scott-Dupree and Les Shipp. Cynthia, your wisdom and words of encouragement have provided a solid base from which I have shaped myself as a scientist. Les, your conversations expanded my entomological knowledge and forced me to reflect and form opinions. Thank-you to my Advisory Committee member Dr. Rose Buitenhuis for your enthusiasm and support in this project. You were always there to answer questions related statistical and technical issues.

I am very grateful to all of the funding agencies that supported this project. Thank-you to Flowers Canada (Ontario) and the Agriculture and Agri-Food Canada Research Affiliate Program.

A big thank-you to all of my lab members and friends at the Agriculture and Agri-Food Canada (AAFC) Greenhouse and Processing Crop Research Centre in Harrow; Yun, Dana, Eric, Nathan, Nic, Dave, and Jon- the mite tamer. You all guided me in the learning journey as I went through the trial and error process.

I would also like to thank my lab mates and friends at the University of Guelph: Angela, Meghann, Kruti, Andrew F., Andrew M., and Braden. Andrew, your plant washing skills are unparalleled, and I would not have made it through all of my plant samples without you. Angela, your confidence and wisdom are inspiring; I will miss our frequent laughs and rants. To my office mates Kruti and 
Meghann, I'm very grateful to have shared the master's experience with two of the best friends anyone could ask for.

Thank-you to my parents and family for your continued support throughout my years spent doing that environmental bug stuff. You are the best support crew anyone could ask for. To my boyfriend Tim, your quiet patience, reassurance and peanut butter cookies have done more for me in the past few months than you know. Here's to the next big adventure. 


\section{TABLE OF CONTENTS}

ACKNOWLEDGEMENTS .iii

TABLE OF CONTENTS ..$v$

LIST OF ACRONYMS vii

LIST OF FIGURES viii

LIST OF TABLES $x$

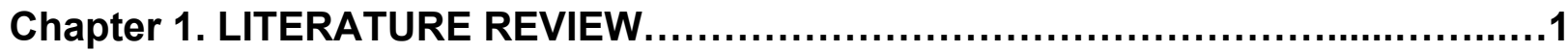

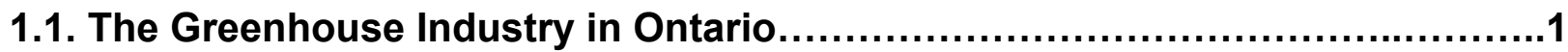

1.1.1. Ontario Greenhouse Sectors.............................................

1.1.2. Location and Distribution......................................................

1.1.3. Economic Impact..............................................................

1.2. Insect Pests of Ornamental Greenhouse Crops......................................

1.2.1. Damage Caused by Pests.................................................

1.2.2. Integrated Pest Management for the Control of Western Flower

Thrips in Greenhouses............................................................ 6

1.2.3. Biological Control Agents for Western Flower Thrips Infestations............10

1.3. Influence of Climatic Parameters on Greenhouse Biological Control............15

1.3.1. Climatic Parameters ....................................................... 16

1.3.2. Seasonal Variation in Climatic Parameters................................19

1.3.3. Potential Impacts of Seasonal Variations..................................20

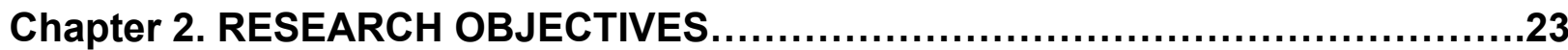

Chapter 3. PREDATION AND OVIPOSITIONAL RESPONSES OF PREDATORY

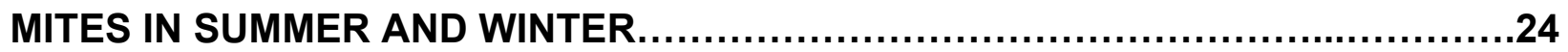

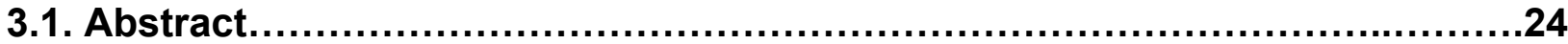

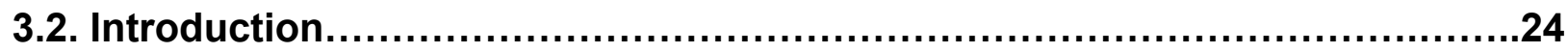

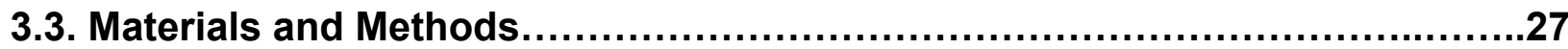

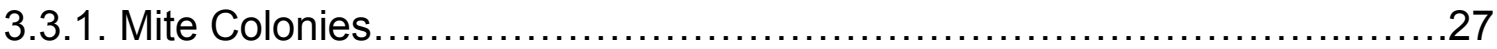

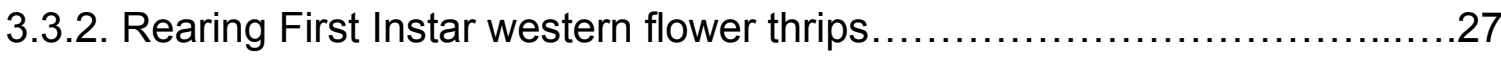

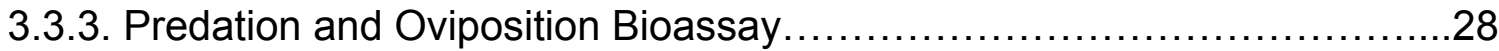

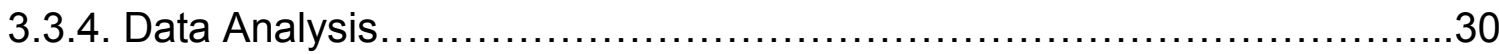

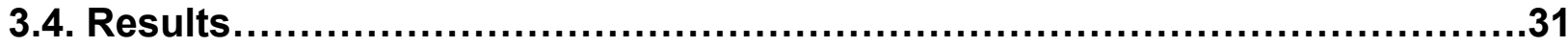

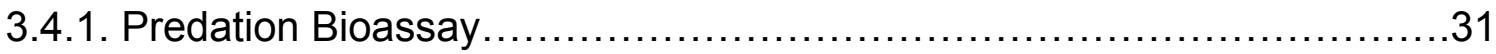

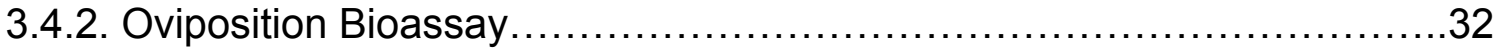




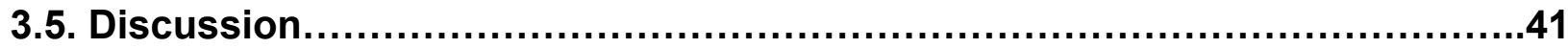

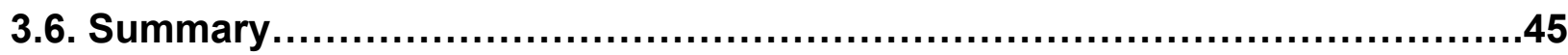

Chapter 4. ESTABLISHMENT OF PREDATORY MITES ON GREENHOUSE CHRYSANTHEMUM AND CONTROL OF WESTERN FLOWER THRIPS

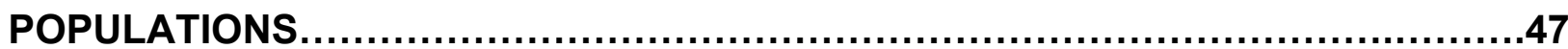

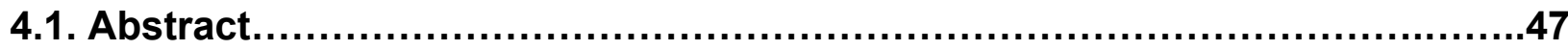

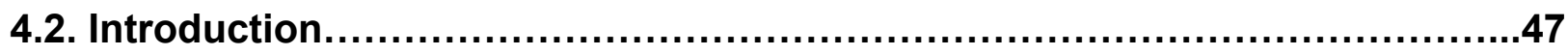

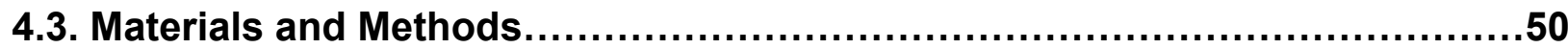

4.3.1. Greenhouse Small-cage Bioassay.....................................50

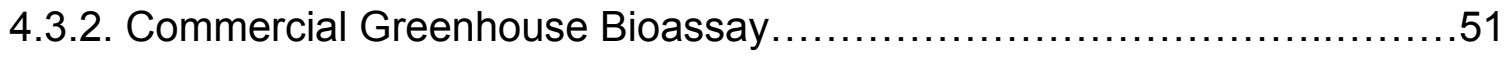

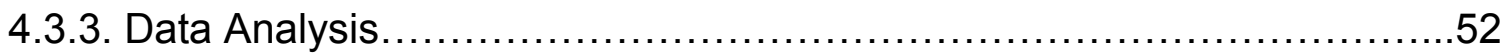

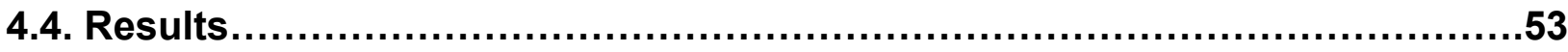

4.4.1. Small Cage Greenhouse Trials: Summer..............................53

4.4.2. Small Cage Greenhouse Trials: Winter...................................57

4.4.3. Commercial Greenhouse Trials: Summer.................................61

4.4.4. Commercial Greenhouse Trials: Winter...................................63

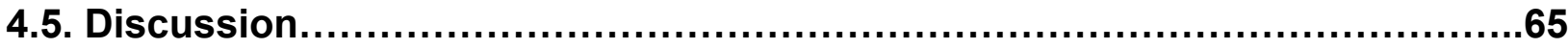

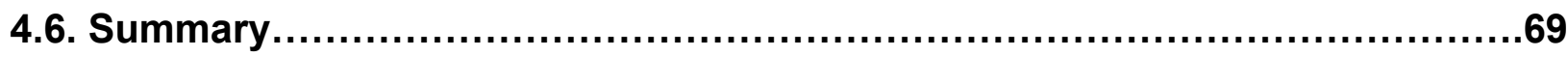

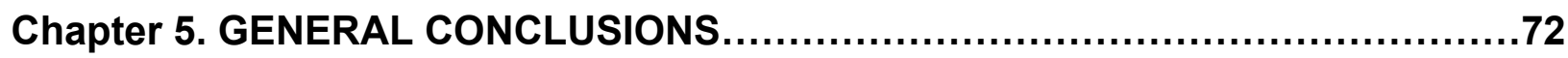

5.1. IPM in Ontario Greenhouse Floriculture .......................................

5.2. Recommendations for Summer....................................................

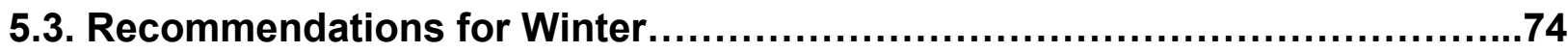

5.4. Future Considerations.............................................................. 74

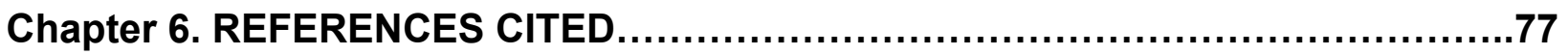
APPENDIX I

ANOVA Tables Associated with Chapter 4 Statistical

Analysis 


\section{LIST OF ACRONYMS}

ABA

AAFC

BCA

CRS

EPN

GPCRC

IPM

LD

$\mathrm{RH}$

ROE

RRGE

SC

$\mathrm{SD}$

SN

WAT

WFT

WN

WW
Acarine biological agents

Agriculture and Agri-Food Canada

Biological control agent

Controlled slow-release system

Entomopathogenic nematode

Greenhouse and Processing Crops Research Centre

Integrated pest management

Long day length (16h light, $83 \mathrm{~W} / \mathrm{m}^{2}$ )

Relative humidity

Rate of encounter

Relative rate of gut emptying

Summer - Cool

Short Day length (8h light, $11 \mathrm{~W} / \mathrm{m}^{2}$ )

Summer - Normal

Week(s) after treatment

Western flower thrips

Winter - Normal

Winter - Warm 


\section{LIST OF FIGURES}

Figure

Page

$\begin{array}{llr}1.1 & \text { An adult western flower thrips } & 5\end{array}$

1.2 An adult Neoseiulus cucumeris $\quad 14$

1.3 Adult Amblyseius swirskii feeding on a first instar western flower thrips 15

3.1 Predation and oviposition experimental arena 29

3.2 Experimental setup for predation and oviposition assessments 30

3.3 Mean number of western flower thrips (WFT) consumed within $24 \mathrm{~h}$ by Neoseiulus cucumeris and Amblyseius swirskii in controlled environment chamber bioassays at short day or long day light levels

3.4 Mean number of western flower thrips (WFT) consumed by Neoseiulus cucumeris and Amblyseius swirskii on Day 2 and Day 3 in controlled environment chamber bioassays at short day or long day light levels

3.5 Mean number of western flower thrips (WFT) consumed in $24 \mathrm{~h}$ by Neoseiulus cucumeris and Amblyseius swirskii in controlled environment chamber bioassays at $20^{\circ} \mathrm{C}$ and $24^{\circ} \mathrm{C}$

3.6 Mean number of western flower thrips (WFT) consumed by Neoseiulus cucumeris and Amblyseius swirskii on Day 2 and Day 3 in controlled environment chamber bioassays at $20^{\circ} \mathrm{C}$ and $24^{\circ} \mathrm{C}$

3.7 Mean oviposition by Neoseiulus cucumeris and Amblyseius swirskii in a controlled environment chamber bioassay over three days

3.8 Mean oviposition within $24 \mathrm{~h}$ by Neoseiulus cucumeris and Amblyseius swirskii in a controlled environment chamber bioassay under short day and long day light conditions

3.9 Mean oviposition by Neoseiulus cucumeris and Amblyseius swirskii on Day 2 and Day 3 in a controlled environment chamber bioassay under short day and long day light conditions

3.10 Mean oviposition in 24h by Neoseiulus cucumeris and Amblyseius swirskii at $24^{\circ} \mathrm{C}$ and $20^{\circ} \mathrm{C}$ in controlled environment chamber bioassays 
3.11 Mean oviposition on Day 2 and Day 3 by Neoseiulus cucumeris and Amblyseius swirskii at $20^{\circ} \mathrm{C}$ and $24^{\circ} \mathrm{C}$ in controlled environment chamber bioassays

4.1 Mean number of western flower thrips (WFT) on Neoseiulus cucumeris and Amblyseius swirskii treated chrysanthemum plants in greenhouse small cages in summer

4.2 Mean number of Neoseiulus cucumeris and Amblyseius swirskii on potted chrysanthemum plants in small greenhouse cages in summer

4.3 Mean number of leaves with heavy, light, or no visible feeding damage Over four weeks post-treatment during summer in a greenhouse

4.4 Week 4 mean number of leaves with heavy, light, or no visible feeding damage calculated as a percentage of the total sample (50 leaves total) in a greenhouse over four weeks during summer.

4.5 Mean number of adult western flower thrips (WFT) on Neoseiulus cucumeris and Amblyseius swirskii treated potted chrysanthemum plants on greenhouse small cages during winter

4.6 Mean number of Neoseiulus cucumeris and Amblyseius swirskii on potted chrysanthemum plants in small greenhouse cages during winter

4.7 Mean number of leaves with heavy, light, or no visible feeding damage over four weeks post-treatment during winter in a greenhouse

4.8 Week 4 mean number of leaves with heavy, light, or no visible feeding damage calculated as a percentage of the total sample (50 leaves total) in a greenhouse over four weeks during winter.

4.9 Mean number of western flower thrips (WFT) on no-mite control, Neoseiulus cucumeris and Amblyseius swirskii- treated potted chrysanthemums over six weeks in a greenhouse during summer

4.10 Mean number of Neoseiulus cucumeris and Amblyseius swirskii over six weeks on potted chrysanthemums in a greenhouse during summer

4.11 Mean number of western flower thrips (WFT) on no-mite control, Neoseiulus cucumeris and Amblyseius swirskii- treated potted chrysanthemums over six weeks in a greenhouse during winter

4.12 Mean number of Neoseiulus cucumeris and Amblyseius swirskii over six weeks on potted chrysanthemums in a greenhouse during winter 


\section{LIST OF TABLES}

Table

Page

1.1 Common predatory mites commercially available for mitigation of western flower thrips populations

3.1 Number of replications of each treatment during Day 1,2 and 3 of controlled environment chamber bioassays

3.2 Mean predation rate of first instar western flower thrips (WFT) by Neoseiulus cucumeris and Amblyseius swirskii in controlled environment chamber bioassays over three days

3.3 Mean oviposition rate of Neoseiulus cucumeris and Amblyseius swirskii feeding on western flower thrips (WFT) over three days 


\section{CHAPTER 1}

\section{LITERATURE REVIEW}

\subsection{The Greenhouse Industry in Ontario}

Despite being located in a temperate climate, the greenhouse industry in Ontario is an important sector of agricultural production, which supplies a vast array of products to national and international markets year-round. As a developing agricultural sector, the Ontario greenhouse industry underwent an incredible rate of growth from 1999 to 2007 that included an approx. 4 mill $\mathrm{m}^{2}$ increase in the land area covered by greenhouses (The Ontario Growers Association, 2009). This number has increased by approx. 1 mill $\mathrm{m}^{2}$ since 2007 to bring the total land area of greenhouses to $12.8 \mathrm{mill}^{2}$ in 2011 (Statistics Canada, 2011). Ontario is the largest exporter of greenhouse products such as vegetables (e.g., sweet pepper, cucumber, tomato) and floricultural products (e.g., cut flowers, potted plants, bedding plants and propagative material) in Canada (Statistics Canada, 2011). Canadian greenhouses are divided into two primary sectors: vegetable and floriculture production.

\subsubsection{Ontario Greenhouse Sectors}

Vegetable Production. In 2011, the farm gate value for greenhouse vegetable production totaled approx. $\$ 689$ mill in Ontario (Statistics Canada, 2011). Greenhouse vegetable production is mainly composed of tomatoes, peppers and cucumbers, with tomatoes accounting for the largest proportion of vegetable sales in Canada. In 2011, tomato production accounted for $45 \%$ of national greenhouse vegetable sales, and remains the most widely cultivated vegetable in greenhouse production systems (Agriculture and Agri-Food Canada, 2012). Farm gate values of greenhouse vegetable crops have shown an increase from 1999 to present, establishing their role in agriculture and their importance to Canadian consumers. A large market exists in North America, especially during the winter, for high quality, fresh vegetables. There is a growing consumer trend of seeking locally grown organic produce. In response to this trend, the greenhouse industry is constantly evolving by choosing to grow vegetable 
varieties that are more appealing to consumers with reduced use of pesticides that are often harmful to bumblebee pollinators.

Vegetable greenhouses tend to be large $\left(38,000 \mathrm{~m}^{2}\right.$ average) and highly mechanized (Ontario Greenhouse Vegetable Growers, 2012). All greenhouse vegetable producers in Ontario are required to pay a license fee and belong to the Ontario Greenhouse Vegetable Growers (OGVG) organization (The Ontario Growers Association, 2009), which represents the industry in lobbying and promotional efforts, and ensures that priority research is conducted on behalf of the greenhouse vegetable industry.

Floriculture and Ornamental Production. Ontario's greenhouse floricultural sector had a total farm gate value of $\$ 571$ mill in 2011 (Statistics Canada, 2011). Greenhouses devoted to producing floricultural products in Ontario have increased in number due to consumer demand, and have had yearly gross earnings increases over the past decade. Floricultural greenhouses tend to be small (3000 $\mathrm{m}^{2}$ average) familyowned and operated businesses which serve local and international markets (The Ontario Growers Association, 2009). Floricultural greenhouses are generally subdivided into three categories: 1) bedding/spring plants; 2) potted flowering plants; and 3) cut flowers (Brown \& Murphy, 2010). Heated greenhouses and freestanding hoop houses are used to grow products from several thousand plant genera (Brown \& Murphy, 2010). Ontario is the third largest North American greenhouse floricultural product producer, behind California and Florida (Brown \& Murphy, 2010). The Ontario agricultural sector, in combination with organizations such as Flowers Canada (Ontario) Inc. and the Ontario Greenhouse Alliance, are particularly focused on funding projects emphasizing marketing of floriculture products in the United States, and more generally, expanding the market for greenhouse floriculture products within Ontario (The Ontario Growers Association, 2009). The ability to attract new investment and develop new markets is becoming more of a reality with a growing demand by consumers for premium floricultural products from greenhouses (Niagara Economic Development Corporation, 2005). 
More than vegetable production, floricultural production is constantly evolving with consumer demand, and great care is taken to predict and prepare for upcoming trends in the market.

\subsubsection{Location and Distribution}

Approximately $75 \%$ of greenhouse production in Ontario occurs in southern Ontario within the counties or regions located around the western end of Lake Ontario, including the Hamilton and Niagara regions, as well as the counties along the northern shore of Lake Erie including Essex, Haldimand and Norfolk (Brown \& Murphy, 2010). The regions of Hamilton and Niagara are home to $50 \%$ of the growers and $60 \%$ of the land area within southern Ontario dedicated to greenhouse floriculture production (Brown \& Murphy, 2010). Greenhouse vegetable production tends to occur more often in the area surrounding Lake Erie. With approx. 550 ha of land devoted to greenhouse vegetable production, one of the largest concentrations of greenhouse vegetable production in the world can be found in the southern portion of Essex county (The Ontario Growers Association, 2009).

\subsubsection{Economic Impact}

The total area occupied by Ontario greenhouses rose by $196,000 \mathrm{~m}^{2}$ between 2008 to 2011 to a total area of 12.8 mill $\mathrm{m}^{2}$, and with it, total greenhouse sales to approx. $\$ 1.4$ bill, over the same time period (Ontario Ministry of Agriculture Food and Rural Affairs, 2012). Greenhouse production is a much more intensive form of land use than traditional agriculture, in that climate variables are regulated and controlled by computer technology, there is year-round crop production, more plants per ha and a more focused nutrient balance for optimized plant growth. Although this level of control reflects a high operating cost incurred to the producer, the returns are also much higher than those in field agriculture on a dollar per hectare basis (The Ontario Growers Association, 2009). Typically, the area devoted to vegetable production in Ontario is higher than that of floriculture, however, floriculture still leads in the value of sales (The Ontario Growers 
Association, 2009). With sales in the greenhouse market sustaining almost a constant rate of growth over the past decade, investments in the industry are also increasing, with approx. \$1.8 bill invested in primary greenhouse production in 2009 in Ontario alone (The Ontario Growers Association, 2009).

\subsection{Insect Pests of Ornamental Greenhouse Crops}

Most greenhouses are state-of-the-art facilities that utilize computers and special software to control temperature, humidity, light intensity and ventilation to ensure optimal plant growth. Unfortunately, conditions optimal for plant growth are also optimal for growth and establishment of insect and mite pests. Pedigo and Rice (2009) define an arthropod pest as a species that interferes with human activities, property, or health, or is objectionable. This heavily anthropocentric definition highlights the fact that humans define insects and mites as pests, based on the perceived detriment of their actions, even though the organism may provide a beneficial ecological service. Therefore, a guideline called the Economic Injury Level (EIL) has been developed to determine whether the cost-benefit of taking actions against an insect pest is worthwhile (Pedigo \& Rice, 2009). Sometimes pest numbers are low enough to not have a negative impact on a crop. An EIL is defined as the lowest number of insects that will cause economic damage in a crop, and is outlined by economic, or action, thresholds to decide when actions need to be taken to disrupt the insect (Pedigo \& Rice, 2009). Producers of ornamentals in greenhouses often have a very low tolerance for any sort of crop damage. Low tolerance exists because the entire plant may be sold to the consumer, and it is therefore imperative that leaves and flowers are cosmetically perfect (Gerson \& Weintraub, 2007). Pests that cause such economic losses are often termed aesthetic pests (Pedigo \& Rice, 2009).

Arthropod Pests. Common insect and mite pests of ornamental greenhouse crops include: the greenhouse whitefly:Trialeurodes vaporariorum (Westwood) and Bemisia tabaci (Gennadius), Tetranychus urticae Koch (two-spotted spider mites), Macrosiphoniella sanborni (Gillette) (chrysanthemum aphid), Aulacorthum solani 
(Kaltenbach) (foxglove aphid), Myzus persicae (Sulzer) (green peach aphid), and Bradysia spp. (fungus gnats) (Gerson \& Weintraub, 2007; Heinz et al., 2004; Yano, 2006). However, Frankliniella occidentalis (Pergande) (Thysanoptera: Thripidae), commonly known as western flower thrips (WFT), is the most important insect pest of greenhouse ornamental production (Buitenhuis et al., 2007; Heinz et al., 2004). Western flower thrips has the largest economic impact worldwide and has a host plant range of at least 244 plant species from 62 different plant families (Heinz et al., 2004). The species of concern to greenhouse producers belong to the suborder Terebrantia, and have a characteristic life cycle involving egg, 2 larval instars, prepupa, pupa and adult stages (Heinz et al., 2004). Adult WFT have a slender body 1.0-2.5 mm long, weak wings, and females have a saw-like ovipositor with which they pierce plant tissues to oviposit (Heinz et al., 2004). These well-hidden eggs hatch into larvae that will feed on plant tissue or flowers. Adult WFT are mainly flower-feeders, but will also feed on stems and leaves of plants as well.

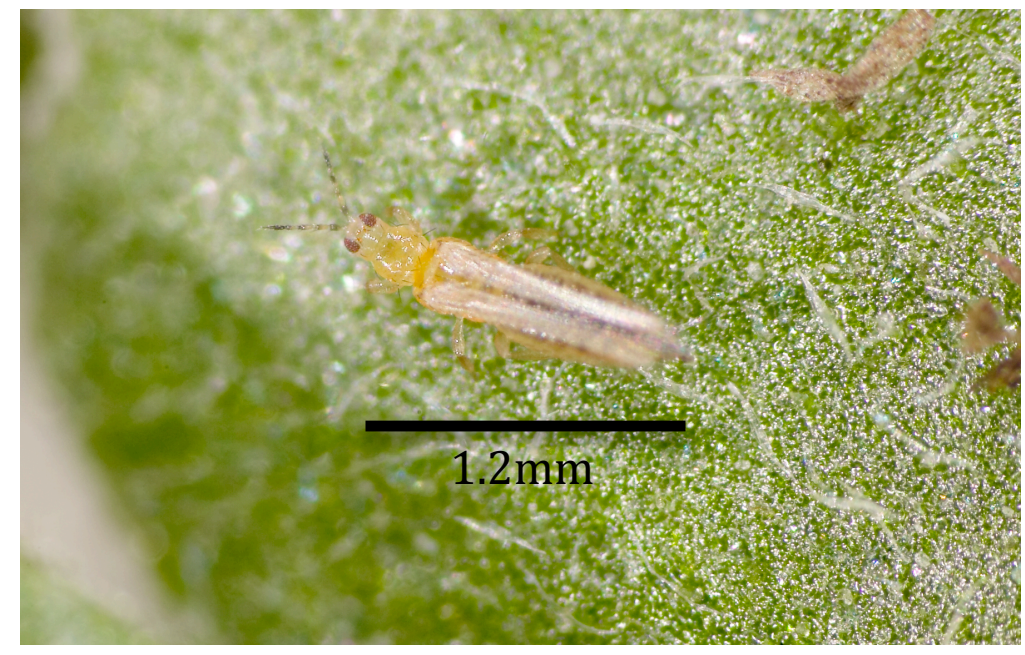

Figure 1.1. An adult western flower thrips. (Photo: Wendy Romero \& Dave Cheung)

\subsubsection{Damage Caused by Pests}

Ornamentals produced in greenhouses are high value crops that are typically scrutinized critically by customers for visual appearance that approaches cosmetic perfection. Symptoms of damage by thrips varies depending on the host plant, but may 
include: discolouration and scarring of open blooms, petals and fruits, and deformation of buds and flower heads, as well as pimpling on some flowers as a result of eggs deposited beneath the tissue (Karnkowski \& Trdan, 2002). Discolouration and dehydration of plant cells occurs when WFT puncture the plant leaf cuticle or stem epidermis and forms a food canal through which photosynthate is ingested (Heinz et al., 2004). After a thrips has fed on a plant, silvery necrotic spots will often appear, which can affect the plant's ability to photosynthesize, distort growth, and further reduce the value of the plant. Thrips have also been known to vector diseases to plants when feeding; most commonly Impatiens necrotic spot virus (INSV) and Tomato spotted wilt virus (TSWV), which further affect the plant value (Heinz et al., 2004). WFT are regarded as one of the most difficult insect pests to control due to their cryptic behaviour associated with oviposition, short development time, high fecundity, and rapid development of resistance to insecticides (Buitenhuis et al., 2007; Shipp et al., 2009).

\subsubsection{Integrated Pest Management for the Control of Western Flower Thrips in} Greenhouses

Integrated pest management (IPM) is often defined as "a pest management system that, in the context of the associated environment and the population dynamics of the pest species, utilizes all suitable techniques and methods in as compatible manner as possible and maintains the pest population at levels below those causing economic injury" (Kogan, 1998). This comprehensive approach to IPM aims to reduce the level of the pest to a tolerable level, while keeping in mind such factors as efficiency, economical viability and the ecological compatibility of the method (Pedigo \& Rice, 2009). IPM involves monitoring and identification of pests, and detailed record keeping. This information is used for assessment and development of a pest management strategy, which is a detailed plan of the methods to be used to reduce damage inflicted by the insect. A pest management strategy involves one, or often a combination, of the four main categories of pest management tactics; cultural/ecological, chemical/biochemical, physical and biological control. 
Cultural/Ecological Control. Cultural control as part of an IPM program involves manipulation of the existing environment in order to decrease the rates of pest damage and population increase (Pedigo \& Rice, 2009). This strategy involves the investigation of the ecology of the insect pest as it relates to the crop, and searches for a vulnerability in the seasonal cycle of the pest to exploit. Most techniques involve disruption of development through modifications to feeding and movement behaviours, modifications to food sources and, consequently, altered reproductive behaviours (Gerson \& Weintraub, 2007; Pedigo \& Rice, 2009). Such techniques often employed in the control of WFT include: sanitation, modification of alternate hosts and habitats (use of lights or reduction of carbon dioxide levels), obscuring host presence, crop spacing, crop location and trap cropping (Gerson \& Weintraub, 2007; Pedigo \& Rice, 2009), as well as plant breeding techniques to confer resistance to WFT or to make the plant less attractive (Heinz et al., 2004). Buitenhuis et al. (2007) used "trap plants" in greenhouse chrysanthemum production systems as a means of distracting thrips from the actual crop. It was found that with the addition of flowering "trap" chrysanthemums in greenhouses, population numbers and damage were reduced on the crop. The main benefit of this approach is that the pests are more concentrated in one area, not on the crop, where other means of reducing their population can be employed (Buitenhuis et al., 2007). Cultural control methods are only effective to a limited extent, and because ornamental production has a very low level of pest tolerance, other methods of control are often used in conjunction with cultural practices.

Chemical Control. Chemical control of insect pests can be a very effective method of quickly reducing population levels below the EIL. Insecticides can be broadspectrum, or tailored to a specific pest in order to avoid negative side effects to other beneficial or harmless species present in the ecosystem. Pesticide applications for the control of WFT should be applied as small droplets ( $<100$ microns) in a mist in order to ensure insecticide reaches the secluded habitat of thrips (Van Driesche \& Hoddle, 1998). Although insecticides are a cost-effective and easy to use method of control in greenhouses, their use is decreasing in popularity because of: environmental and human health issues, increased use of biological control programs which are not always 
compatible with insecticides, and a growing interest in organic production systems. In addition, many insect pests including WFT are able to develop resistance to insecticides relatively rapidly making them ineffective (Pedigo \& Rice, 2009). The number of products that are registered for WFT control is dwindling. In the past, the use of insecticides to control insect pests in greenhouse ornamental crops was deemed more acceptable compared to greenhouse vegetable crops because the product is not being sold for human consumption. More recently, there has been a move to increasingly focus on the use of biological control to deal with insect pests in ornamental greenhouse operations and to decrease the reliance on insecticides in the long term. This shift has been brought about by various pressures. With only one chemical that is effective against thrips registered for use in Canada, biological control is expected to play an increasing role in the control of thrips populations. In addition, to avoid harm to BCAs, greenhouse operators must choose to control all pests without the use of pesticides, or by using only 'predator-friendly' pesticides (Gerson \& Weintraub, 2007).

Biopesticides. Biopesticides are pesticides that are derived from natural materials such as animals, plants, microorganisms and minerals (Pedigo \& Rice, 2009). Biopesticides are differentiated from conventional chemical pesticides by a unique mode of action, narrow pest range, low use volume and natural occurrence. Commercial biopesticides must meet criteria for safety, purity and efficacy in some cases (Heinz et al., 2004). Biopesticides are more likely to decompose quickly, making them a safer option than conventional chemical pesticides. Biopesticides are divided into three major classes: microbial biopesticides, biochemical biopesticides and plantincorporated protectants (PIPs). The most common biopesticides marketed for thrips control are microbial in nature - fungi such as Beauveria bassiana (Balsamo) sold as Mycotrol $^{\circledR}$ or BotaniGard ${ }^{\circledR}$ (Laverlan International Corp.) or Naturalis-L ${ }^{\circledR}$ (Intrachem Bio Italia), Metarhizium anisopliae (Metchnikoff) known as Met52 ${ }^{\circledR}$ (Novozymes Biologicals Inc.), and Paecilomyces fumosoroseus (Wize) or NoFly WP ${ }^{\circledR}$ (Plant Products Co. Ltd.) (Pedigo \& Rice, 2009). Fungi such as these offer effective control of insect populations because they are able to penetrate the cuticle of an insect and then insert toxins or deplete the host of nutrients until they die. Another increasingly attractive option for 
conventional pesticide-free crop production is the entomopathogenic nematode (EPN) Steinernema feltiae (Filipjev).

Physical Control. Physical control as part of an IPM strategy uses physical implements to alter pest activity and numbers within a crop. Screening placed over vents is a tactic to reduce the number of pests entering a greenhouse from outside; however, consideration should be given to the altered airflow within the greenhouse that they cause. Yellow sticky tape or sticky cards can be used to trap flying insect pests. These cards are often yellow or blue (attractive colours for insect pests) and are hung throughout the greenhouse just above the top of the crop. These cards serve a dual purpose as both an insect trap and monitoring device. Light traps can also aid in reducing numbers of flying moths such as cabbage loopers or tomato pinworms. These traps attract the moths with light and then electrocute them on contact.

Biological Control. Biological control is defined as the use of natural enemies to maintain pest densities below the level at which economic plant damage would occur (Heinz et al., 2004). Biological control aims to either introduce or manipulate existing natural enemies of the pest population to regulate the density of the pest population (Pedigo \& Rice, 2009). There are three general approaches to biological control: importation, augmentation, and conservation of natural enemies. Importation, or "classical biological control", involves importation and establishment of non-native organisms. Augmentation is when populations of natural enemies are artificially increased via mass culture and then periodically released by either inoculative or inundative colonization for suppression of pests. Conservation biological control modifies ecosystems to ensure conservation of indigenous natural enemies. This includes identification and remediation of influences that impact natural enemies negatively, and enhancement of ecosystems to ensure they have optimal habitats in which to establish and reproduce (Rechcigl \& Rechcigl, 1998).

Increasingly, IPM strategies involving biological control are being investigated and employed in ornamental greenhouse operations due to: health and safety considerations for greenhouse staff and the general public; reduced availability of 
effective insecticides as a result of de-registration of older chemistries and lack of novel products replacement; and, concerns about insect pests developing insecticide resistance (Heinz et al., 2004). Although biological control agents (BCA) are becoming increasingly available from commercial suppliers, there still remain barriers to their successful control of greenhouse insect pests.

Biological Control Problems. Many factors influence the ability of a BCA to effectively reduce pest populations in greenhouses. Often, cost effectiveness or rates of success of natural enemies are perceived barriers to successful biological control programs (Buitenhuis et al., 2007). Greenhouse conditions such as the physical and climatic environments, the crop plant, and other pest control practices can all affect the ability of a BCA to reduce pest populations (Heinz et al., 2004). Western flower thrips biology and behaviour is complex, in that eggs are embedded in plant tissue, different life stages are found on different parts of the plant and substrate (Buitenhuis et al., 2007), and it prefers to inhibit tightly confined areas. Due to this thigmotactic behavior, WFT biological control programs are multifaceted and variable (Heinz et al., 2004). By jerking their abdomen and producing a drop of rectal fluid in response to predator attack, thrips also exhibit defense behaviours which can hinder the success of BCAs (Bakker \& Sabelis, 1989; Buitenhuis et al., 2010b). Multiple BCAs are often necessary to ensure WFT control at every life stage.

\subsubsection{Biological Control Agents for Western Flower Thrips Infestations}

Parasitoids. Parasitoids develop either inside or on their host, depending on the species (Heinz et al., 2004). Parasitoids are often smaller than their host and are only free-living as adults because they are laid as eggs either inside or on their host, and then use host resources to develop into adults (Heinz et al., 2004). For the control of WFT in greenhouse ornamental crops, two hymenopteran parasitoid species, Ceranisus menes (Walker) and Ceranisus americensis (Girault) have been tested as possible biocontrol agents. Although parasitoids have been successful in controlling other insect pests such as greenhouse whiteflies (Hoddle, 1994), C. menes and C. americensis 
were unable to offer adequate suppression of WFT populations in commercial greenhouse trials (Loomans, 2006) and are therefore not commercially available in Canada.

\section{Predators.}

Coleopterans. For the control of thrips in greenhouses, the rove beetle Dalotia coriaria (Kraatz) (Coleoptera: Staphylinidae) is often deployed (Birken \& Cloyd, 2007). This small (3-4mm), dark brown, soil-dwelling beetle preys on thrips that live in the substrate (Birken \& Cloyd, 2007). Both larval and adult $D$. coriaria feed on multiple life stages of fungus gnats, shore flies and thrips (Birken \& Cloyd, 2007).

Heteropterans. Orius insidiosus (Say) (Heteroptera: Anthocoridae) have proven themselves as effective BCAs against thrips. Orius insidious attacks both larval and adult WFT life stages. Due to their relatively inexpensive rearing process, Orius are widely available for use in commercial greenhouses (Heinz et al., 2004).

Nematodes. Entomopathogenic nematodes (EPNs) such as Steinernema feltiae (Filipjev) are able to access tightly enclosed plant structures and flowers in which WFT are often found. However, the soil dwelling life stages of western flower thrips (prepupa and pupa) are the most susceptible to nematode attack (Buitenhuis \& Shipp, 2005; Ebssa et al., 2001). Nematodes are generally applied to the substrate as a drench where they are most likely to contact pupae of western flower thrips. Nematodes offer good control of WFT and have been shown to be compatible with other BCAs (Ebssa et al., 2006; Jacobson et al., 2001).

Acari (Mites). Although there are many types of mites that are pests of greenhouse plants such as Tetranychus urticae (Spider Mites), a broad range of predatory mites are also commercially available as BCAs in greenhouses. Mites belong to the subclass Acari of the Arachnida, which differ from insects in that they lack a true head, conspicuous body segmentation, and have four sets of legs instead of the three found in insects (Zhang, 2003). The anterior-most part of the body is called the gnathosoma (capitulum) and the main body part, the idiosoma (Zhang, 2003). Most mites used for biological control in greenhouses belong to the family Phytoseiidae, which is divided into 
three subfamilies: Amblyseiinae, Phytoseiinae and Typhlodrominae, with the most commercially available species belonging to the Amblyseiinae and the genera Neoseiulus or Phytoseiulus (Zhang, 2003). Phytoseiids have a characteristic dorsal shield with 20 or less pairs of setae (Gerson \& Smiley, 1990). With a worldwide distribution of more than 1600 species belonging to over 70 known genera, phytoseiid mites, often referred to as generalist predators (Symondson et al., 2002), are known to feed on many pests such as spider mites, small insects on plants, nematodes, fungal spores, pollen and exudates, while avoiding plant tissues (Zhang, 2003). Table 1.1 outlines the known predatory mite species for thrips control.

Table 1.1. Common predatory mites commercially available for mitigation of western flower thrips populations.

\begin{tabular}{ll}
$\begin{array}{l}\text { Predator Species (Phytoseiidae)* } \\
\text { Geolaelaps aculeifer (Canestrini) }\end{array}$ & $\begin{array}{l}\text { Prey } \\
\text { fungus gnats \& western flower } \\
\text { thrips }\end{array}$ \\
\hline Stratiolaelaps scimitus (Wormersley) & $\begin{array}{l}\text { fungus gnats \& western flower } \\
\text { thrips }\end{array}$ \\
\hline $\begin{array}{l}\text { Iphiseius (= Amblyseius) degenerans (Berlese) } \\
\text { weoseiulus (= Amblyseius, = Phytoseiulus) } \\
\text { barkeri ( = mckenziei) (Hughes) }\end{array}$ & thrips \\
$\begin{array}{l}\text { Neoseiulus (= Amblyseius) cucumeris } \\
\text { (Oudemans) }\end{array}$ & thrips, cyclamen, broad mites \\
$\begin{array}{l}\text { Amblyseius (Typhlodromips) swirskii } \\
\text { (Athias-Henroit) }\end{array}$ & western flower thrips \& whiteflies \\
\hline
\end{tabular}

(Reproduced from: (Gerson \& Weintraub, 2007; Heinz et al., 2004; Wiethoff et al., 2004)

* Geolaelaps aculeifer (Canestrini) and Stratiolaelaps scimitus (Wormersley) are members of the Laelapidae, not Phytoseiidae

Two species of laelapid mites - Geolaelaps aculeifer (Canestrini) and Stratiolaelaps scimitus (Wormersley) feed on thrips pupae, shore fly larvae and acarid mites within the top $4 \mathrm{~cm}$ of soil (Gerson et al., 2003; Zhang, 2003). Adults are $1 \mathrm{~mm}$ in length, dark brown, lay their eggs in soil with a development time of $12-13$ days at $25^{\circ} \mathrm{C}$ 
and have an optimal temperature range of $16-22^{\circ} \mathrm{C}$ (Gerson et al., 2003). Their optimal habitats are moist, but not water-logged soils, and they are able to live for several weeks without preferred prey (Gerson et al., 2003). Although these predators can reduce the survival of thrips pupae in soil, they do not provide a sufficient level of control against thrips on their own, and it is suggested that they be used in combination with other management strategies (Gerson et al., 2003).

Neoseiulus (= Amblyseius) cucumeris (Oudemans) is the most commonly used predatory mite species as a biocontrol agent against WFT (Bakker \& Sabelis, 1989; Skirvin et al., 2007). Originating in the temperate climate of New Zealand (Messelink et al., 2006), the commercially-available non-diapausing strain of Neoseiulus cucumeris is a light brown, $1 \mathrm{~mm}$ long, mobile mite that preys on mainly first instar thrips (Heinz et al., 2004), although they are classified as a Type III generalist predator and feed on pollen and other small mites as well (Zhang, 2003). The dorsal shield of adult N. cucumeris is reticulate with 17 pairs of setae, with setae $Z 5$ slightly serrated and three microsetae on leg IV (Zhang, 2003). The development cycle takes approx. 6-7 days when suitable prey is provided, at a temperature of $27^{\circ} \mathrm{C}$ and $60-90 \%$ relative humidity $(\mathrm{RH})$ (Gerson \& Smiley, 1990). During their oviposition period, females usually produce about 53 eggs, an average of 1.9 eggs per day (Zhang, 2003). Reproduction rates are increased in greenhouses when pollen is offered as a secondary food source, although this practice might decrease the efficacy of this mite species as a BCA (Zhang, 2003). Neoseiulus cucumeris was the first phytoseiid found to feed on thrips (Gerson \& Weintraub, 2007; MacGill, 1939), and has been utilized as a BCA on greenhouse vegetable and ornamental crops with substantial success, generally when applied in a high predator:prey ratio with repeated releases, or as a preventative measure (Buitenhuis et al., 2010b; Zhang, 2003). This predator is sold in a bulk mixture of bran and the storage mite Tyrophagus putrescentiae (Schrank), or in small sachets as a controlled slowrelease system (CRS) (Gerson \& Weintraub, 2007; Weintraub et al., 2003). 


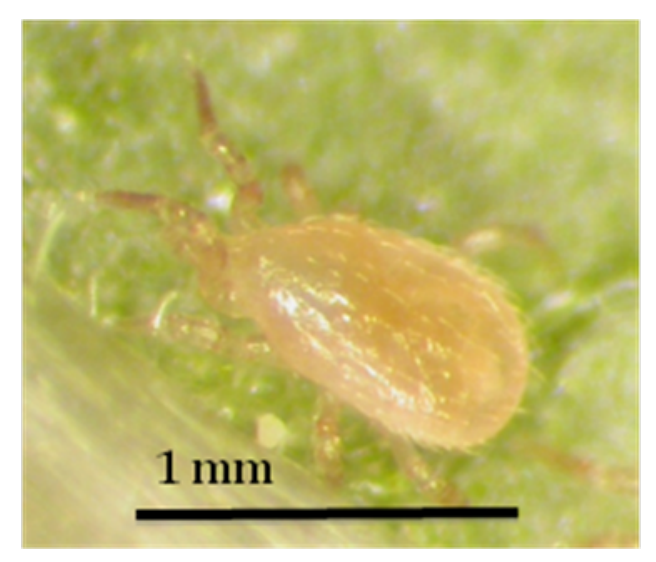

Figure 1.2. An adult Neoseiulus cucumeris. (Photo: Rose Buitenhuis)

Amblyseius (Typhlodromips) swirskii (Athias-Henroit) is a non-diapausing phytoseiid mite species that is very similar to $N$. cucumeris in appearance, prey species, and efficacy as a BCA. Amblyseius swirskii is a relatively new commercially available BCA which costs more than double the amount of $N$. cucumeris (Messelink et al., 2006; Nomikou et al., 2001). The dorsal shield of $A$. swirskii contain 3-4 sets of setae. A microscope must be used to distinguish between species. The intrinsic rate of natural population increase is similar for both species (Cloutier et al., 1995; Lee \& Gillespie, 2011). The life cycle of $A$. swirskii feeding on spider mite nymphs at $26^{\circ} \mathrm{C}, 70 \% \mathrm{RH}$ was $5.5 \pm 0.5$ days (El-Laithy \& Fouly, 1992). Amblyseius swirskii generally live for $27.87 \pm 2.4$ days and lay approx. 27.8 \pm 3.8 eggs during their oviposition period (El-Laithy \& Fouly, 1992). A population of $A$. swirskii increases most quickly when fed its preferred prey of thrips or whiteflies; although, as a polyphagous generalist predator, A. swirskii will feed on other prey if preferred prey are not available (Gerson \& Weintraub, 2007; Messelink et al., 2005). Messelink et al. (2008) observed A. swirskii populations to increase to densities up to 15 times greater when two pests species were presented, instead of one. They suggested that this success was due to increased juvenile survival and development rate when provided a mixed diet. As this mite originates from the Mediterranean basin, mostly found in humid coastal areas, $A$. swirskii prefer high temperatures and have a critical $\mathrm{RH}$ limit of $\sim 70 \%$, anything lower may cause their eggs to desiccate (de Moraes et al., 2004; Ferrero et al., 2010; Porath \& Swirski, 1965). Buitenhuis et al. (2010a) recently discovered that $A$. swirskii does not disperse well 
when applied to separated plants. Only a small percentage of the population applied to the upper foliage of the plant moved down to the soil in order to disperse through the greenhouse to neighbouring plants. Buitenhuis et al. (2010a) found that $A$. swirskii were more likely to move between plants when interplant connections were present, and suggest configuring plants so that they have a more continuous canopy in order to facilitate dispersal and predation. Within greenhouses, predatory mites are released in many different ways. Slow release sachets that are hung over plants for several weeks, direct application onto leaves, and aerial broadcast sprays are all methods of deploying mites in commercial greenhouses (Buitenhuis et al., 2010a).

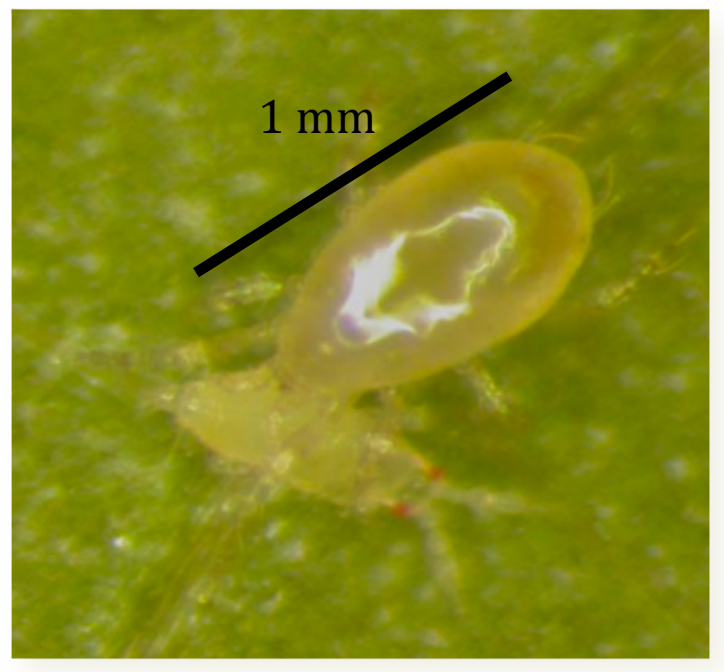

Figure 1.3. An adult Amblyseius swirskii feeding on a first instar western flower thrips. (Photo: Rose Buitenhuis)

\subsection{Influence of Climatic Parameters on Greenhouse Biological Control}

A greenhouse structure is typically built as a means of enhancing control over climatic variables in order to maximize crop production and extend growing seasons to yearround, regardless of the external environment (Mutwiwa et al., 2005). The climate within a greenhouse can be discussed in terms of the macroclimate or general greenhouse climate (i.e. upper area of a greenhouse above the crop canopy), as well as the microclimate (i.e. climate within the canopy and around the plant) (Shipp et al., 2009). The typical commercial greenhouse is moderated and monitored to control the 
temperature and humidity of the air to meet the optimal growing conditions for plants. Maximizing plant production is the ultimate goal in greenhouses, and although insects generally share similar climatic preferences as plants, the climatic variables within greenhouses are not always optimal for insect growth and development. It has been demonstrated that the physical environment has a strong impact on insect pest activity and their natural enemies (Hajek, 2004), although details of these relationships have not been fully elucidated. With knowledge of climatic influences on greenhouse BCAs, some measures can be taken to ensure that cost-effective control of pests is achieved. Although greenhouse temperature and humidity levels are set for optimal crop production, selection of a pest control strategy should fit with the crop type and growing environment.

\subsubsection{Climatic Parameters}

Greenhouse Temperature. In commercial greenhouses, the air temperature of the macroclimate is computer-controlled to remain within narrow limits $\left( \pm 1^{\circ} \mathrm{C}\right)$ (Jones et al., 2005). The set temperature is determined based on plant type and species to provide optimal growing conditions. Although temperature is relatively easy to measure and control at the macroclimate level, BCAs tend to reside within the plant canopy at the plant leaf surface, which is much less investigated and more difficult to measure accurately. The temperature at the leaf surface is often slightly warmer and more humid than ambient greenhouse conditions due to leaf transpiration, and even small changes here can have substantial impact on mite activity. Leaf temperature is known to influence body temperature and food conversion rate of predatory mites (Jones et al., 2005), with a higher temperature leading to an increased metabolic rate and consequently, increased predation activity (Jones et al., 2005; Shipp et al., 1996).

Development and oviposition rates generally increase for arthropods as temperature increases, with an optimal temperature occurring between $20-32^{\circ} \mathrm{C}$ for $N$. cucumeris and A. swirskii (Cloutier et al., 1995; Lee \& Gillespie, 2011). However, the recommended production temperatures in greenhouses usually falls between $17-25^{\circ} \mathrm{C}$ (Shipp et al., 1996). 
Humidity and Vapor Pressure Deficit. As with temperature, humidity within a greenhouse is strictly regulated, and can vary between microclimatic and macroclimatic measurement levels (Shipp et al., 2009). Humidity levels in the typical commercial greenhouse space are computer-controlled, and altered plant densities can impact humidity levels at the microclimatic level occupied by phytoseiids (Hajek, 2004). It seems a boundary layer of $0.5-5.0 \mathrm{~mm}$ exists around leaves where humidity levels are slightly increased due to leaf transpiration (Shipp et al., 2009). Jones et al. (2005) observed $\mathrm{RH}$ measured at $5 \mathrm{~mm}$ from a tomato leaf surface in a greenhouse to be 20 $30 \%$ greater than that of ambient measurements. The level of moisture within a greenhouse can also be affected by the type of greenhouse, with double-layered polycovered greenhouses tending to have higher humidities than glass-covered greenhouses (Heinz et al., 2004). In addition, humidity levels can be modified by adjusting the heating and venting systems of the greenhouse, or by installing a misting system (Shipp \& van Houten 1997). Van Houten et al. (1995) found that even when greenhouse ambient humidity levels are low, $N$. cucumeris egg survivorship was higher than would be expected at the measured humidity level due to a higher humidity at the leaf boundary layer. At $40 \% \mathrm{RH}$, nearly all the eggs of $\mathrm{N}$. cucumeris hatched on greenhouse cucumber plants at $20^{\circ} \mathrm{C}$ and $30^{\circ} \mathrm{C}$ (van Houten \& van Lier, 1996). Amblyseius swirskii are considered a drought sensitive mite species, as egg hatching for mites is largely related to humidity levels, with a higher egg hatch rate in more humid conditions (Ferrero et al., 2010). Humidity levels can interact with temperature to affect the level of efficacy of natural enemies in greenhouses (Heinz et al., 2004). At ambient temperatures between $10-30^{\circ} \mathrm{C}$, mites tend to be more effective predators at higher humidity levels (Heinz et al., 2004).

In the literature, humidity levels are often expressed as a measurement of vapor pressure deficit (VPD). Because temperature and humidity levels can influence each other, VPD measurements give an accurate representation of the atmospheric moisture in an area, independent of temperature. VPD measurements are based on the fact that vapor pressure is a measure of the quantity of water vapor present, and a VPD is the difference between amount of water vapor actually present and the amount that could 
exist without condensation at the same temperature (Anderson, 1936). A high VPD value means that the humidity is low and vice versa. During the winter in Ontario, VPDs can range from $1.36-1.85 \mathrm{kPa}$ throughout a $24 \mathrm{~h}$ period when a greenhouse is held at the recommended greenhouse temperature of $20^{\circ} \mathrm{C}$ (Shipp \& Van Houten, 1997). However, in high-gutter greenhouses, it is difficult to change the leaf boundary layer VPD substantially (Jones et al., 2005), as VPD over leaves has been calculated to range only from 0.09-0.69 kPa (Shipp et al., 2009). Nonetheless, changes in VPD can have a major impact on BCA activity and survival. At high VPDs, predatory mites can become dehydrated, which may decrease egg survival (Shipp \& Van Houten, 1997; van Houten et al., 1995a), or cause adults to feed more in order to compensate for water loss (Jones et al., 2005). At the recommended greenhouse production temperature, the optimal VPD range to ensure the maximum amount of predation by $N$. cucumeris is VPD $\leq 0.75 \mathrm{kPa}$ (Shipp et al., 1996). To obtain a $50 \%$ hatch rate of $N$. cucumeris eggs, VPD should be between $0.80-1.30 \mathrm{kPa}$ over a temperature range of $20-30^{\circ} \mathrm{C}$ (Shipp \& Van Houten, 1997).

Solar Radiation and Photoperiod. Light quality and quantity can have a substantial impact on the growth, development and efficacy of BCAs. Although it is known that predatory mites perform differently under varying light intensities and day lengths (Auger et al., 1999; Kazak et al., 2004; Weintraub et al., 2005), only a few studies have investigated possible interactions between these factors, and the impacts this may have on greenhouse BCAs (Johansen et al., 2011; Weintraub et al., 2005; Zilahi-Balogh et al., 2007). The actions of phytoseiids can be impacted directly by light reception and photophase (Gerson et al., 2003), or indirectly, through such effects as altered nutritional quality of the plant, plant defense mechanisms, volatile compound emission levels (Shipp et al., 2009; Vanninen et al., 2010) and behaviours associated with activity and movement when dehydrated (Gerson et al., 2003). Some strains of $N$. cucumeris enter a reproductive diapause or inactive state when they are exposed to short day lengths of less than 12-14h of light per day (Heinz et al., 2004), thus, a non-diapausing strain of $N$. cucumeris has been selected for use in greenhouses (Zilahi-Balogh et al., 2007). Although day length does not affect the non-diapausing strain of $N$. cucumeris, it 
may still affect other behaviours such as walking, feeding and oviposition, and may affect their efficacy as a BCA as well. There is an increasing trend in greenhouse production toward the use of supplemental lighting, especially during the winter months of the year, to maintain high crop yields (Zilahi-Balogh et al., 2007). By artificially modifying light intensity and quality, the efficacy of BCAs may be affected negatively or positively. Arthropods use sight cues to orient, navigate, avoid predators, and locate prey, mates and suitable host plants (Johansen et al., 2011). A close relative of $A$. swirskii and N. cucumeris; Amblyseius largoensis (Muma), produced the most eggs under L12/D12h conditions when tested against continuous light or continuous dark conditions (Gerson et al., 2003). Overall, oviposition has been shown to be highest during the day, and it is thought that this could be related to the fact that WFT are diurnal, and many phytoseiids tend to lay eggs where they can feed (Whittaker \& Kirk, 2004; Zilahi-Balogh et al., 2007).

The quality of light entering a greenhouse may be affected by the materials used to cover the greenhouse. Most plastic-covered greenhouses use a polyethylene plastic that absorbs UV light and blocks light wavelengths of 200-400nm (Mutwiwa et al., 2005). Many insect species have UV light receptors which influence vision and olfaction (Doukas \& Payne, 2007). It is presumed that pest infestation levels may be associated with exposure to different UV wavelengths, and WFT have been shown to be attracted to UV light (Costa et al., 2002). Lower numbers of aphids and thrips were recovered on crops in greenhouses that blocked UV light at $380 \mathrm{~nm}$ than those that blocked UV of $360 \mathrm{~nm}$ and below (Costa et al., 2002).

\subsubsection{Seasonal Variation in Climatic Parameters}

In northern temperate regions of the world such as Canada, climatic conditions vary drastically from one season to the next. Although the purpose of a greenhouse is to provide a controlled and constant environment suitable for plant growth year-round, variation does still exist from one season to the next. Light quality (or light intensity), and quantity (daylength) are reduced during the winter months in northern temperate regions (Zilahi-Balogh et al., 2007). Zilahi-Balogh et al. (2006) measured the average 
natural light intensity entering a glass greenhouse at $\sim 1 \mathrm{~m}$ above the crop canopy in the winter in Harrow, ON (latitude: $42.02^{\circ} \mathrm{N}$; longitude: $82.93^{\circ} \mathrm{W}$ ), and found it is reduced by approx. $36 \%$ compared to the summer months. Summer conditions normally involve a high light intensity $\left(82.0-83.6 \mathrm{~W} / \mathrm{m}^{2}\right)$ and long daylength $(\mathrm{L} 16: \mathrm{D} 8 \mathrm{~h})$ at $24^{\circ} \mathrm{C}$, while low light intensity $\left(10.8-11.1 \mathrm{~W} / \mathrm{m}^{2}\right)$ and short daylength $(\mathrm{L} 8: \mathrm{D} 16 \mathrm{~h})$ at $20^{\circ} \mathrm{C}$ are characteristic of winter months (Shipp et al., 2009). VPD is also affected by changes occurring in the climate in the winter months. In Ontario, decreasing temperatures normally cause an increased VPD in the greenhouse (Shipp et al., 1996).

\subsubsection{Potential Impacts of Seasonal Variations}

Northern temperate climate seasonal variations can dramatically impact the efficacy of BCAs within greenhouses. It has long been recognized that during winter months, changes in greenhouse microclimates seem to affect the ability of BCAs such as $N$. cucumeris and $A$. swirskii to prey on WFT (van Houten et al., 1995b; Zilahi-Balogh et al., 2007). Efficacy of natural enemies often decreases in the winter, even if the species is non-diapausing (Shipp et al., 2009). Seasonal variations involve fluctuations in temperature, humidity and light intensity, and although greenhouse operators attempt to maintain ambient conditions as stable as possible, even slight fluctuations in microclimate within plant canopies can result in BCAs with reduced ability to establish and control pest populations.

Variation in day length and light intensity. In the $24 \mathrm{~h}$ trials of Zilahi-Balogh et al. (2007), light intensity and photoperiod differences had no effect on the number of first instar WFT killed by $N$. cucumeris adults when tested at $24^{\circ} \mathrm{C}$. Light intensity had minimal impact on number of eggs laid, but photoperiod did not affect this test parameter. When seasonal light variations were tested for $24 \mathrm{~h}$ periods, there was not a significant effect on the number of WFT killed or the number of $N$. cucumeris eggs laid. However, regardless of whether they were exposed to short or long day light periods, female $N$. cucumeris only oviposited during the photophase. There was, however, no preference for light or dark when $N$. cucumeris was feeding. Females preferred to 
oviposit during the photophase. Therefore, $N$. cucumeris may have lower establishment success in the winter, which could explain why they are not as effective at lowering pest populations during this time. Zilahi-Balogh et al. (2007) recommended growers use supplemental lighting in greenhouses to improve biological control of WFT to increase oviposition rates of $N$. cucumeris and thereby increase their establishment in greenhouses. However, A. swirskii had the highest levels of predation under complete darkness or a short photophase $(8 \mathrm{~h})$, with a greater fecundity under the $8 \mathrm{~h}$ photophase as well (El-Tawab et al., 1982).

Variation in humidity or vapor pressure deficit and temperature. Vapor pressure deficit measurements are a method of accurately measuring humidity levels at the leaf surface level, and can be used to predict microclimatic changes within the habitat of predatory mites. VPD has been shown to impact the feeding, oviposition and survival of predatory mites in greenhouses. For example, Shipp et al. (1996) found that with $N$. cucumeris, at a constant temperature and an increasing VPD, predation rates decreased for VPDs $\leq 1.24-1.44 \mathrm{kPa}$ and then started to increase for VPDs $>1.44 \mathrm{kPa}$. Vapor pressure deficit and temperature are very closely related, and although they both affect rates of predation for $N$. cucumeris, VPD has a higher level of influence over their activity than temperature (Jones et al., 2005; Shipp et al., 1996). The proposed model of Shipp et al. (1996) can be used to predict predation rates by N. cucumeris over a range of temperatures and VPDs. The success of BCAs also depends on the level of activity of their prey. Shipp et al. (1996) observed WFT to be less mobile at higher temperatures and VPDs. Vapor pressure deficit and temperature fluctuations also affect survival rates of different life stages of predatory mites. Predictably, the larval stage had the smallest percentage survival rate, and the adult stage had the highest rate of survival success (Shipp \& Van Houten, 1997). Eggs and immature phytoseiids are small in size with limited ability to access free water or move to more favorable environments, thus making them more susceptible to desiccation.

Through research conducted on the influence of variable VPD levels, guidelines can be developed for growers to increase the success rate of establishment of predatory mites. When VPD levels are greater than $1.54 \mathrm{kPa}$, establishment of $N$. 
cucumeris may be delayed, while a VPD that exceeds $2.04 \mathrm{kPa}$ will result in the inability of N. cucumeris to establish in greenhouses (Shipp \& Van Houten, 1997). It is important to note however that ambient VPD levels are often much different than VPDs measured at the leaf boundary layer where BCAs and their prey reside. In high gutter greenhouses, it is more difficult to change the VPD at the microclimatic level than to change ambient VPD conditions (Jones et al., 2005). Therefore, measurements of ambient conditions are not sufficient to accurately predict whether suitable climatic conditions exist for maximizing the efficiency of predatory mites. 


\section{CHAPTER 2 \\ RESEARCH OBJECTIVES}

The goal of this research was to determine the influence of seasonal greenhouse climate variations on the efficacy of the predatory mites, Neoseiulus cucumeris and Amblyseius swirskii, to control Frankliniella occidentalis (WFT) on greenhouse ornamental crops. This information will be of use to commercial greenhouse growers when considering which predatory mite species will best complement their IPM strategy in various growing seasons. My research objectives were to:

1. Determine the effects of several northern temperate climate seasonal temperature, humidity and light conditions on the predation and oviposition rates of $A$. swirskii and $N$. cucumeris in laboratory studies; and,

2. Assess the establishment and survival of $N$. cucumeris and $A$. swirskii preying on WFT on potted chrysanthemum in greenhouse conditions. 


\section{CHAPTER 3}

\section{PREDATION AND OVIPOSITIONAL RESPONSES OF PREDATORY MITES UNDER SUMMER AND WINTER CLIMATIC CONDITIONS}

\subsection{Abstract}

Often in North American commercial greenhouse ornamental production, IPM programs to control thrips incorporate the use of the predatory mites Neoseiulus cucumeris in the winter season and Amblyseius swirskii in summer. This use pattern is based on the assumption that there are seasonal differences in efficacy of these mite species in northern temperate climates, although this hypothesis has never formally been tested. As a newer BCA on the market, $A$. swirskii often costs at least three times that of $N$. cucumeris, causing commercial growers to spend more money on their IPM programs. Through laboratory bioassays, this research evaluated and quantified differences in the predation and oviposition capacities of both mite species, to determine if there is a seasonal advantage to mite species selection. Four controlled environment chambers were used to simulate the temperature, light intensity, and day length of two summer and two winter climates typical in North American greenhouse production systems. Temperature, more than light intensity or photoperiod, affected the reproductive success of both predatory mite species. Predation and oviposition increased in both mite species when subjected to a higher temperature. At $24^{\circ} \mathrm{C}, A$. swirskii consumed significantly more thrips than N. cucumeris. Photoperiod and light intensity affected predation with more thrips consumed at short day, low light intensity levels. Oviposition rates of $A$. swirskii were not affected by light regime; but $N$. cucumeris laid more eggs under short day conditions. These results suggest seasonality needs to be considered when recommendations for application timing and rate are provided for the use of $A$. swirskii and $N$. cucumeris in biological control programs.

\subsection{Introduction}

The order Acari contains many mite species of agricultural importance. Although some mites are ubiquitous crop pests, such as the two-spotted spider mite (Tetranychus urticae), there are also non plant-feeding predatory mites that can be beneficial in 
greenhouse IPM programs. Approximately 20 species within the Phytoseiidae are mass reared and sold as BCAs (Gerson \& Weintraub, 2007). Many factors determine the success of a BCA as a predator in greenhouse crops. Behavioural actions such as walking, resting, attacking and feeding are observed at different proportions depending on species (van Rijn et al., 2005). Presumably, a phytoseiid that spends more time walking and attacking is a more successful predator than one that prefers long periods of rest. Unlike other BCAs such as Orius insidiosus, predatory mites tend to kill prey and spend time consuming the contents. The time spent handling the prey and the gut capacity of the mite thus affect the maximum amount of pest reduction possible in a given time. Because predatory mites often consume most or all of the edible content of their prey, rates of gut emptying, handling time, and rate of food conversion in the gut all play a role in determining how many pest individuals a mite can consume in a given period of time (van Rijn et al., 2005).

As poikilothermic organisms, natural history parameters for the predatory mites A. swirskii and $N$. cucumeris are greatly influenced by seasonal variations of climate. Feeding and oviposition influence the intrinsic rate of natural increase of a population, thereby affecting how well a predator is able to establish within a crop and control prey (i.e. pests) in a greenhouse. Considerable research has focused on one or more of the concurrent climatic factors that govern the life history of predatory phytoseiid mites used for pest management, including studies that have attempted to quantify the effects of temperature (Cloutier et al., 1995; Jones et al., 2005; Lee \& Gillespie, 2011; Lee \& Ahn, 2000; Shipp et al., 1996), and light intensity and photoperiod (Weintraub et al., 2005; Zilahi-Balogh et al., 2007) on predatory mite development. When N. cucumeris were reared in light or dark conditions and then placed on greenhouse sweet pepper leaves, significantly more mites were recovered from apical leaves and flowers in the corresponding sampling time of midnight or noon (Weintraub et al., 2005). In a laboratory experiment measuring predation and oviposition by $N$. cucumeris under varying temperatures, light intensities and photoperiods, Zilahi-Balogh et al. (2007) found light intensity to have the largest effect on oviposition rate, while photoperiod had no effect. Temperature affected predation rate, with more thrips killed at $24^{\circ} \mathrm{C}$ than $20^{\circ} \mathrm{C}$, while light regimes had no impact on predation. This result suggests that 
phytoseiid mites are able to prey on thrips regardless of time of day, while their oviposition may be more closely linked with a day and night cycle. However, this study was only $24 \mathrm{~h}$ in duration, and may not have captured variation in day-to-day behaviours of $N$. cucumeris. Furthermore, Sabelis (1981) measured the influence of temperature on relative rate of gut emptying (RRGE), and found a near-linear relationship when RRGE values were plotted against temperature. A higher rate of gut emptying may lead to an increased appetite, and therefore higher predation rates by BCAs.

Prey activity can also influence the success of predators. Western flower thrips is a successful pest because of its thigmotactic behavior which decreases the likelihood of predator capture and consumption (Gerson \& Weintraub, 2012). Whittaker and Kirk (2004) studied the amount of walking, pollen consumption and oviposition of WFT under five photoperiod combinations. At increased photoperiods, all three behaviours increased as well. The authors suggest light regimes may be used to increase exposure of predatory mites to WFT, and increase pest reduction.

During spring and summer months, $N$. cucumeris have been successfully used for the control of WFT in greenhouses (Gerson \& Weintraub, 2007; Skirvin et al., 2007; van Houten et al., 1995a); however, commercial growers do not find them to be as effective in the winter and early spring months. Reduced efficacy seems to be most prevalent when the winter is dry and cold (Shipp \& Van Houten, 1997). In other studies, A. swirksii have prevailed over N. cucumeris as the better BCA for thrips (Buitenhuis et al., 2010b; Messelink et al., 2006; van Houten et al., 2005). Amblyseius swirskii increase population levels after application which allows for more effective thrips control (Messelink et al., 2006). However, A. swirskii may cost approx. three times that of $N$. cucumeris. The average cost of 50,000 bulk $N$. cucumeris is $\$ 36.00$, while the same amount of $A$. swirskii are approx. $\$ 115.00$ (MGS Horticultural Inc., Leamington, ON; Koppert Biological Systems Canada, Scarborough, ON; and Plant Products Co. Ltd., Brampton, ON). To determine if there is a difference in efficacy between the predatory mite species $N$. cucumeris and $A$. swirskii in summer or winter seasonal climate conditions, predation and oviposition were monitored every $24 \mathrm{~h}$ over a 3-day period for 
each mite species under simulated seasonal climates in a controlled environment chamber trial.

\subsection{Materials and Methods}

\subsubsection{Mite Colonies}

To establish a laboratory colony of predatory mites, bulk containers of $N$. cucumeris and A. swirskii were obtained from Biobest via MGS Horticultural Inc., Leamington, ON. Adult mites were separated from the bran matrix onto a filter paper-lined Petri dish using a modified Berlese funnel and light, and then transferred to an artificial mating arena. Each mating arena consisted of a $250 \mathrm{~mL}$ plastic cup containing a water-saturated sponge with a bean (Phaseolus vulgaris) leaf disk $(8 \times 6 \mathrm{~cm})$ placed upside down atop the sponge. Water was added to the cup to the level of the sponge top and a vented lid sealed the cup. The cups of each mite species were placed into separate growth chambers at $25 \pm 1^{\circ} \mathrm{C}, 75 \pm 10 \% \mathrm{RH}(0.8 \mathrm{VPD}), \mathrm{L} 16: \mathrm{D} 8 \mathrm{~h}$. Mites were fed cattail pollen (Typha latifolia) and frozen $1^{\text {st }}$ instar WFT daily, and eggs were collected and moved to new mating arenas every 1-2 days to obtain cohorts of mites.

\subsubsection{Rearing First Instar Western Flower Thrips}

A colony of WFT was maintained on flowering yellow chrysanthemums (Dendranthema grandiflorum var. Chesapeake) in a small greenhouse $(6 \times 7 \mathrm{~m})$. To rear first larval instar WFT, $9 \mathrm{~cm}$ Petri dishes were filled halfway with agar and a bean or pepper leaf square $(7 \times 7 \mathrm{~cm})$ was placed on the surface of the agar. Adult WFT were obtained by tapping plants from the colony over a white larval tray and then aspirated into vented vials. Fifty female adult WFT were placed on each agar dish, the thrips-proof mesh vented lid sealed with Parafilm, and dishes placed in a growth chamber $\left(25 \pm 1^{\circ} \mathrm{C}\right.$, $75 \pm 5 \% \mathrm{RH}(0.8 \mathrm{VPD}))$. After $24 \mathrm{~h}$, the adult WFT were removed and the Petri dishes were replaced in the chamber for an additional $72 \mathrm{~h}$, or until first larval instar WFT emerged. 


\subsubsection{Predation and Oviposition Bioassay}

To conduct predation and oviposition trials, $37 \mathrm{~mL}$ plastic Solo ${ }^{\circledR}$ cups were prepared with a $2 \times 2 \times 2 \mathrm{~cm}$ cube of sponge glued to the bottom. The cups were filled with water level to the top of the sponge, where a $1.8 \times 1.8 \mathrm{~cm}$ bean leaf (Phaseolus vulgaris) square was placed abaxial-side up (Figure 3.1). Fifteen first instar WFT were placed on the leaf along with one mated female adult $N$. cucumeris or $A$. swirskii. A single piece of bran was also placed on the $N$. cucumeris-treated leaves, to discourage mites from wandering off into the water. Adult female predatory mites were isolated for $24 \mathrm{~h}$ before the trial in gelatin capsules to control for satiation and ensure they were of egg-laying ability. Only females that laid an egg in the capsule were used in the trial. For the nomite control, $N$. cucumeris and $A$. swirskii treatments, the cups were sealed with a vented lid and placed randomly in one of four controlled environment chambers. Two chambers were set to simulate warm $\left(24 \pm 1^{\circ} \mathrm{C}\right)$ and cool $\left(20 \pm 1^{\circ} \mathrm{C}\right)$ summer greenhouse conditions with a long day (LD) 16L:8D (light:dark) photoperiod, light intensity of $83 \pm 1 \mathrm{Wm}^{-2}$ and $65 \pm 5 \% \mathrm{RH}$. The two remaining chambers were programmed to simulate winter conditions with: short day (SD) (8L:16D) photoperiod, low light intensity $\left(11 \pm 0.5 \mathrm{Wm}^{-2}\right)$ and either cool or warm $\left(20 \pm 1^{\circ} \mathrm{C}, 24 \pm 1^{\circ} \mathrm{C}\right)$ temperatures. Climate settings were rotated among the four chambers between replicates to control for any possible effects observed due to chamber variation (Figure 3.2). After $24 \mathrm{~h}$, the cups were removed from the chambers and number of consumed WFT and eggs laid by the mite were recorded using a stereomicroscope at 20x magnification. WFT consumed by predatory mites appeared flattened and dry. New leaf disks with prey were constructed in the same manner and the predatory mite was transferred with a fine camel hair paintbrush to the new cup and placed back into its' respective environment chamber. This procedure was continued for 3 days $(72 \mathrm{~h}$ ) in order to follow the predation and oviposition of each mite in each seasonal climate regime over time. In the case of mite absence due to escape, the data were discarded. A minimum of 11 replicates for each mite treatment in each climate were collected for each day (Table 3.1). 


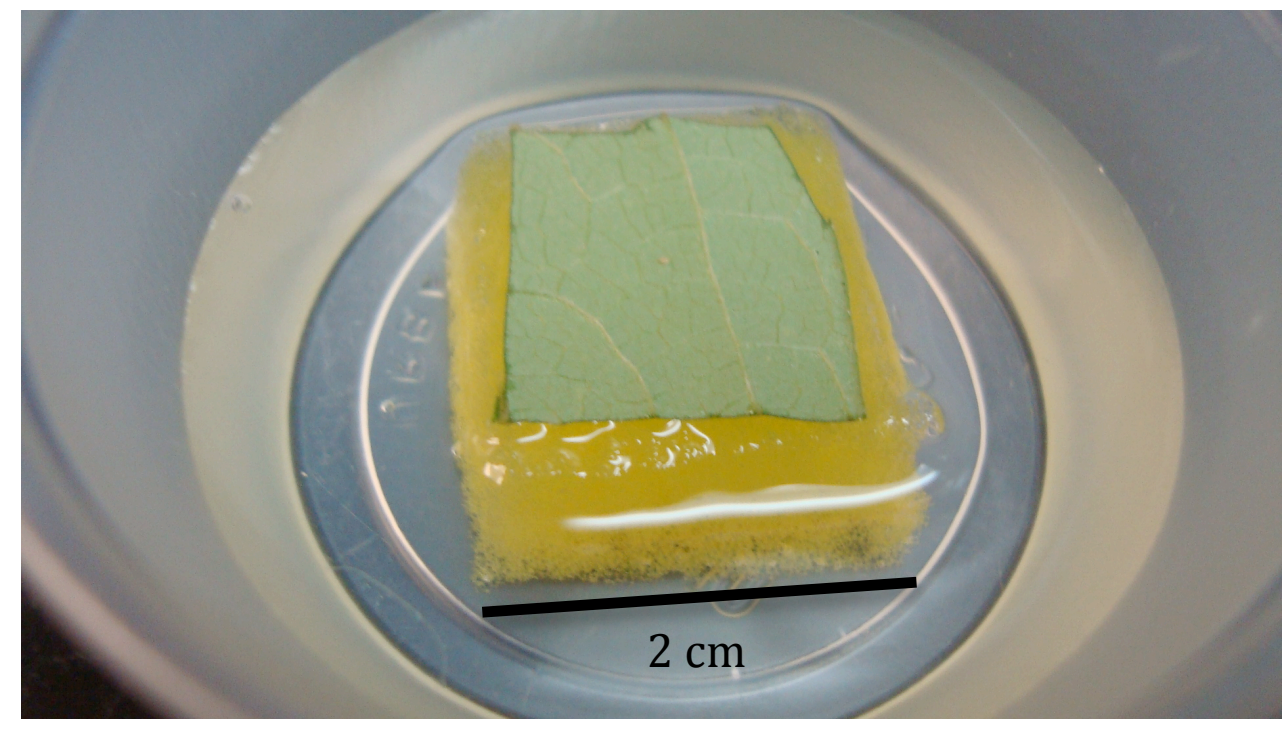

Figure 3.1. Predation and oviposition experimental arena; bean leaf square atop a water-soaked sponge square in a sealed plastic cup.

Table 3.1. Number of replications of each treatment during Day 1, 2, and 3 of controlled environment chamber predation and oviposition bioassays for Neoseiulus cucumeris and Amblyseius swirskii. The numbers reflect the corrected total of replicates after some cups were discounted due to mites being absent from the arena. Day 1 is the first observation period, $24 \mathrm{~h}$ after trial initiation.

\begin{tabular}{|c|c|c|c|c|}
\hline & \multicolumn{4}{|c|}{$\begin{array}{l}\text { Number of } \\
\text { Replications }\end{array}$} \\
\hline N. cucumeris & Day 1 & Day 2 & \multicolumn{2}{|c|}{ Day 3} \\
\hline $\mathrm{SN}_{1}$ & 22 & 12 & \multicolumn{2}{|c|}{11} \\
\hline $\mathrm{SC}_{2}$ & 24 & 15 & \multicolumn{2}{|c|}{11} \\
\hline $\mathrm{WN}_{3}$ & 27 & 17 & \multicolumn{2}{|c|}{15} \\
\hline $\mathrm{WW}_{4}$ & 28 & 18 & \multicolumn{2}{|c|}{16} \\
\hline \multicolumn{5}{|l|}{ A. swirskii } \\
\hline SN & 22 & 16 & \multicolumn{2}{|c|}{15} \\
\hline SC & 22 & 17 & \multicolumn{2}{|c|}{16} \\
\hline WN & 24 & 19 & \multicolumn{2}{|c|}{16} \\
\hline WW & 30 & 30 & \multicolumn{2}{|c|}{22} \\
\hline \multicolumn{4}{|c|}{${ }^{1} \mathrm{SN}$ : Summer Normal- $24^{\circ} \mathrm{C}$, day length 16 light :8 dark, light intensity } & $83 \mathrm{~W} / \mathrm{m}^{2}$ \\
\hline \multicolumn{4}{|c|}{${ }^{2}$ SC: Summer Cool- $20^{\circ} \mathrm{C}$, day length 16 light: 8 dark, light intensity } & $83 W / m^{2}$ \\
\hline \multicolumn{4}{|c|}{${ }^{3} \mathrm{WN}$ : Winter Normal- $20^{\circ} \mathrm{C}$, day length 8 light: 16 dark, light intensity } & $11 \mathrm{~W} / \mathrm{m}^{2}$ \\
\hline \multicolumn{4}{|c|}{${ }^{4} \mathrm{WW}$ : Winter Warm- $24^{\circ} \mathrm{C}$, day length 8 light: 16 dark, light intensity } & $11 \mathrm{~W} / \mathrm{m}^{2}$ \\
\hline
\end{tabular}


Normal Summer

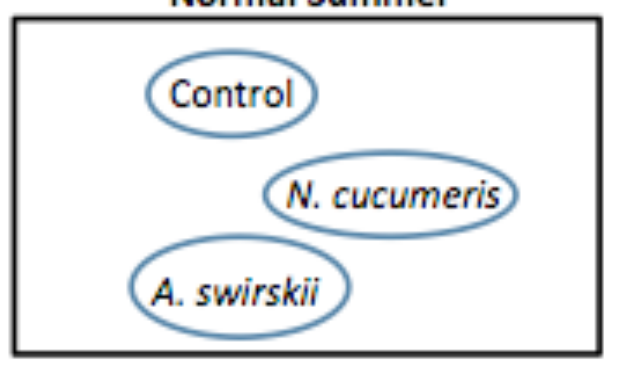

Normal Winter

\section{Control}

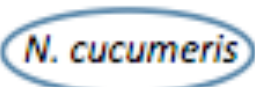

\section{A. swirskii}

Cool Summer

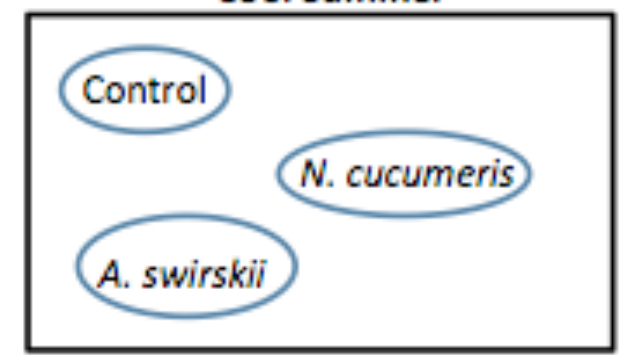

Warm Winter

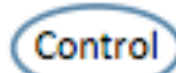

N. cucumeris

A. swirskii

Figure 3.2. The experimental setup for predation and oviposition assessments. Four seasonal controlled environment chambers were set up, each containing equal replicates of three randomly placed, equally spaced treatments: no-mite control, Neoseiulus cucumeris-treated, and Amblyseius swirskii- treated.

\subsubsection{Data Analysis}

All data were analyzed using SAS v. 9.1, SAS Institute, Cary, N.C. A Shapiro-Wilk test was performed to ensure normality of the data. A two-way ANOVA using PROC MIXED on untransformed data was performed with the model $Y=\mu+$ light + temperature + day + mite treatment*light + mite treatment ${ }^{\star}$ temperature + mite treatment ${ }^{*}$ day + error for predation and oviposition data. The fixed effects were light, temperature, day, light*mite treatment, temperature*mite treatment, day ${ }^{*}$ mite treatment. Random effects were chamber and residual error. A Tukey's adjusted multiple means comparison was used to detect significant differences among fixed effects. In all cases the critical $p$ value for significance was $\alpha=0.05$. 


\subsection{Results}

\subsubsection{Predation Bioassay}

Analysis of the predation data revealed that rates of predation on Day 1 of the bioassay were significantly higher than Day 2 and Day $3\left(F_{2,500}=47.00, P<0.0001\right)$. The mite treatment ${ }^{*}$ day interaction was significant $\left(F_{4,500}=9.07, P<0.0001\right)$. Therefore, data from Day 1 were analyzed separately for the remainder of the analysis (Table 3.2).

On Day $1, A$. swirskii consumed significantly more WFT larvae than $N$. cucumeris under SD conditions, but the mite treatments were not significantly different from each other under LD light conditions $\left(F_{2,202}=3.34, P=0.0374\right)$ (Figure 3.3). Amblyseius swirskii showed no difference in predation rate at the varying light levels. Neoseiulus cucumeris had the lowest predation rate under the SD conditions (Figure 3.3).

When SD and LD light levels were compared for Day 2 and 3, predation rates were significantly higher under the $S D$, low light intensity conditions $\left(F_{1,292}=27.81\right.$, $\mathrm{P}<0.0001)$. Amblyseius swirskii consumed significantly more WFT under LD conditions than $N$. cucumeris. $\left(F_{2,292}=12.42, \mathrm{P}<0.0001\right)$ (Figure 3.4). There was no difference between predation levels of $N$. cucumeris and $A$. swirskii under SD conditions.

The predation rates of $N$. cucumeris and $A$. swirskii were not significantly different at high or low temperatures on Day 1 of the trial $\left(F_{2,202}=0.44, P=0.6447\right)$; however, A. swirskii consumed more WFT larvae than N. cucumeris at both temperatures ( $\mathrm{F}=2.64, \mathrm{P}=0.0254)$ (Figure 3.5).

On Day 2 and 3, more WFT were consumed at $24^{\circ} \mathrm{C}$ than $20^{\circ} \mathrm{C}\left(\mathrm{F}_{1,292}=22.03\right.$, $\mathrm{P}<0.0001$ ) (Figure 3.6). At high temperature, $A$. swirskii had a significantly higher predation rate than $N$. cucumeris $(F=5.76, P=0.0132)$, but there was no difference between mite species for predation rates at low temperature. Control mortality was $<2 \%$ in all cases. 
Table 3.2. Mean predation rate of first instar western flower thrips (WFT) $\pm S E$ by Neoseiulus cucumeris and Amblyseius swirskii in controlled environment chamber bioassays over three days. Means with the same lowercase letter are not significantly different (Tukey's test, $P<0.05$ ).

\begin{tabular}{cll}
\hline Day & \multicolumn{1}{c}{ Treatment } & $\begin{array}{c}\text { Predation Rate } \\
\text { (thrips/day) }\end{array}$ \\
\hline 1 & A. swirskii & $7.3 \pm 0.2 \mathrm{a}$ \\
& N. cucumeris & $6.7 \pm 0.1 \mathrm{~b}$ \\
2 & A. swirskii & $5.3 \pm 0.2 \mathrm{C}$ \\
& N. cucumeris & $4.8 \pm 0.2 \mathrm{~d}$ \\
3 & A. swirskii & $5.5 \pm 0.2 \mathrm{C}$ \\
& N. cucumeris & $5.1 \pm 0.2 \mathrm{~cd}$ \\
\hline
\end{tabular}

\subsubsection{Oviposition bioassay}

The effect of day was significant $\left(\mathrm{F}_{2,385}=15.54, \mathrm{P}<.0001\right)$, with more eggs laid on Day 2 and Day 3 than Day 1 (Table 3.3). Day 1 data were analyzed separately for the remainder of the analysis.

The day ${ }^{*}$ mite treatment interaction was not significant $(F=0.69, P=0.5036)$ indicating the performance of the mite treatments relative to each other was the same each day (Figure 3.7). Oviposition rates on Day 2 were significantly higher for $A$. swirskii and N. cucumeris (Figure 3.7). On Day 3, A. swirskii had significantly decreased oviposition rates from Day 2, but $N$. cucumeris did not.

On Day 1, the two light levels examined did not have a significant impact on the oviposition rate of either mite treatment (Figure 3.8). On Day 2 and 3, the overall impact of light levels on oviposition was not significant $\left(F_{1,213}=1.20, P=0.2736\right)$. However, when SD and LD light regimes were analyzed for each mite treatment, $N$. cucumeris laid more eggs under the shorter daylength (Figure 3.9).

Day 1 oviposition rates were significantly higher for both mite treatments at the higher temperature of $24^{\circ} \mathrm{C}\left(\mathrm{F}_{1,202}=28.60, \mathrm{P}<0.0001\right)$. At $20^{\circ} \mathrm{C}$ and $24^{\circ} \mathrm{C}$, oviposition rates for both mite treatments were the same (Figure 3.10).

Oviposition rates on Day 2 and Day 3 were significantly higher at $24^{\circ} \mathrm{C}$ than $20^{\circ} \mathrm{C}$ when mite treatments were pooled $\left(F_{1,215}=11.31, P=0.0009\right)$. There was no significant 
difference in oviposition rates between $A$. swirskii and $N$. cucumeris at high or low temperature $\left(F_{2,215}=1.21, P=0.3013\right)$. Amblyseius swirskii oviposition rate was higher at $24^{\circ} \mathrm{C}$ than $20^{\circ} \mathrm{C} ; \mathrm{N}$. cucumeris oviposition rates did not differ between the two temperatures (Figure 3.11).

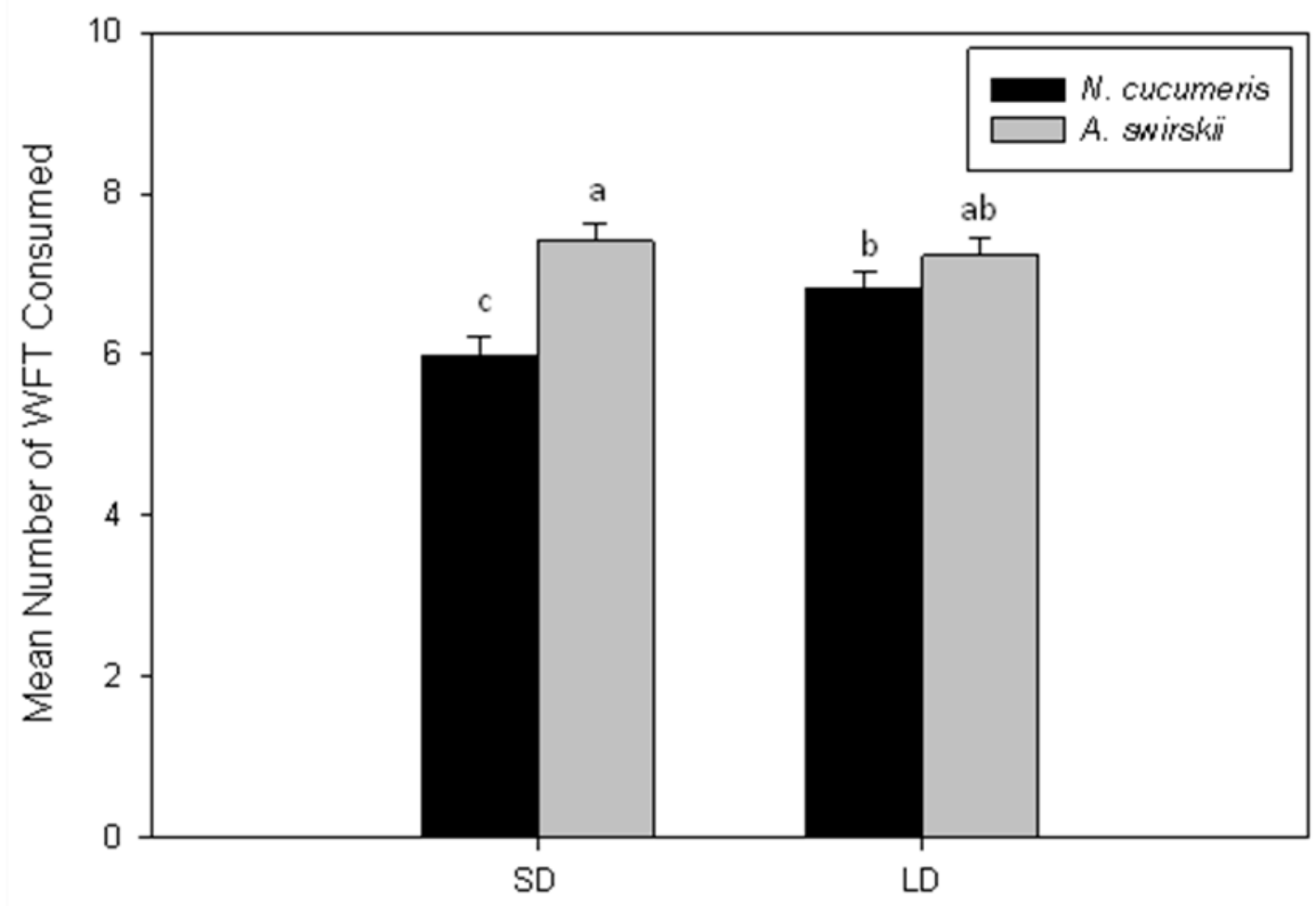

\section{Day Length/Light Intensity}

Figure 3.3. Mean number of first instar western flower thrips (WFT) larvae consumed \pm SE on Day 1 in controlled environment chamber bioassays by Neoseiulus cucumeris and Amblyseius swirskii at two light levels: short day (SD) low (8h light, $11 \mathrm{~W} / \mathrm{m}^{2}$ ), and long day (LD) high (16h light, $83 \mathrm{~W} / \mathrm{m}^{2}$ ). Means with the same letter are not statistically different by Tukey's test $(P=0.05)$. 


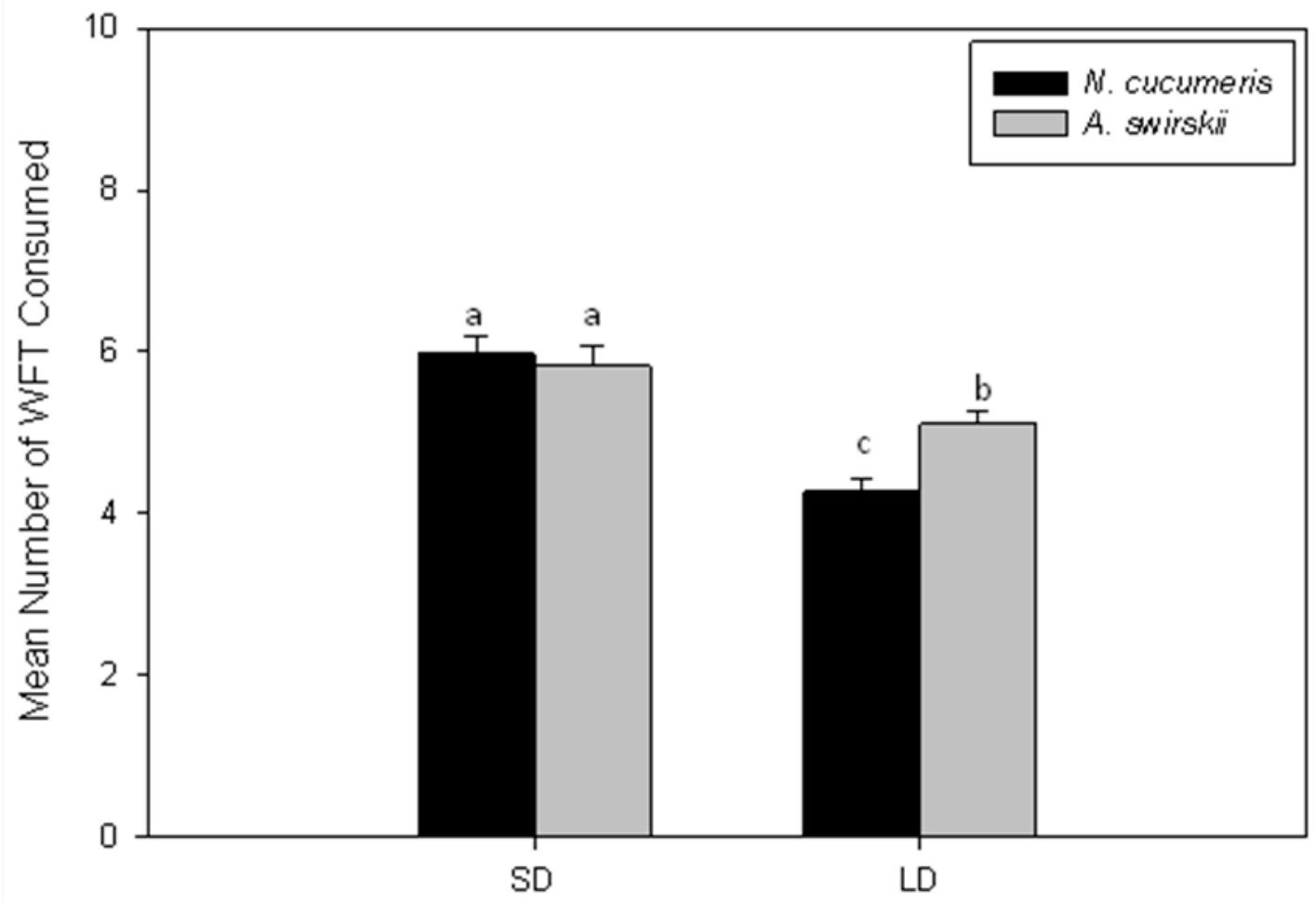

Day Length/Light Intensity

Figure 3.4. Mean number of first instar western flower thrips (WFT) larvae consumed \pm SE on Day 2 and Day 3 in controlled environment chamber bioassays by Neoseiulus cucumeris and Amblyseius swirskii at two light levels: short day (SD) low (8h light, 11 $\mathrm{W} / \mathrm{m}^{2}$ ), and long day (LD) high (16h light, $83 \mathrm{~W} / \mathrm{m}^{2}$ ). Means with the same letter are not statistically different by Tukey's test $(P=0.05)$. 


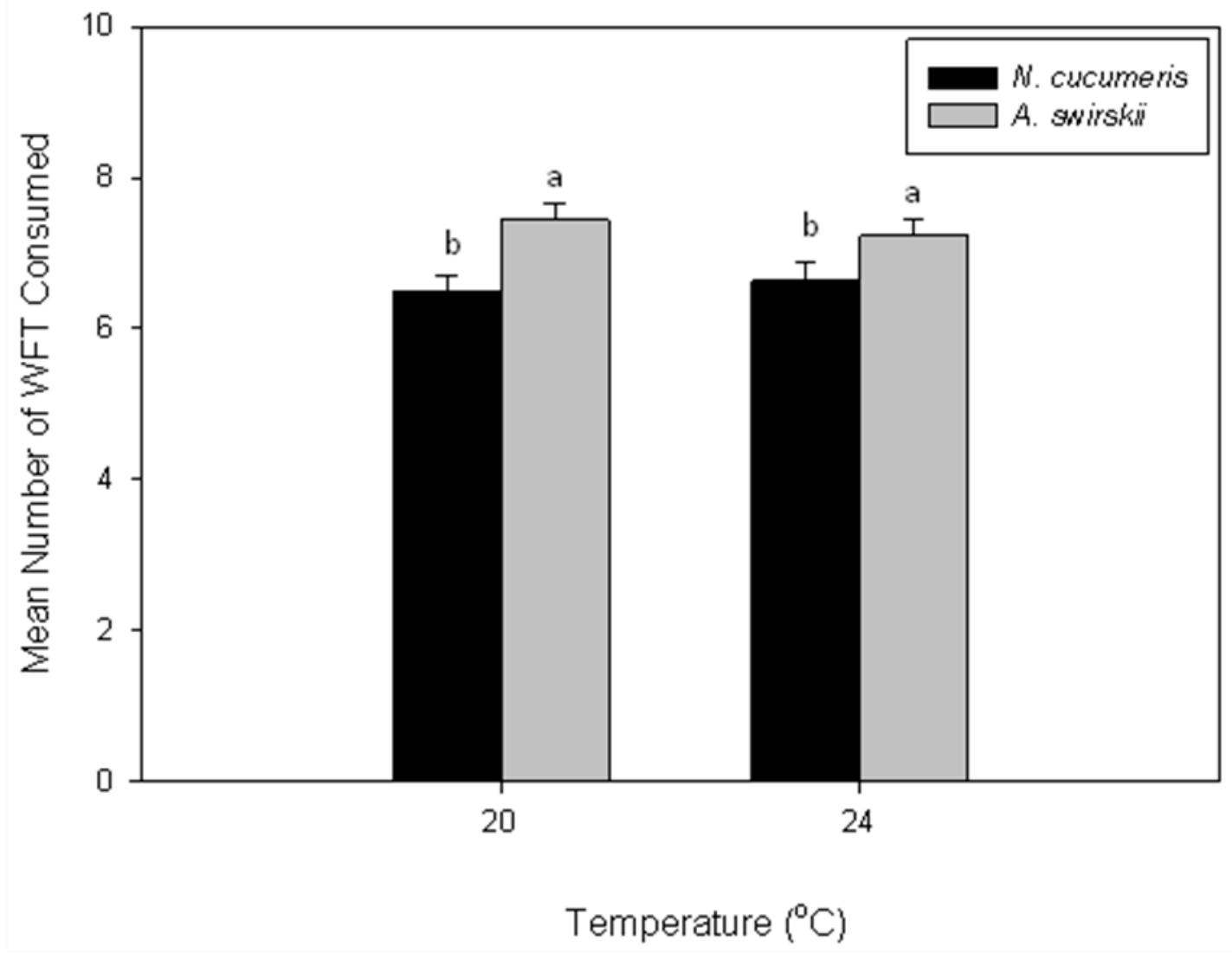

Figure 3.5. Mean number of first instar western flower thrips (WFT) larvae consumed \pm SE on Day 1 by Neoseiulus cucumeris and Amblyseius swirskii in controlled environment chamber bioassays at 20 and $24^{\circ} \mathrm{C}$. Means with the same letter are not statistically different by Tukey's test $(P=0.05)$. 


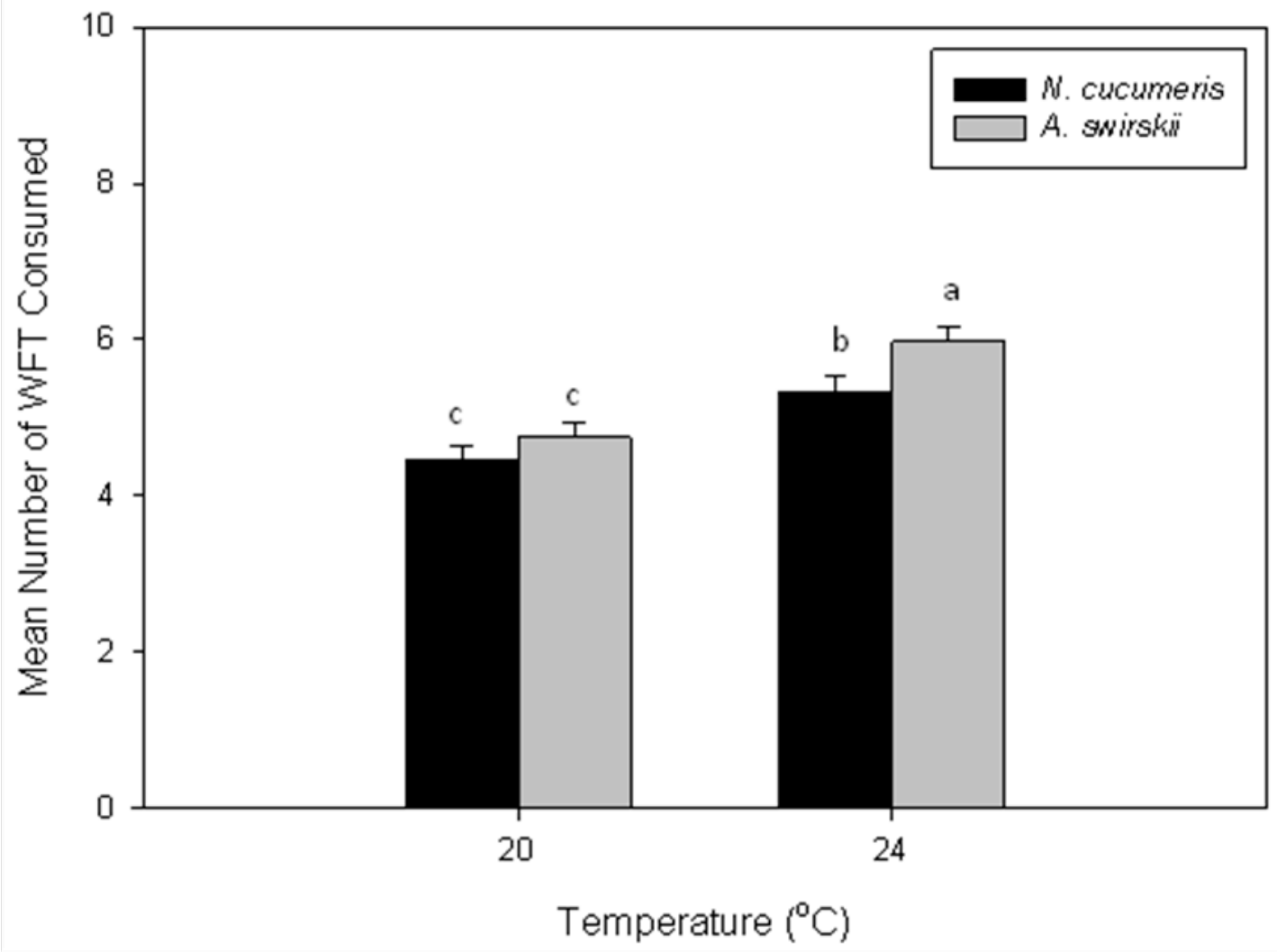

Figure 3.6. Mean number of first instar western flower thrips (WFT) larvae consumed \pm SE by Neoseiulus cucumeris and Amblyseius swirskii on Day 2 and Day 3 in controlled environment chamber bioassays at 20 and $24^{\circ} \mathrm{C}$. Means with the same letter are not statistically different by Tukey's test $(P=0.05)$.

Table 3.3. Mean oviposition rate (eggs/day) of Neoseiulus cucumeris and Amblyseius swirskii when feeding upon first instar western flower thrips (WFT) in a controlled environment chamber bioassay over three days. Means with the same lowercase letter are not significantly different (Tukey's test, $\mathrm{P}=0.05$ ).

\begin{tabular}{cc}
\hline Day & $\begin{array}{c}\text { WFT oviposition rate } \\
\text { (eggs/day) }\end{array}$ \\
\hline 1 & $0.7 \pm 0.09 \mathrm{c}$ \\
2 & $1.2 \pm 0.09 \mathrm{a}$ \\
3 & $1.0 \pm 0.10 \mathrm{~b}$ \\
\hline
\end{tabular}




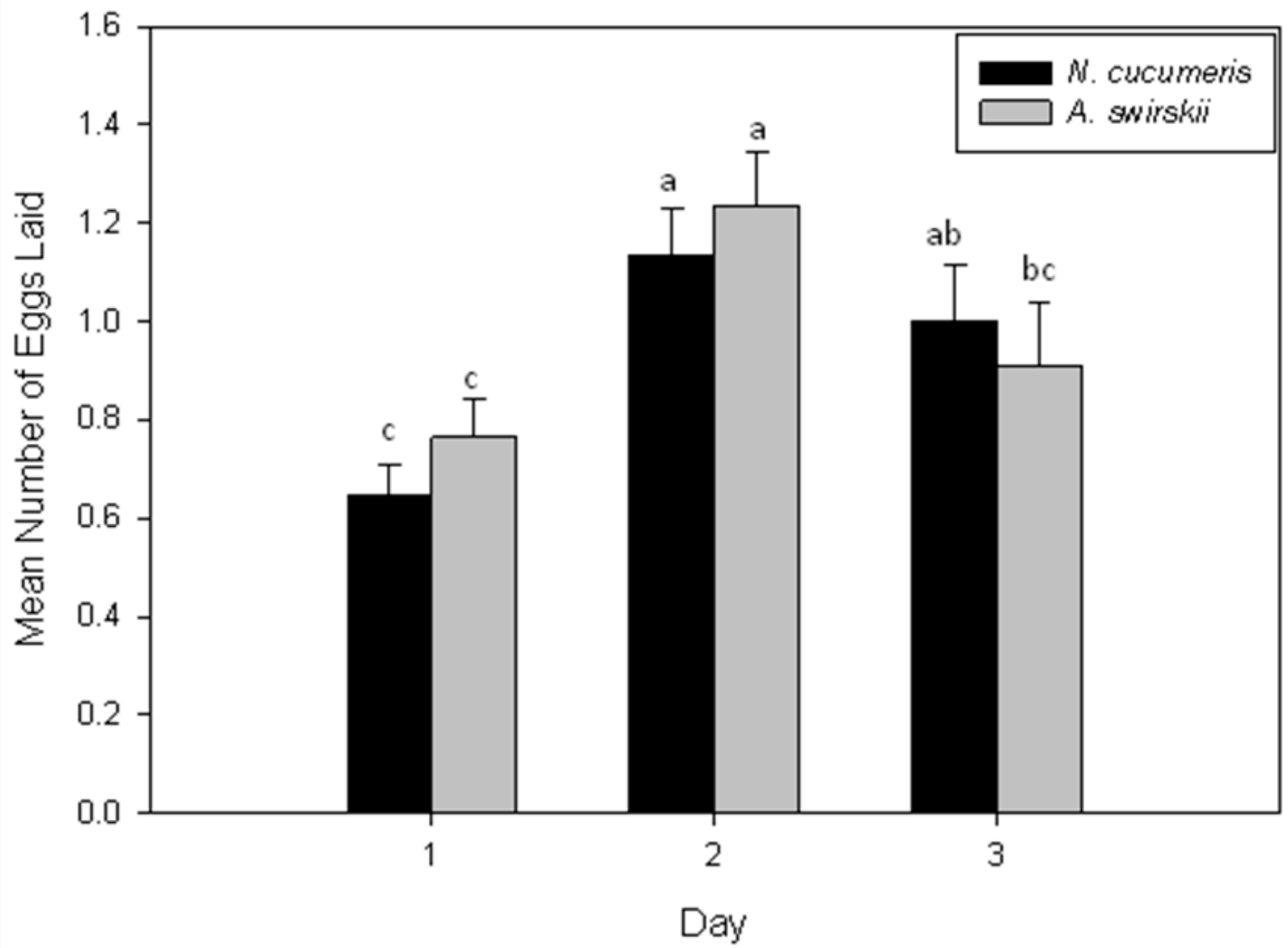

Figure 3.7. Mean number of eggs laid $\pm S E$ by Neoseiulus cucumeris and Amblyseius swirskii in a controlled environment chamber bioassay on Day 1,2 and 3. Means with the same letter are not statistically different by Tukey's test $(P=0.05)$. 


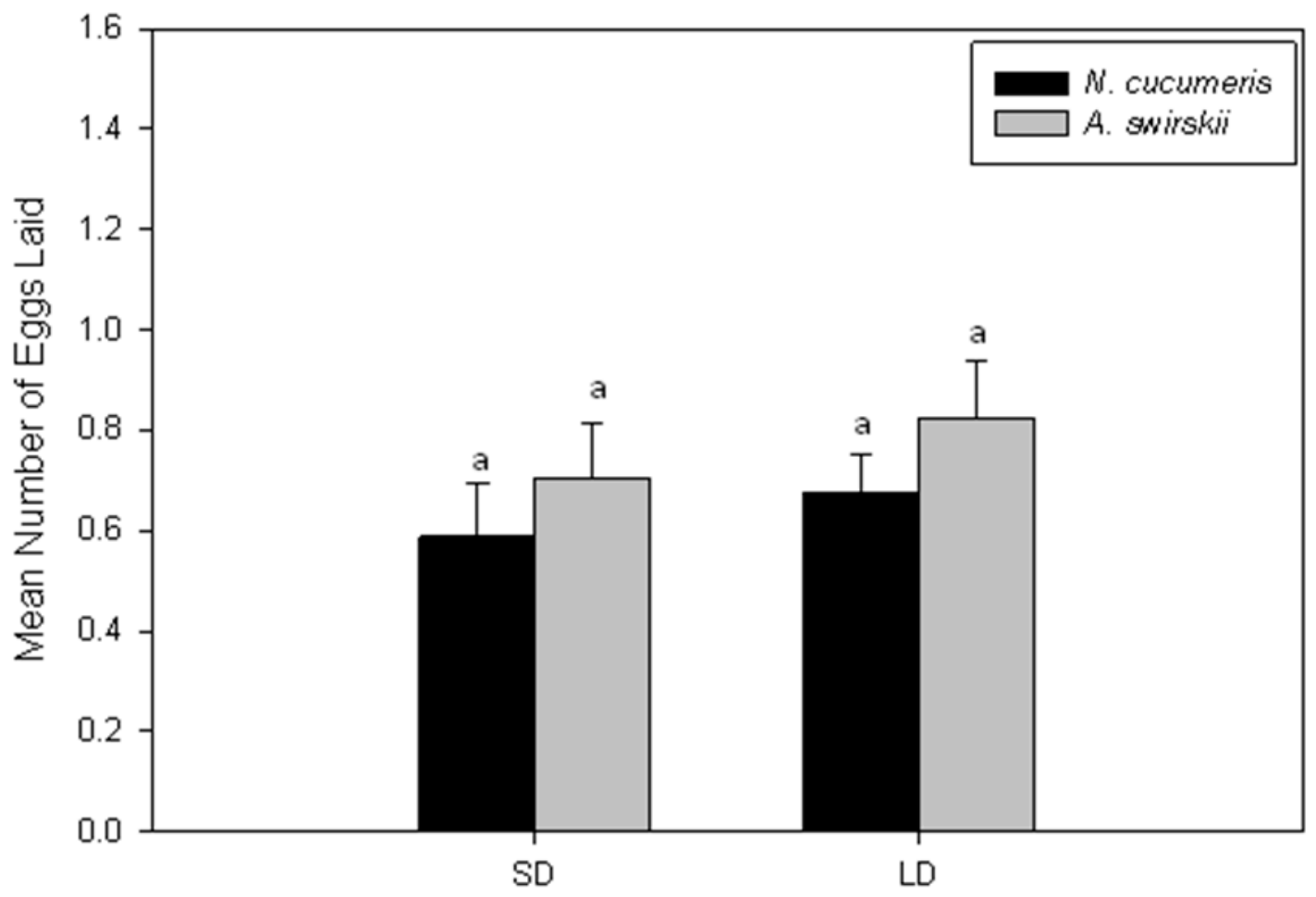

Day Length/Light Intensity

Figure 3.8. Mean number of eggs laid $\pm S E$ on Day 1 by Neoseiulus cucumeris and Amblyseius swirskii in a controlled environment chamber bioassay under short day (SD) conditions ( $8 \mathrm{~h}$ light, $11 \mathrm{~W} / \mathrm{m}^{2}$ ), and long day (LD) conditions (16 h light, $83 \mathrm{~W} / \mathrm{m}^{2}$ ). Means with the same letter are not statistically different by Tukey's test $(P=0.05)$. 


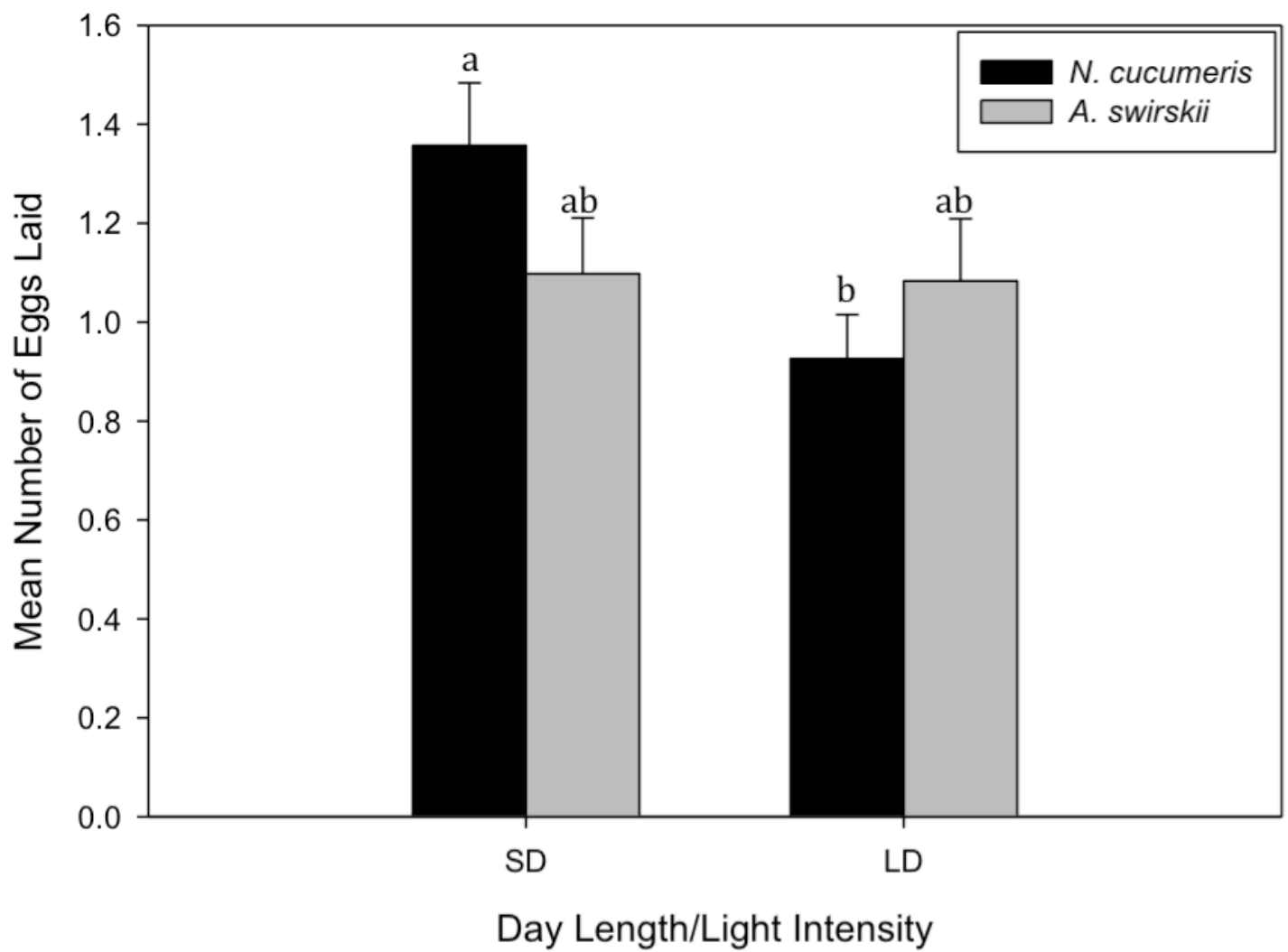

Figure 3.9. Mean number of eggs laid \pm SE by Neoseiulus cucumeris and Amblyseius swirskii on Day 2 and Day 3 in a controlled environment chamber bioassay under short day (SD) conditions ( $8 \mathrm{~h}$ light, $11 \mathrm{~W} / \mathrm{m}^{2}$ ), and long day (LD) conditions (16 h light, 83 $\mathrm{W} / \mathrm{m}^{2}$ ). Means with the same letter are not statistically different by Tukey's test $(P=0.05)$. 


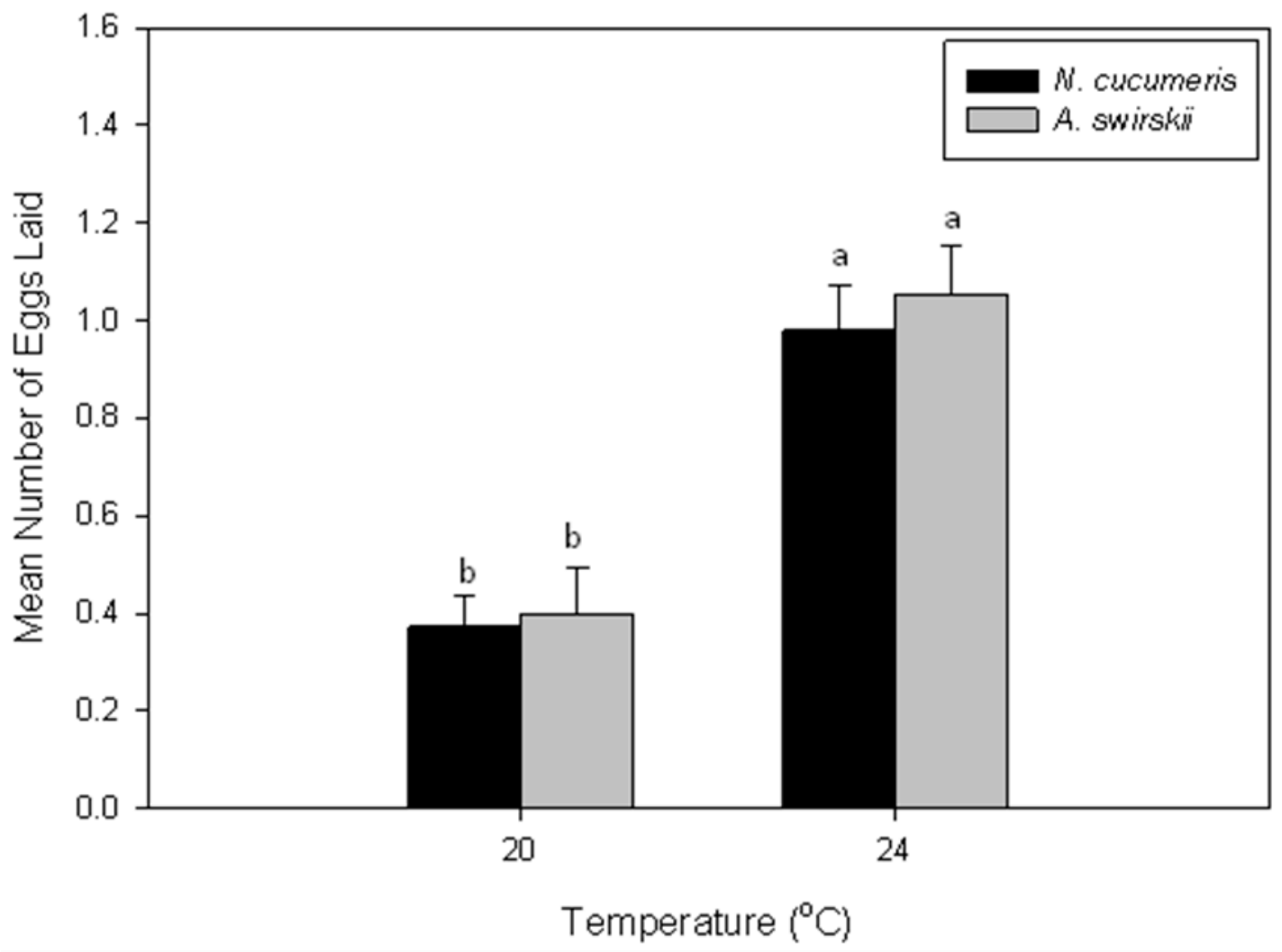

Figure 3.10. Mean number of eggs laid $\pm S E$ on Day 1 by Neoseiulus cucumeris and Amblyseius swirskii at 20 and $24^{\circ} \mathrm{C}$ in controlled environment chamber bioassays. Means with the same letter are not statistically different by Tukey's test $(P=0.05)$. 


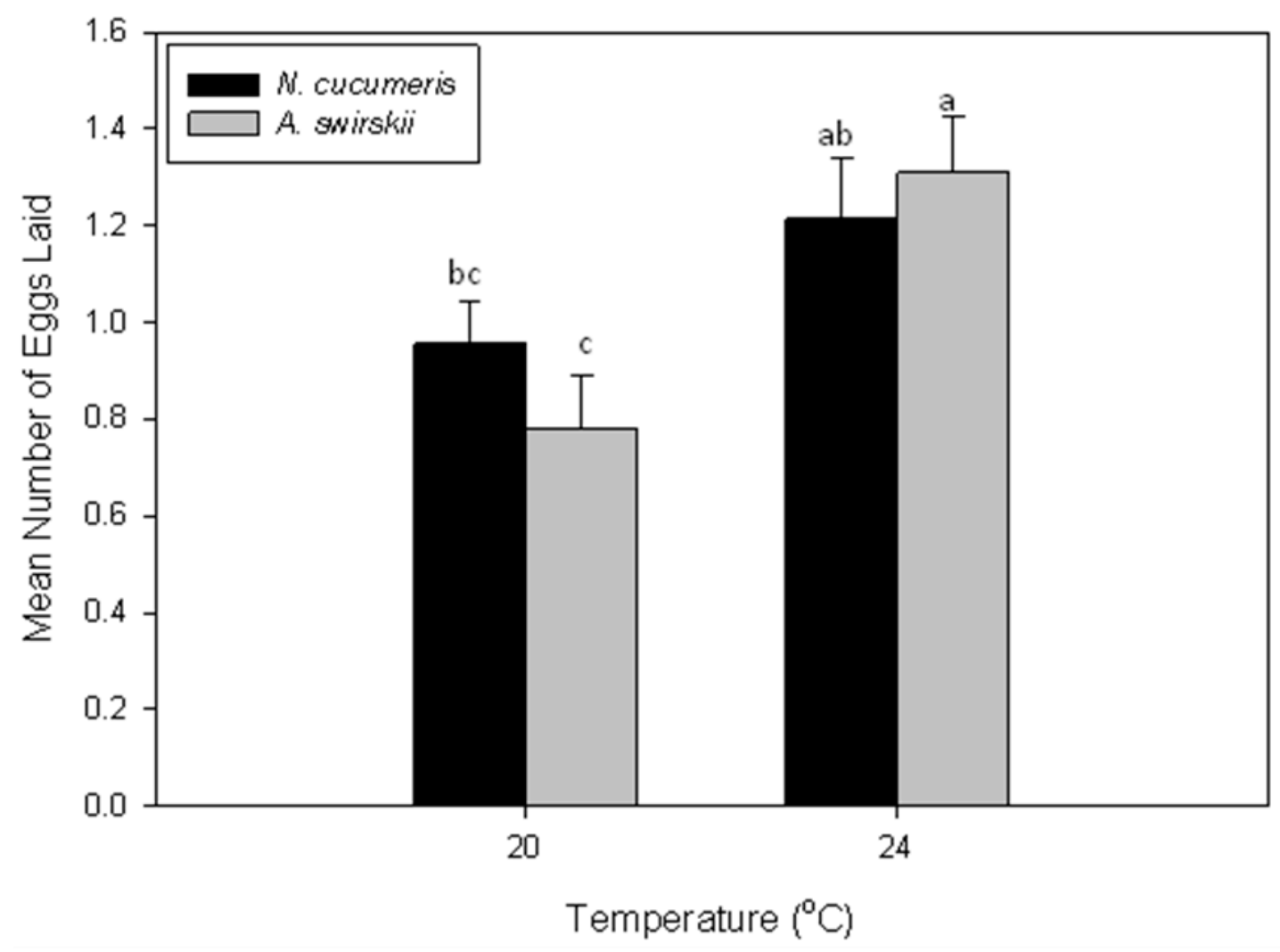

Figure 3.11. Mean number of eggs laid \pm SE on Day 2 and Day 3 by Neoseiulus cucumeris and Amblyseius swirskii at 20 and $24^{\circ} \mathrm{C}$ in controlled environment chamber bioassays. Means with the same letter are not statistically different by Tukey's test $(\mathrm{P}=0.05)$.

\subsection{Discussion}

Daily Predation. It is likely the Day 1 data differed due to experimental design. Female mites were starved for $24 \mathrm{~h}$ prior to the bioassay initiation to ensure a consistent satiation starting point; therefore, the mites consumed more thrips during the first day. The 48 and $72 \mathrm{~h}$ predation counts were not significantly different, suggesting that when adequate prey is available, predatory mites are able to adjust the number of prey consumed daily. In an actual greenhouse setting, this would likely not be the case, as thrips are often scarce and not uniformly distributed on plants, unless there is an outbreak. Also, WFT exhibit thigmotactic behaviour in which they seek a tight physical place in proximal contact with a plant, e.g. a gall, calyx, or fruit (Gerson \& Weintraub, 
2012). Thus, predators are required to spend time searching for and capturing prey. The conditions presented to the mite treatments on Day 1 were more representative of an actual biocontrol program involving their use. When mites are applied to greenhouse plants out of a bulk container, they are most likely not fully satiated. They are then introduced into a crop in which there is often not a large amount of food/prey available. They must spend time searching for, and capturing prey, which means they are likely very hungry by the time they find a suitable food source.

Light Dependent Predation. The results of this trial indicate that light-dependent predation is increased under SD conditions ( $8 \mathrm{~h}$ light, $11 \mathrm{~W} / \mathrm{m}^{2}$ ). On Day $1, A$. swirskii predation rates were equal under both light conditions, while N. cucumeris had a higher predation rate under LD conditions. There was no difference between the mite treatments under LD conditions, however $A$. swirskii consumed more thrips than $N$. cucumeris under SD light levels. Opposite to these results, on Day 2 and Day 3 , predation rates were higher for both mite treatments under SD conditions. Under LD conditions (16h light, $83 \mathrm{~W} / \mathrm{m}^{2}$ ), A. swirskii killed more thrips than N. cucumeris. In a similar experiment, Zilahi-Balogh et al. (2007) found that predation by $N$. cucumeris at $24^{\circ} \mathrm{C}$ was not affected by light intensity or photoperiod. However, the activity of $N$. cucumeris has been linked to the diel cycle under which they have been reared. When reared in complete darkness, Weintraub et al. (2005) collected more N. cucumeris from apical leaves and flowers at a midnight sampling than at noon. The opposite was also true when mites were reared under $24 \mathrm{~h}$ light. Bioassays similar in design to this trial have yielded higher predation under SD conditions for predatory mites (L. ShippPersonal Communication ${ }^{1}$ ). The $N$. cucumeris used in this bioassay were commercially obtained. Successive generations were then reared under long day photoperiods (16L:8D).

\footnotetext{
${ }^{1}$ Dr. Les Shipp, Agriculture and Agri-Food Canada - Greenhouse \& Processing Crops Research Centre,
} 2585 County Road \#20, R. R. \#2 Harrow, Ontario N0R 1G0 Email: Les.Shipp@agr.gc.ca 
These rearing conditions may explain the result of $N$. cucumeris predation rates being higher under LD rather than SD light conditions on Day 1 . The mites may require an adjustment period when introduced to new light regimes, and therefore did not show increased predation under SD conditions until Day 2 and 3. Neoseiulus fallacis (Garman) were more efficient predators at a photoperiod of 10:14 h (L:D) than at the other photoperiods studied: 24:0, 14:10 and 0:24 h (Smith \& Newsom, 1970). The number of $T$. urticae eggs consumed per hour by Galendromus occidentalis (Nesbitt) (Acari: Phytoseiidae) declined as the length of the photophase increased in experiments that commenced during the photophase (Kazak et al., 2004). Predation rates could therefore have been increased at the SD setting because of increased mite activity.

Temperature Dependent Predation. On Day 1 of this trial, temperature did not have an impact on the number of thrips consumed, with no overall difference observed in predation rate at $20^{\circ} \mathrm{C}$ or $24^{\circ} \mathrm{C}$. At both temperatures, $A$. swirskii consumed more WFT than $N$. cucumeris on Day 1 . The number of thrips killed by $N$. cucumeris and $A$. swirskii increased at $24^{\circ} \mathrm{C}$ on Day 2 and 3 . This result supports the findings of ZilahiBalogh et al. (2007), in which $N$. cucumeris killed significantly more thrips at $24^{\circ} \mathrm{C}$ than $20^{\circ} \mathrm{C}$, regardless of light regime, over a $24 \mathrm{~h}$ period. Jones et al. (2005) linked increased leaf temperature with higher body temperature and increased food conversion rate for $N$. cucumeris. An increased food conversion rate explains the need to kill more thrips at higher temperatures. At the higher temperature, A. swirskii consumed more WFT than N. cucumeris. This difference could ultimately be a consequence of the mites' origins. Poikilothermic insects are adapted to the climate in which they originate, and therefore they are best suited to environmental conditions that most closely resemble those of their origin (Trudgill et al., 2005). Based on this theory, A. swirskii activity should be optimized in warmer, drier climates.

Daily Oviposition. The oviposition rate was the highest on Day 2 of this trial, with significantly more eggs observed at the $48 \mathrm{~h}$ count than those of 24 and $72 \mathrm{~h}$ (Table 3.1). These results indicate that oviposition for $N$. cucumeris and $A$. swirskii is dependent on amount of prey consumed by the female, as well as an associated 
processing time for food energy to be converted to eggs. A female phytoseiid mite is capable of producing an egg mass equaling her own weight every day (Sabelis, 1981), but only if optimal climatic and food availability conditions are met. Oviposition among mites is closely related to gut content and the associated processing time of recently ingested food (van Rijn et al., 2005). The rate of gut emptying in P. persimilis is linked to temperature (Sabelis, 1981). A higher temperature may also increase the rate of gut emptying for $A$. swirskii; thereby allowing for motivation to attack prey. Sabelis (1981) found that when mites were starved for three days at $25^{\circ} \mathrm{C}$, they did resume egg production, but only after a period of food handling and digestion. The mites of this trial were initially isolated and starved for $24 \mathrm{~h}$ at $25^{\circ} \mathrm{C}$, but recovered to regular egg-laying ability within $48 \mathrm{~h}$.

Light dependent oviposition. Overall, light intensity and day length did not have a large impact on oviposition rates in this experiment. On Day 1, there was no difference in oviposition rate between the two light treatments or mite treatments. On Day 2 and 3 , the oviposition rate of $A$. swirskii did not differ between SD and LD conditions. The oviposition rate of $N$. cucumeris was increased under SD conditions. This result was not expected considering $N$. cucumeris only lay eggs during the photophase in a day (Zilahi-Balogh et al., 2007). However, in the LD light treatment, the light intensity was also increased. Predatory mites are generally found on the underside of leaves out of direct sunlight and lay their eggs in locations where they are less susceptible to desiccation (R. Buitenhuis- Personal Communication ${ }^{2}$ ). The combination of a longer light period with a greater light intensity $\left(83 \mathrm{~W} / \mathrm{m}^{2} \mathrm{vs} .11 \mathrm{~W} / \mathrm{m}^{2}\right)$ may have been too extreme for $N$. cucumeris, a temperate-climate species.

\footnotetext{
${ }^{2}$ Dr. Rose Buitenhuis, Research Scientist, Vineland Research and Innovation Centre. 4890 Victoria Ave. N., Box 4000, Vineland Station, ON LOR 2E0 Email: Rose.Buitenhuis@vinelandresearch.com
} 
Temperature dependent oviposition. The results of this trial indicate oviposition rates are highly temperature-dependent for both $N$. cucumeris and $A$. swirskii (Figure 3.7). More eggs were laid at $24^{\circ} \mathrm{C}$ than $20^{\circ} \mathrm{C}$ on all days. On Day 2 and 3 , A. swirskii laid the largest number of eggs at $24^{\circ} \mathrm{C}$. Higher fecundity at increased temperatures has been observed in other studies (Cloutier et al., 1995; Lee \& Gillespie, 2011). Oviposition rates increase at higher temperatures because the rates of other physiological processes, such as digestion time, are decreased at higher temperatures. This, along with an increased predation rate provides energy for rapid egg production rates (Jones et al., 2005). This result indicates that at a higher temperature, a population of phytoseiids may be able to increase in size at a more rapid rate.

\subsection{Summary}

From this data, it appears that seasonal climate regimes have an impact on the oviposition and predation rates of $A$. swirskii and $N$. cucumeris in laboratory/greenhouse settings. Predation and oviposition rates increased at higher temperatures. Photoperiod and light intensity also have an impact on predatory mites, but the effect was less clear. At Day 2 to 3, predation rates for both mite species were increased when subjected to short day light conditions ( $8 \mathrm{~h}$ light, $11 \mathrm{~W} / \mathrm{m}^{2}$ ). Neoseiulus cucumeris also laid more eggs at the short day light levels than those tested under long day settings.

Variation in oviposition rate can impact the ability of a mite species to establish and spread throughout the crop, and thus, may also contribute to the success of one species or another. Mite populations that are able to establish within a crop may reduce the frequency or total amount of mite releases necessary for a commercial grower. In relation to temperature, the intrinsic rate of natural population increase $\left(r_{m}\right)$ is similar for N. cucumeris fed WFT and A. swirskii fed cattail pollen (Typha latifolia) (Cloutier et al., 1995; Lee \& Gillespie, 2011). If temperature were the only climatic parameter affecting the population growth rate of predatory mites, one would expect similar responses from both species at equal temperatures. There were differences in predation and oviposition rates between $N$. cucumeris and $A$. swirskii when they were subjected to differing photoperiod and light intensities. 
It is clear that when incorporating predatory mites into their IPM program, commercial greenhouse growers need to be more aware of season i.e. time of year and average daily temperature, and seasonal differences in mite species efficacy, in order to incorporate the most appropriate predatory mite in their biocontrol programs. Factors such as timing and mite release frequency must also be taken into consideration. Predatory mites are most effective when applied as a preventative measure, rather than a curative option. If a mite population is expected to establish and increase upon application, as is often the case in biological control programs, the environment they are being introduced to must be considered (Lee \& Gillespie, 2011). From this experiment, A. swirskii are the better choice for the warmer temperatures of summer. They had higher predation rates than N. cucumeris at higher temperatures. At the cooler temperatures and reduced light conditions of winter, $N$. cucumeris were the better mite in terms of oviposition rate. The higher oviposition rate of $N$. cucumeris under short day conditions may positively affect the population increase capacity of this mite during winter. However, there may be other factors within a greenhouse microclimate that impact predator and prey activity and populations. To extend upon these findings, experiments were conducted within greenhouses in summer and winter to determine if these trends carry over into actual greenhouse production systems. 


\section{CHAPTER 4}

\section{ESTABLISHMENT OF PREDATORY MITES ON GREENHOUSE CHRYSANTHEUM AND CONTROL OF WESTERN FLOWER THRIPS POPULATIONS}

\subsection{Abstract}

The reliance on conventional pesticides in greenhouse floricultural production is declining because of government and consumer pressure, and lack of efficacy. Instead, other IPM options such as biological control, are becoming more widely adopted by commercial growers, and are incorporated into their IPM programs. To control one of the most ubiquitous pests of ornamental production: the western flower thrips (WFT), the predatory mites Amblyseius swirskii and Neoseiulus cucumeris are mass-produced and sold to growers. However, the cost of $A$. swirskii is at least three times that of $N$. cucumeris. Some evidence suggests that $A$. swirskii is a better predator, though this is not universally accepted. Seasonal climatic differences in greenhouses may be a possible explanation for discrepancies. When the efficacy and population densities of $N$. cucumeris and $A$. swirskii were compared in greenhouses in winter, there was no difference between mite species in either small cage trials or commercial greenhouse trials. In summer small cage and commercial greenhouse trials, populations of $A$. swirskii were significantly higher than N. cucumeris, and WFT populations were lower when treated with $A$. swirskii. Heavy feeding damage on leaves was significantly reduced by both mite treatments in summer and winter. Amblyseius swirskii reduced heavy feeding damage in the summer to a significantly lower level than that of $N$. cucumeris. Based on these results, it is suggested that growers incorporate the more cost-effective $N$. cucumeris into their winter IPM programs, while use of $A$. swirskii in the summer should provide the best WFT control.

\subsection{Introduction}

In ornamental greenhouse production, damage due to western flower thrips (WFT) feeding and oviposition causes reduced crop quality leading to monetary losses for growers. Also, WFT is a vector of serious plant viruses that can devastate a crop. In the past, commercial growers have utilized synthetic pesticides to combat WFT populations. 
However, because thrips have a cryptic lifestyle and rapidly develop resistance to insecticides, pesticide applications often fail to contact and control populations (Reitz, 2009). In addition, consumers are exerting increasing pressure for products that are produced in an environmentally- and greenhouse worker-friendly manner, thus severely restricting pesticides as an IPM option. Some sanitation practices such as high temperature and vapor pressure deficit (VPD) combinations can be used at the end of a cropping cycle to sanitize the growing area and kill any remaining thrips. Shipp \& Gillespie (1993), found that $40^{\circ} \mathrm{C}$ and VPD $\geq 4.76 \mathrm{kPa}$ will control all thrips. However, this control method is not an option during regular production periods. Biological control agents (BCAs) have been incorporated into commercial greenhouse IPM programs for many years; however, they are not without shortcomings. Because BCAs are living organisms, they are sensitive to environmental conditions and have a limited shelf life. There are many known predators of WFT, but growers need to maximize efficiency and choose a single species or combination of species that will reduce pest populations optimally. Neoseiulus cucumeris and Amblyseius swirskii are two commercially available BCAs used for control of WFT. Although both of these mites are voracious predators, $N$. cucumeris is limited to attacking only first instar thrips, presumably because of their body size and limited defense mechanisms (Bakker \& Sabelis, 1989; Buitenhuis et al., 2010b). Amblyseius swirskii feeds mainly on first instar thrips larvae, but occasionally will kill second instar larvae. A grower may be tempted to apply both mites to a crop in hopes of increased pest control. Buitenhuis et al. (2010b) have found that given the choice, $A$. swirskii and $N$. cucumeris will partake in intra-guild predation and feed on each other's eggs, thereby potentially decreasing the efficacy of both species. Intra-guild predation was tested in the laboratory, but it is unclear what distance the mites will travel within a greenhouse, and whether it would be detrimental to apply different mite species to different greenhouse sections. As the potential for negative interactions exists, growers should choose just one of these predators for use.

To purchase $A$. swirskii in bulk is approx. three times the price of the same amount of N. cucumeris in southwestern Ontario. Based on the prices of MGS Horticultural Inc. (Leamington, ON), Koppert Biological Systems Canada (Scarborough, ON), and Plant Products Co. Ltd. (Brampton, ON), it costs approx. \$40.00 CDN for 
50,000 bulk $N$. cucumeris, and $\$ 115.00 \mathrm{CDN}$ for the same amount of $A$. swirskii. Neoseiulus cucumeris is, therefore, more economical, and growers will often choose this predator for their thrips biocontrol program. However, studies suggest that $A$. swirskii may be a better thrips predator (Messelink et al., 2006; van Houten et al., 2005). When their efficacy for thrips control on cucumber plants was tested, A. swirskii, as well as Typhlodromalus limonicus (Garman \& McGregor) and Euseius ovalis (Evans) reached higher population numbers and thus controlled thrips more efficiently than $N$. cucumeris (Messelink et al., 2006). Neoseiulus cucumeris has also been labeled as an ambush predator (Messelink et al., 2006), while A. swirskii are generally more active in seeking their prey (Personal Observation $-\mathrm{L}$. Hewitt). It is interesting that $N$. cucumeris and $A$. swirskii exhibit differences in efficacy when they are morphologically very similar. One reason for the apparent difference may be due to origin. Amblyseius swirskii is a sub-tropical species, while $N$. cucumeris is a more temperate species originating from New Zealand. Greenhouse crops are produced year-round; and even though greenhouses are heavily mechanized to maintain strict climate regimes, some climatic variation is still possible. For instance, the different seasons experienced in northern temperate climates produce differing temperature, photoperiod, and light intensity levels in the greenhouse. Even minute variations in climate can have dramatic impacts on the activity of pests and predators (Heinz et al., 2004). Laboratory experiments described in Chapter 3, determined that predation and oviposition rates are higher at higher temperatures. Photoperiod and light intensity also have an impact on predatory mites. Predation rates for both mite species were higher when subjected to short day light conditions ( $8 \mathrm{~h}$ light, $11 \mathrm{~W} / \mathrm{m}^{2}$ ). Neoseiulus cucumeris also laid more eggs at the short day light levels than those tested under long day settings (16 h light, $83 \mathrm{~W} / \mathrm{m}^{2}$ ) (Chapter 3 ). With this in mind, the ability of $N$. cucumeris and $A$. swirskii to increase their numbers and control WFT in greenhouse environments in both summer and winter climates of Ontario, Canada was tested. 


\subsection{Materials and Methods}

\subsubsection{Greenhouse small-cage trials}

Greenhouse setup and sampling procedure. During the summer and winter of 2011 and 2012, greenhouse cage trials were conducted the Greenhouse and Processing Crops Research Centre (GPCRC) in Harrow, ON, Canada, and the University of Guelph, Guelph, ON, Canada. The experimental design consisted of 52 small $\left(60 \times 60 \mathrm{~cm}\right.$ ) Bugdorm ${ }^{\odot}$ cages (Megaview Science Co. Ltd., Taichung, Taiwan) in a greenhouse compartment $(13 \times 8 \mathrm{~m})$. Each cage contained a $15 \mathrm{~cm}$ potted chrysanthemum (var. Chesapeake) obtained from Keepsake Plants Ltd. (Leamington, ON) or propagated at the University of Guelph, approx. seven weeks after cuttings were planted. Each plant consisted of 4-5 cuttings. All plants in each cage were watered and fertilized according to standard production practices. The greenhouse heating set points were $23^{\circ} \mathrm{C}$ (day) and $18^{\circ} \mathrm{C}$ (night) for summer trials, and $21^{\circ} \mathrm{C}$ (day), $18^{\circ} \mathrm{C}$ (night) for winter trials. Venting set points were set $1^{\circ} \mathrm{C}$ higher than each heating set point. $\mathrm{HOBO}^{\circledR}$ data loggers (Onset Computer Corporation, Cape Cod, Massachusetts) were suspended inside two of the cages to monitor temperature and VPD levels in the cages. The summer max/min temperature inside the cages was $36.4 / 16.5^{\circ} \mathrm{C}$, with a mean temperature of $24.4 \pm 0.06^{\circ} \mathrm{C}$. The mean winter temperature was $18.3 \pm 0.03^{\circ} \mathrm{C}$, max $/ \mathrm{min}$ $32.7 / 14.4^{\circ} \mathrm{C}$. Four additional plants were sampled and washed using the methods of Buitenhuis et al. (2007) to determine WFT numbers prior to initiation of the experiment. The WFT level on the potted plants at this time was $<3$ thrips/plant. To standardize the number of thrips on each plant in the cages and ensure adequate increase in WFT numbers, five adult female WFT were introduced onto each plant, along with one adult male WFT to ensure all females were mated. After one week (i.e., week 0), four plants were sampled and washed. The number of WFT female and male adults, pupae, and larvae were recorded for each plant. With the remaining cages (48 total), one of the three treatments was randomly assigned in a completely random design (CRD): no-mite control cages, $50 \mathrm{~N}$. cucumeris or $50 \mathrm{~A}$. swirskii. The mites were obtained in bulk loose bran from Biobest Canada Ltd (Leamington, ON, Canada). To estimate mite densities 
within the bulk mixture, five samples of $1 \mathrm{ml}$ each were taken from the homogenized bulk and adult mites counted. The mean of the five samples was used to estimate the number of mites $/ \mathrm{ml}$ of bulk mixture. Loose bran was then measured and carefully applied to plant foliage until approx. 50 mites were present on the plant. Weekly, for four weeks post-treatment (weeks 1,2,3 and 4), four plants from each treatment (one plant per cage) were sampled, washed and counted. All life-stages of WFT and predatory mites were recorded. Trials were repeated twice over time to obtain 8 replicates of each treatment during each week.

Leaf damage assessments. During each of the four sampling weeks, leaves of the sampled plants were dried after washing in order to assess WFT feeding damage. Fifty leaves of each plant were randomly selected and ranked on a damage scale from 0-2. A score of 0 was assigned to leaves with no visible feeding damage. Light feeding damage was assigned a score of 1 and classified as having 1-3 feeding scars of less than $1 \mathrm{~mm}$. A leaf with 4 or more feeding scars was defined as heavily damaged, and assigned a score of 2 . Plants with more than $10 \%$ of their leaves heavily damaged were considered unmarketable. Plants with more than $25 \%$ of their leaves containing light feeding damage were also considered unmarketable.

\subsubsection{Commercial greenhouse trials}

Sample plots were set up during the winter and summer of 2012 in commercial potted chrysanthemum greenhouse operations. In winter, two replicates were set up at Boekestyn Greenhouses (Jordan Station, ON), and one at Meyers Farms (Niagara-onthe-Lake, ON) (February \& March). In summer, four replicates were set up at Meyers Farms (July \& August). An area containing 100 chrysanthemum plants of the same variety (var. Chesapeake or Brighton) on a greenhouse bench was marked off with flags and designated as control (no additional BCAs applied), A. swirskii treated (50 mites per plant) or $N$. cucumeris treated (50 mites per plant). Yellow flowering varieties of chrysanthemum were chosen because of their attractiveness to WFT (Blumthal et al., 2005). Mite densities within the bulk bran mixture were determined using the same 
methods described for the small cage greenhouse trials (Section 4.3.1). An appropriate quantity of scoops was then applied to each plant to total $\sim 50$ mites/plant. Three plants from each plot were sampled, washed and counted during the first week of the trial to determine initial WFT and BCA levels. Predatory mite treatments were also applied during week 1.

One week post-treatment, three plants of each plot were sampled, washed and counted to quantify WFT control and predatory mite recovery rate according to methods of Buitenhuis et al. (2007). Each mite recovered from sampled plants was slide mounted and identified to species. Plants were sampled and washed in the same manner for an additional five weeks, ensuring sampled plants were taken from the center of a cluster of plants to eliminate edge effects. Mite treatments were applied on weeks 1,3 and 5 . WFT leaf damage was observed to be low (below the marketability threshold) or non-existent throughout the trial.

\subsubsection{Data Analysis}

For the summer and winter small cage greenhouse trials, a two-way ANOVA using PROC MIXED on untransformed data was performed with the model $Y=\mu+$ mite treatment + week + mite treatment ${ }^{*}$ week + error with WFT and live mite adults that were identified to species as dependent variables. Fixed variables in the model were mite treatment, week, and mite treatment ${ }^{*}$ week. The random effects were repetition and residual error. A Shapiro-Wilk test was performed to ensure normality of the data. A Tukey's adjusted multiple means comparison was used to detect significant differences among fixed effects.

Commercial greenhouse trial data was analyzed with a two-way ANOVA. The fixed effects week, mite treatment, replicate and week ${ }^{*}$ mite treatment were used to test the dependent variables: live WFT and live adult mites that were identified to species. Random effects in the model were repetition and residual error. No significant difference was found among the four replicates; therefore data were pooled for the remainder of the analysis. The data were tested for normality using a Shapiro-Wilk test. 
Significant differences between fixed effects were detected using a Tukey's adjusted multiple means comparison.

Leaf damage assessments were analyzed using PROC MIXED with the fixed effects of week and mite treatment used to test the dependent variables heavy, light or no leaf damage. Random error was also measured in the model. The data were tested for normality using a Shapiro-Wilk test. Significant differences between fixed effects were detected using a Tukey's adjusted multiple means comparison.

All data were analyzed using SAS v. 9.1, SAS Institute, Cary, N.C. In all cases the critical $p$ value for significance was $\alpha=0.05$.

\subsection{Results}

\subsubsection{Small Cage Greenhouse Trials: Summer}

During the four week treatment period WFT numbers were significantly reduced by $N$. cucumeris and $A$. swirskii treatments $\left(\mathrm{F}_{2,81}=43.16, \mathrm{P}<.0001\right)$ (Appendix Table 1). When treated with $A$. swirskii, WFT numbers were significantly lower at week 2 than on $N$. cucumeris treated plants (Figure 4.1). When adult mite populations were compared, $A$. swirskii populations were significantly higher than that of $N$. cucumeris at week 2 in the sample period $\left(F_{1,54}=10.92, P=.0017\right)$ (Figure 4.2) (Appendix Table 2).

Leaf Damage. With the exception of week 1, the leaves of treated plants had significantly reduced heavy feeding damage compared to controls in this study $\left(F_{2,36}=79.53, P<0.0001\right)$ (Figure 4.3). Amblyseius swirskii-treated plants had the lowest number of leaves with heavy feeding damage at the end of the four-week observation period (Figure 4.3). The number of leaves with heavy feeding damage increased in the control over the trial, but remained low and relatively stable on treated plants (Figure 4.3).

Treatments did not have a significant impact on the amount of light feeding damage observed on sampled leaves $(F=2.53, P=0.0941)$. The number of leaves with a damage score of 0 at the end of the four weeks was significantly different for treated 
plants $(\mathrm{F}=42.24, \mathrm{P}<0.0001)$, with $A$. swirskii-treated plants having the largest proportion of undamaged leaves. For heavy and no feeding damage leaf assessments, damage levels in each category changed over the four weeks of the trial $\left(F_{3,36}=33.85\right.$, $\mathrm{P}<0.0001 ; \mathrm{F}=21.16, \mathrm{P}<0.0001$ ) (Figure 4.3). The number of leaves classified in the light leaf damage category was overall not significantly different during the course of the trial ( $F=2.86, P=0.0501$ ) (Appendix Table 5,6,7).

After 4 weeks, plants from all treatments contained greater than the $10 \%$ threshold for heavily damaged leaves, and were therefore not marketable (Figure 4.4). Plants treated with $A$. swirskii had the greatest proportion of leaves $(\sim 70 \%)$ with no feeding damage at the end of the trial (Figure 4.4).

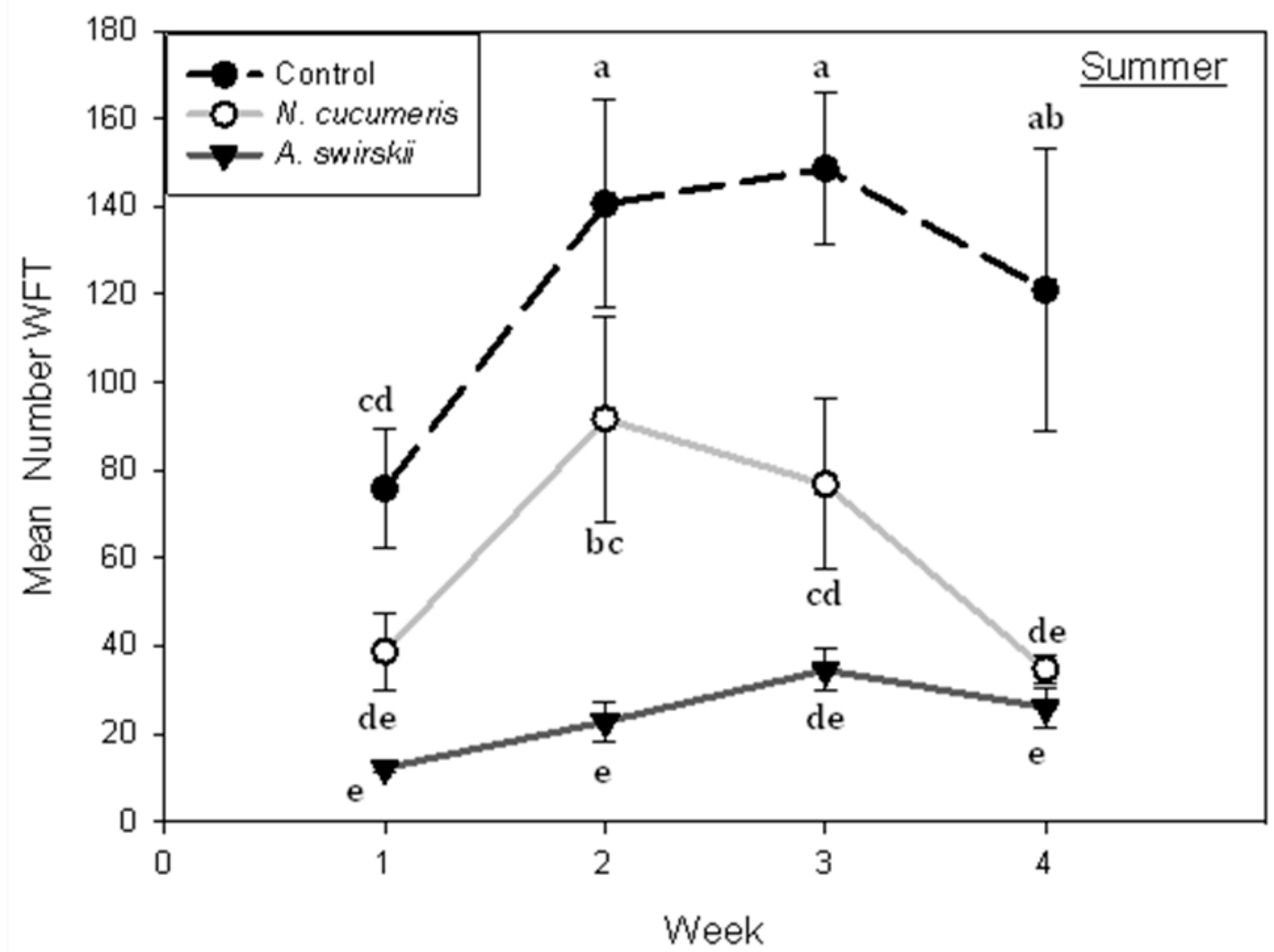

Figure 4.1. Mean number of western flower thrips (WFT) (all life stages) $\pm S E$ on Neoseiulus cucumeris and Amblyseius swirskii treated chrysanthemum plants (cv. Chesapeake) in small cages in a greenhouse over four weeks during the summer. Data points with different letters indicate a significant difference between treatments and weeks by Tukey's test $(P=0.05)$. 


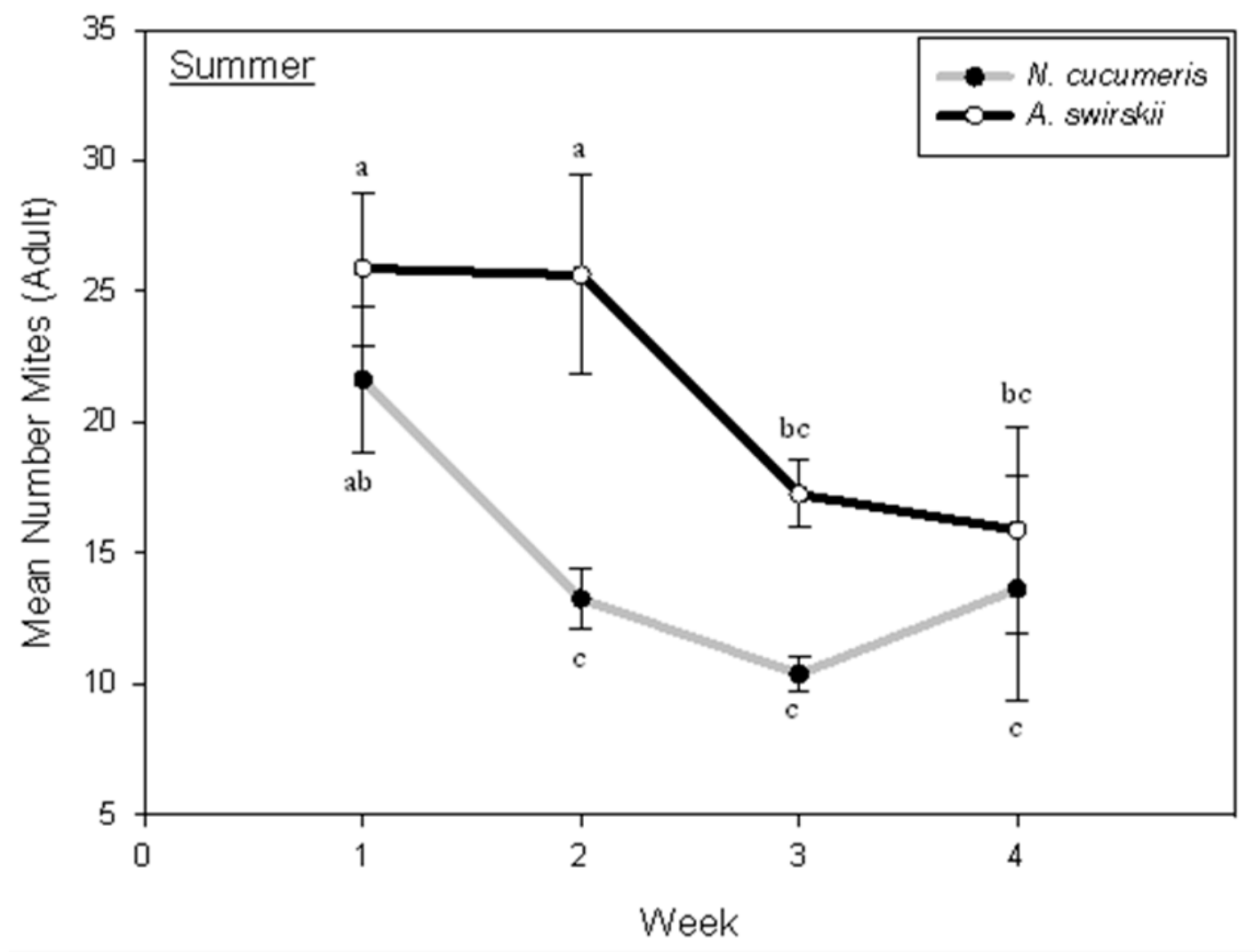

Figure 4.2. Mean number of Neoseiulus cucumeris and Amblysieus swirskii $\pm S E$ on potted chrysanthemum plants (cv. Chesapeake) in small cages in a greenhouse over four weeks during the summer. Data points with different letters indicate a significant difference between treatments and weeks by Tukey's test $(P=0.05)$. 


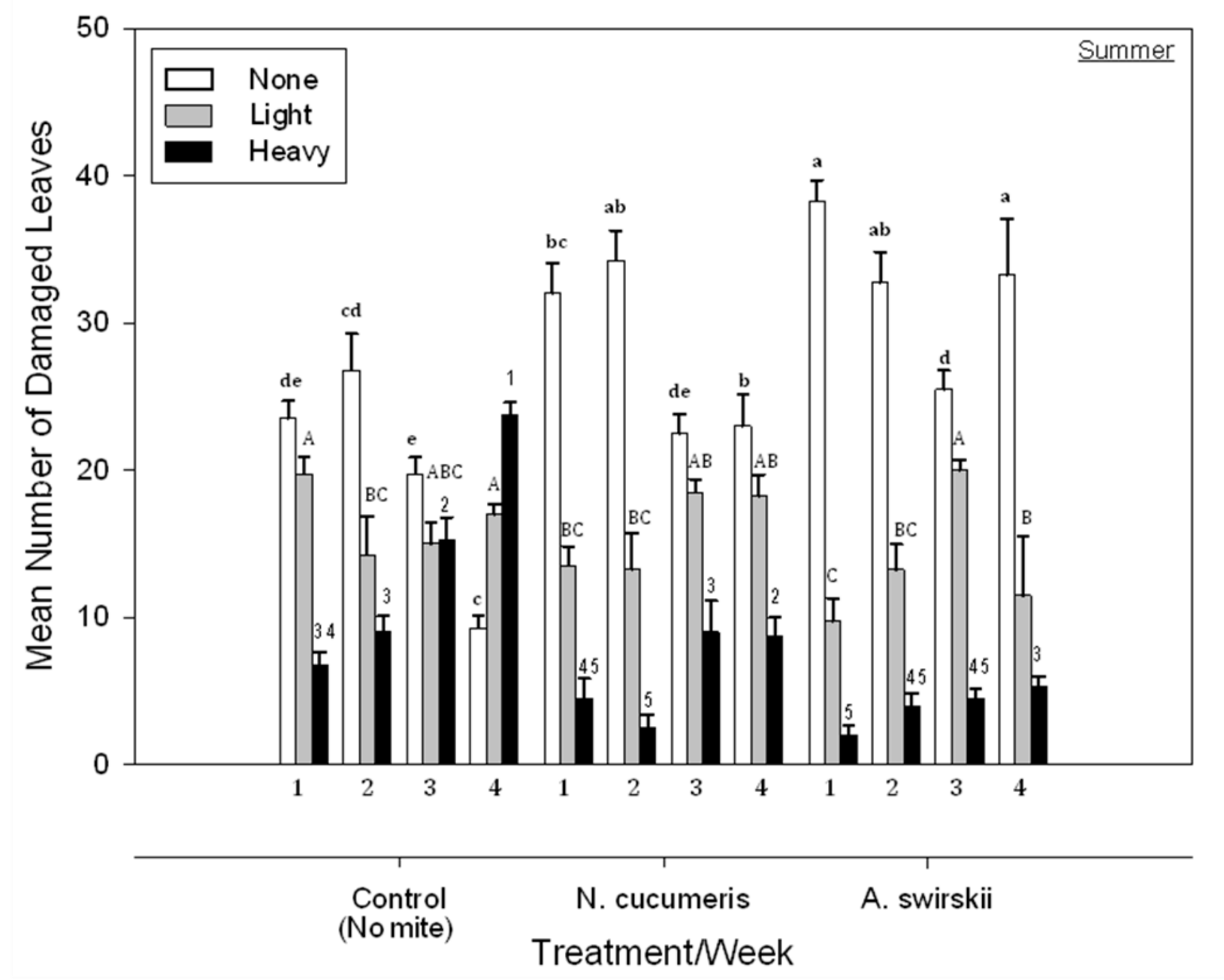

Figure 4.3. Mean number of leaves with heavy (4 or more feeding scars), light (1-3 feeding scars of $<1 \mathrm{~mm}$ ), or no visible western flower thrips feeding damage $\pm S E$ in small cages in a greenhouse over four weeks during summer. Treatments were Neoseiulus cucumeris, Amblysieus swirskii, or no-mite control. Means with different letters (upper or lower case) or numbers indicate a significant difference between treatments within each week by Tukey's test $(P=0.05)$. 


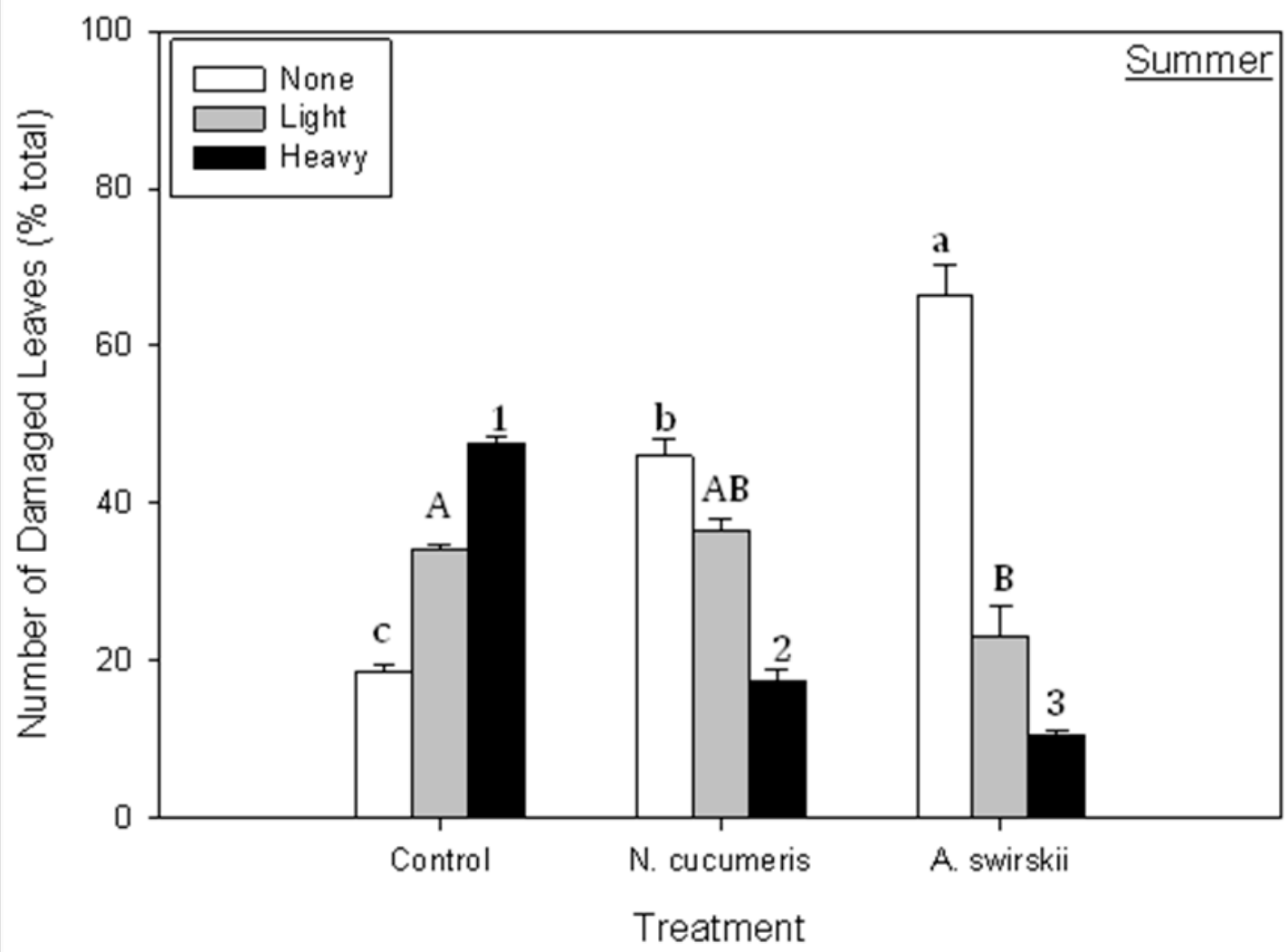

Figure 4.4. Week 4 mean number of leaves with heavy (4 or more feeding scars), light (1-3 feeding scars of $<1 \mathrm{~mm}$ ), or no visible western flower thrips feeding damage $\pm S E$ calculated as a percentage of the total sample (50 leaves total) in small cages in a greenhouse over four weeks during summer. Treatments were Neoseiulus cucumeris, Amblysieus swirskii, or no-mite control. Means with different letters (upper or lower case) or numbers indicate a significant difference between treatments by Tukey's test $(P=0.05)$.

\subsubsection{Small cage greenhouse trials: Winter}

During winter, WFT numbers in the small cage greenhouse trials were significantly reduced during throughout the sampling period, when treated with $N$. cucumeris and $A$. swirskii $\left(\mathrm{F}_{2,78}=46.70, \mathrm{P}<.0001\right)$ (Appendix Table 3). There was no difference in WFT numbers for either mite treatment over the trial period (Figure 4.5). The number of adult $N$. cucumeris and $A$. swirskii did not statistically differ from each other at any sampling period $\left(F_{1,52}=1.05, P=.3098\right)$, but declined during the trial (Figure 4.6) (Appendix Table $4)$. 


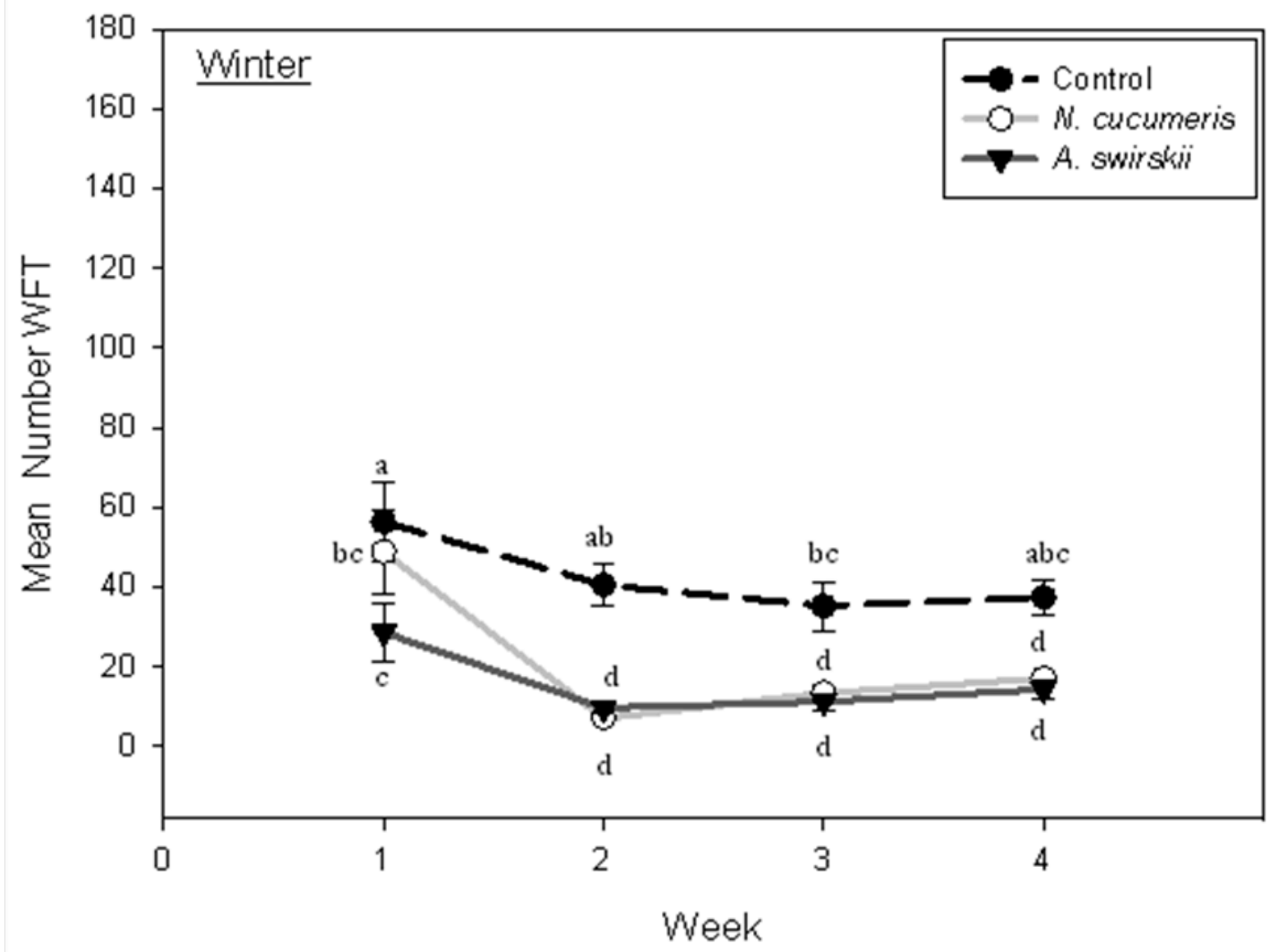

Figure 4.5. Mean number of western flower thrips (WFT) (all life stages) $\pm S E$ on Neoseiulus cucumeris- and Amblysieus swirskii-treated potted chrysanthemum plants (cv. Chesapeake) in small cages in a greenhouse over four weeks during the winter. Data points with different letters indicate a significant difference between treatments and weeks by Tukey's test $(P=0.05)$. 


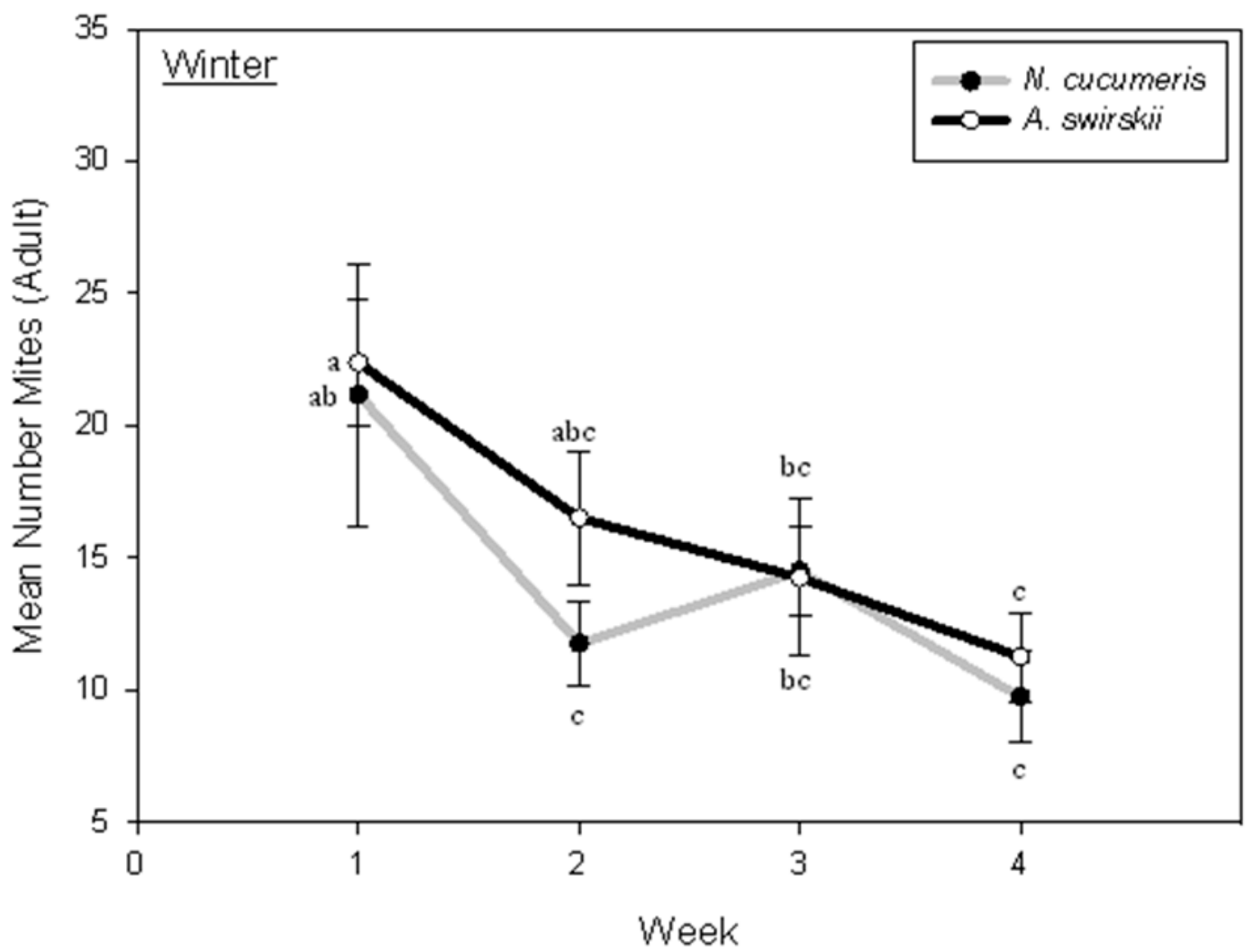

Figure 4.6. Mean number of Neoseiulus cucumeris and Amblysieus swirskii $\pm S E$ on potted chrysanthemum plants (cv. Chesapeake) in small cages in a greenhouse over four weeks during winter. Data points with different letters indicate a significant difference between treatments and weeks by Tukey's test $(P=0.05)$.

Leaf Damage. Heavy feeding damage was significantly reduced on treated plants during the winter $\left(F_{2,81}=9.23, P=0.0002\right)$. Heavy feeding damage on $N$. cucumeris - and A. swirskii-treated plants was significantly different from the control at week 4 (Figure 4.7). Both $N$. cucumeris and $A$. swirskii reduced heavy feeding damage to the same level at the 4-week post-treatment sampling period. Light feeding damage was significantly reduced by $A$. swirskii, but not by $N$. cucumeris $\left(F_{2,81}=6.28, P=0.0029\right)$ (Figure 4.7). The amount of leaves with no visible feeding damage was significantly higher for treated plants than the control at weeks 1 and 4 , with $A$. swirskii-treated plants having the highest amount of undamaged leaves at the end of the trial $(F=15.69$, $P<0.0001$ ). For leaf damage assessments, damage levels in each category (none, light, 
heavy) changed over the four weeks of the trial $\left(F_{3,81}=8.70, P<0.0001 ; F=7.67\right.$, $\mathrm{P}=0.0001 ; \mathrm{F}=17.79, \mathrm{P}<0.0001$ ) (Figure 4.7) (Appendix Table 8,9,10).

Based on the $10 \%$ threshold for heavily damaged leaves, plants of all treatments were not marketable at the end of the four-week trial (Figure 4.8).

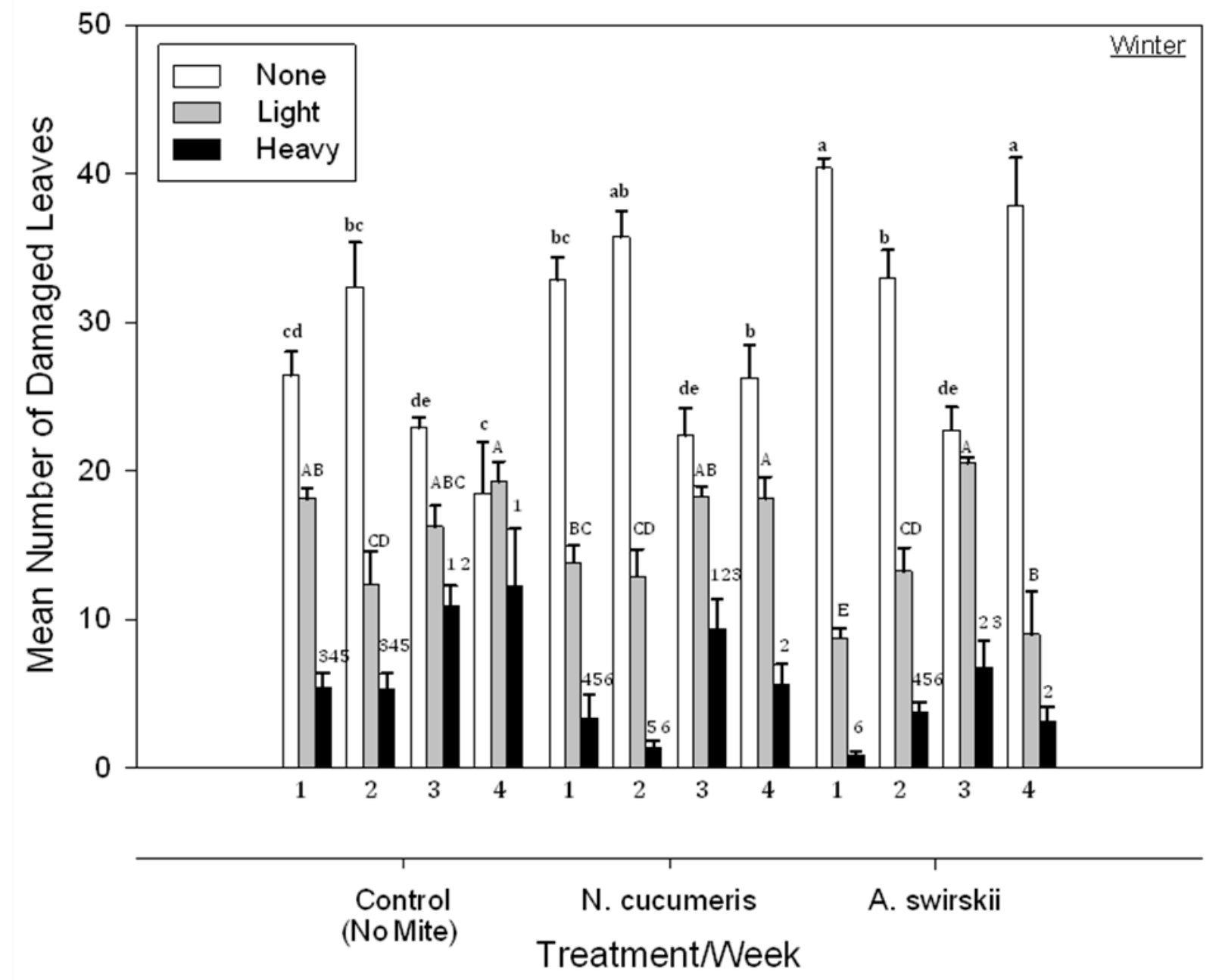

Figure 4.7. Mean number of leaves with heavy (4 or more feeding scars), light (1-3 feeding scars of $<1 \mathrm{~mm}$ ), or no visible western flower thrips feeding damage $\pm S E$ in small cages in a greenhouse over four weeks during winter. Treatments were Neoseiulus cucumeris, Amblysieus swirskii, or no-mite control. Means with different letters (upper or lower case) or numbers indicate a significant difference between treatments within each week by Tukey's test $(P=0.05)$. 


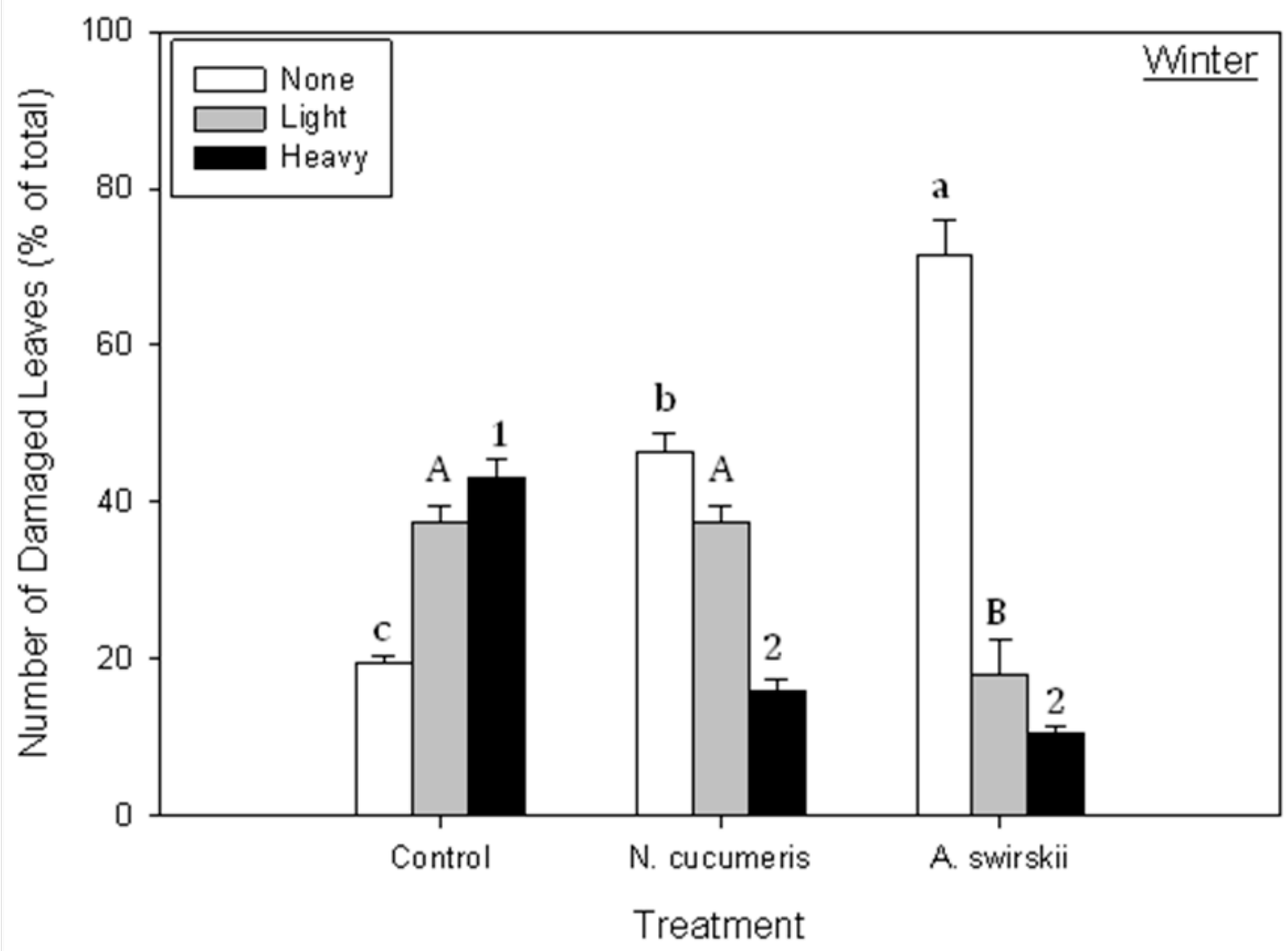

Figure 4.8. Week 4 mean number of leaves with heavy (4 or more feeding scars), light (1-3 feeding scars of $<1 \mathrm{~mm}$ ), or no visible western flower thrips feeding damage $\pm S E$ calculated as a percentage of the total sample (50 leaves total) in small cages in a greenhouse over four weeks during winter. Treatments were Neoseiulus cucumeris, Amblysieus swirskii, or no-mite control. Means with different letters (upper or lower case) or numbers indicate a significant difference between treatments by Tukey's test $(P=0.05)$.

\subsubsection{Commercial greenhouse trials: Summer}

For the duration of this trial, the growers did not experience outbreaks of WFT. As a result of WFT numbers remaining low in the commercial greenhouses, no heavy feeding damage was observed on the plants and consequently no crop losses were sustained. Despite low WFT numbers, the number of WFT recovered from plants was significantly lower for both $N$. cucumeris and $A$. swirskii than compared to the control $\left(F_{2,195}=28.61\right.$, $\mathrm{P}<.0001$ ) at week 2 and week 3 (Appendix Table 11). There was no significant 
difference in number of WFT recovered from plants of either mite treatment (Figure 4.9). Overall, the number of recovered $A$. swirskii was significantly higher than that of $N$. cucumeris on commercially-grown chrysanthemums $\left(\mathrm{F}_{1,129}=41.08, \mathrm{P}<.0001\right)$ (Figure 4.10) (Appendix Table 12). Amblyseius swirskii were recovered in higher numbers than N. cucumeris during weeks $2,3,4$ and 6.

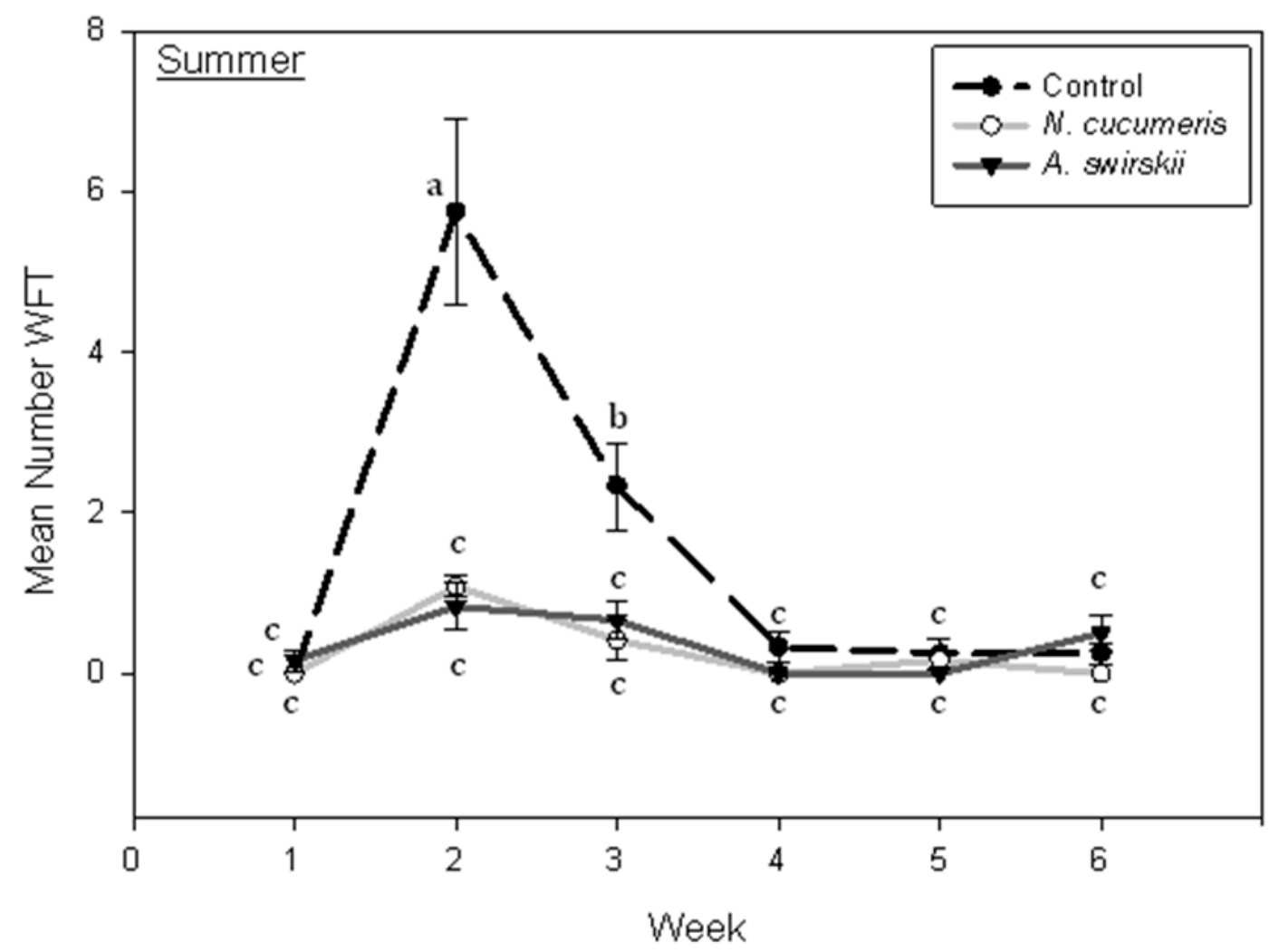

Figure 4.9. Mean number of western flower thrips (WFT) (all life stages) $\pm S E$ on control (no-mites), Neoseiulus cucumeris and Amblyseius swirskii-treated potted chrysanthemums over six weeks in a commercial greenhouse during summer. Means with different letters indicate a significant difference between treatments and weeks by Tukey's test $(P=0.05)$. 


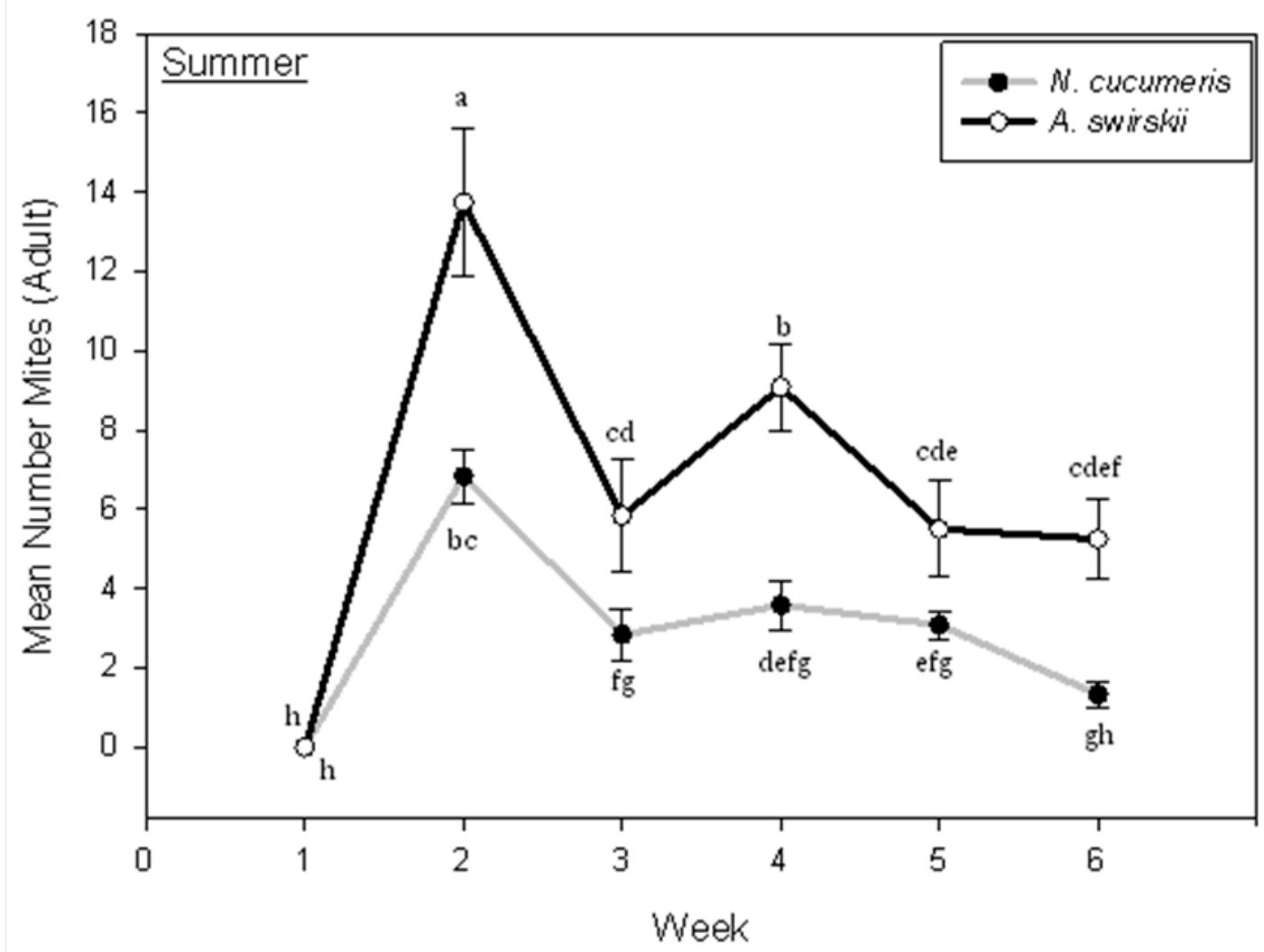

Figure 4.10. Mean number of Neosieulus cucumeris and Amblysieus swirskii $\pm S E$ over six weeks on potted chrysanthemums in a commercial greenhouse during summer. Data points with different letters indicate a significant difference between treatments and weeks by Tukey's test $(P=0.05)$.

\subsubsection{Commercial greenhouse trials: Winter}

Because of overall low WFT numbers present, there was no significant difference in number of recovered WFT among all treatments $\left(F_{2,179}=0.30, P=0.7431\right)$; however, from plant samples control plots significantly fewer WFT were recovered than from mitetreated plants at week 3 (Figure 4.11) (Appendix Table 13). Overall, the number of $N$. cucumeris and $A$. swirskii recovered from chrysanthemums in the winter was not significantly different between the mite treatments $\left(F_{1,119}=3.81, P=0.0533\right)$ (Appendix Table 14). More A. swirskii than N. cucumeris were recovered at weeks 2 and 5 (Figure 4.12). More adult $N$. cucumeris were recovered at week 6 than $A$. swirskii. Mite treatments were applied on a biweekly basis throughout the trial, and thus the 
interaction of week ${ }^{*}$ mite treatment was significant $\left(F_{5,119}=12.22, P<.0001\right)$, meaning there was a difference between mite species in number of mites recovered over the trial period. Neoseiulus numbers steadily increased, while $A$. swirskii numbers fluctuated over the trial period. As a result of WFT numbers remaining low in the commercial greenhouses, no heavy feeding damage was observed on the plants and consequently no crop losses were sustained.

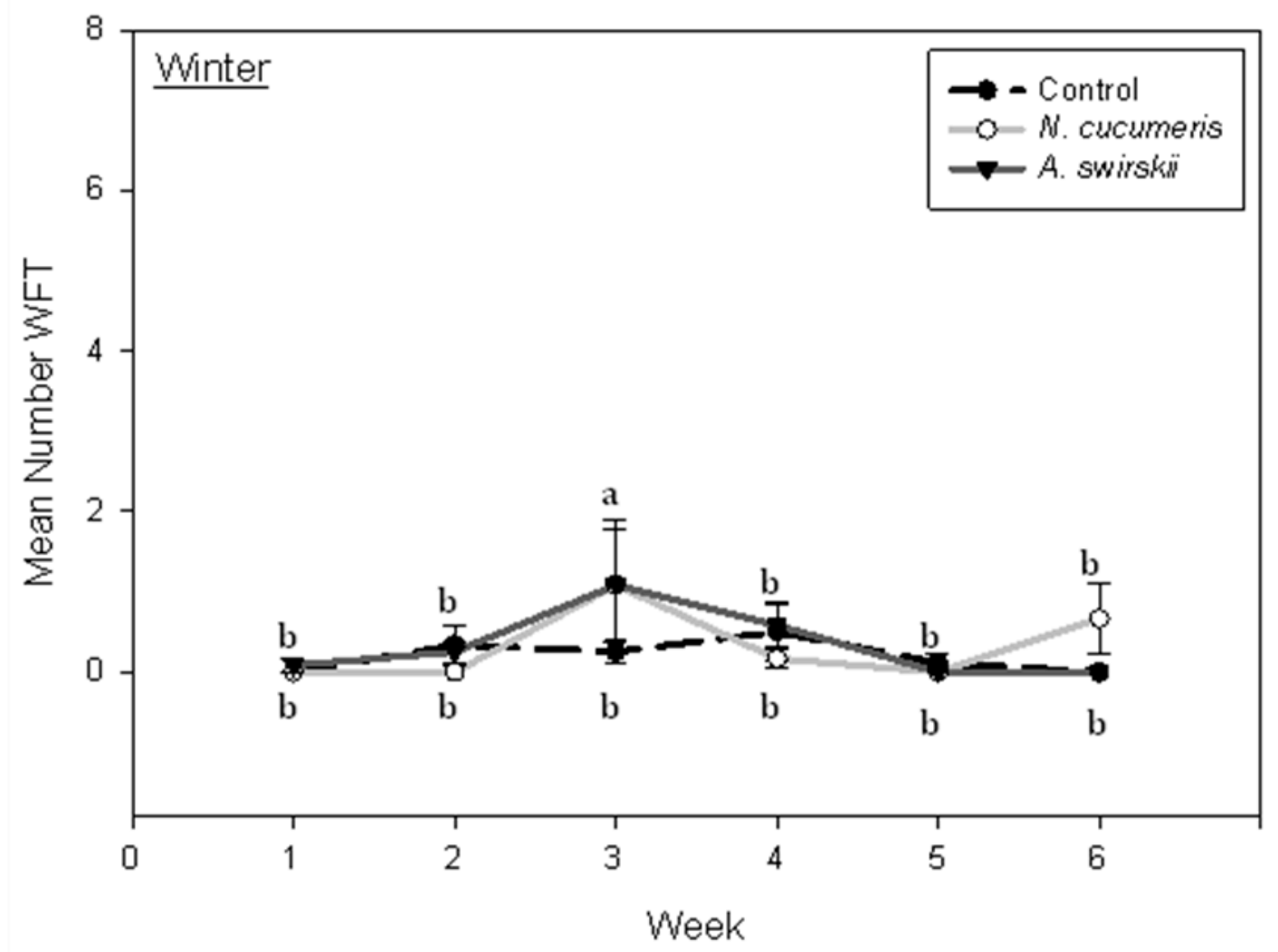

Figure 4.11. Mean number of western flower thrips (WFT) (all life stages) $\pm S E$ on nomite control, Neoseiulus cucumeris and Amblyseius swirskii- treated potted chrysanthemums over six weeks in a commercial greenhouse during winter. Means with different letters indicate a significant difference between treatments and weeks by Tukey's test $(P=0.05)$. 


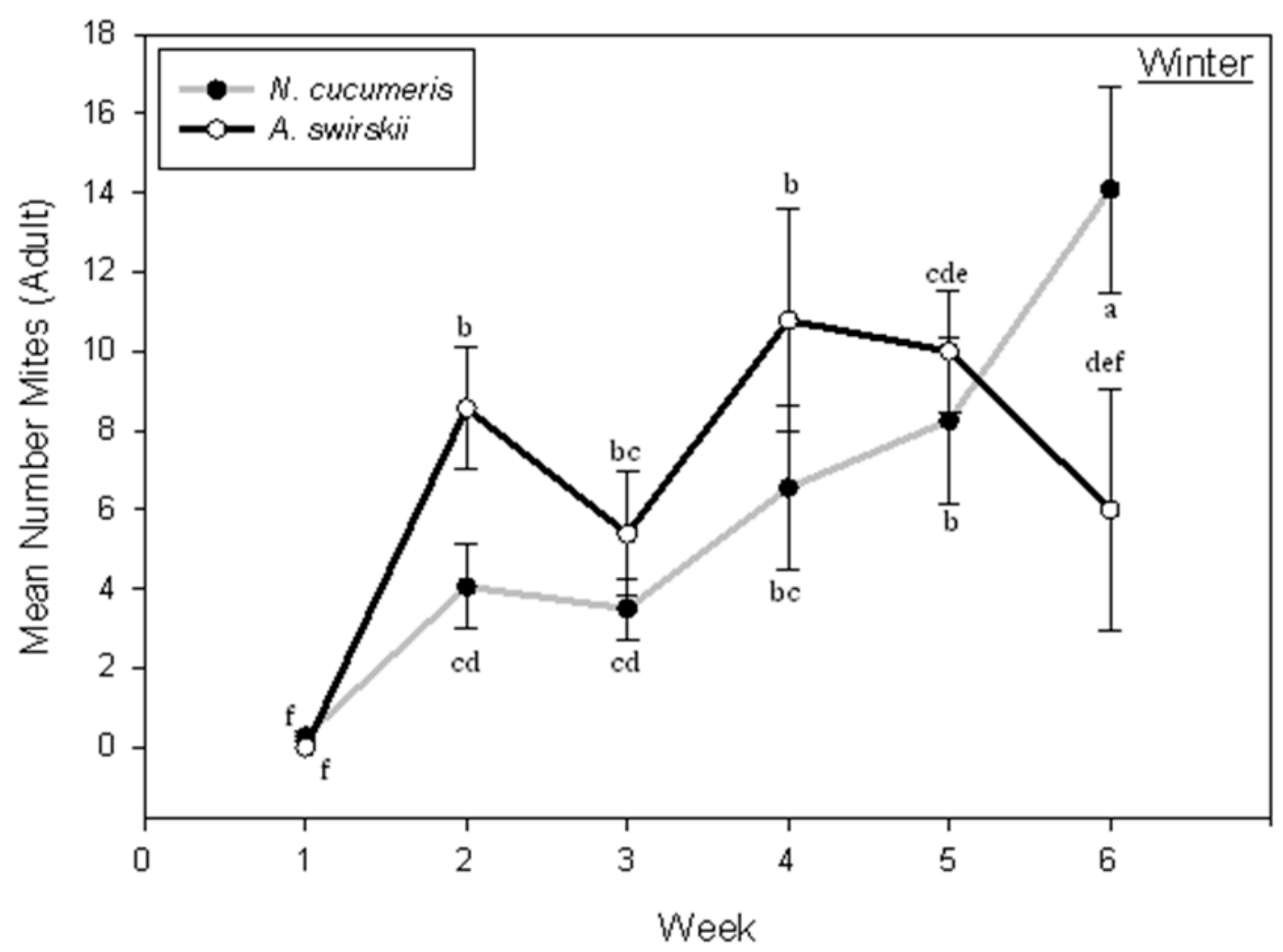

Figure 4.12. Mean number of Neosieulus cucumeris and Amblysieus swirskii \pm SE over six weeks on potted chrysanthemums in a commercial greenhouse during winter. Data points with different letters indicate a significant difference between treatments and weeks by Tukey's test $(P=0.05)$.

\subsection{Discussion}

Results of the summer cage trials indicate that both mite species are effective for reducing WFT numbers; however, in week 2 of the cage trials, $A$. swirskii reduced the thrips numbers to a significantly lower level than $N$. cucumeris. In winter trials, WFT numbers were significantly reduced compared to the control, but were not significantly different for the mite treatments. A higher number of $A$. swirskii than $N$. cucumeris were recovered in both the summer small cage and commercial greenhouse trials.

During the summer commercial greenhouse trials, the number of WFT on control plants significantly increased in weeks 2 and 3 (Figure 4.9). Although the increase was relatively small (approx. $5 \mathrm{WFT} /$ plant), this result indicates that there was a pest outbreak in the area of the control plots. During week 3 of the winter commercial trial, 
WFT numbers were significantly higher on both the N. cucumeris- and A. swirskiitreated plants than the controls, indicating again, that a pest outbreak must have occurred (Figure 4.11). However, because pest numbers were still low, the outbreak was controlled by the following week. The number of mites during the summer commercial trials fluctuated during the first 3 weeks of the trial (Figure 4.10). The trend in WFT numbers follows a similar pattern during the same time of the trial. When the WFT numbers stabilize after week 3 , the recovery of mites stabilizes as well. This indicates that in the summer, mite numbers are highly reflective of WFT numbers. The establishment of a mite population may be dependent on WFT numbers in summer greenhouses. Conversely, in the winter trials, $A$. swirskii numbers continually increased and decreased with reapplication; while $N$. cucumeris numbers steadily increased over the six weeks (Figure 4.12). This indicates that with repeated releases, N. cucumeris may be able to establish a population in winter greenhouse conditions, while $A$. swirskii would have more trouble with establishment. Neoseiulus cucumeris would provide a better return on investment during the winter than $A$. swirskii. Mite treatments were only applied once at the beginning of the small cage trials, but recovery of mites showed a decreasing trend in both summer and winter. This indicates an inability of both mite species to establish a population within a crop without regular re-application.

At $25^{\circ} \mathrm{C}$, there is $\sim 1$ day difference in development time, with $N$. cucumeris requiring more time to reach maturity (Buitenhuis et al., 2010b). At $13^{\circ} \mathrm{C}$, Lee \& Gillespie (2011) observed no development of $A$. swirskii. The upper threshold for temperature-dependent development was $37.4 \pm 1.12^{\circ} \mathrm{C}$, while the optimal development temperature was calculated as $31.5^{\circ} \mathrm{C}$. Measuring the impacts of variable temperatures and VPDs on the survival of N. cucumeris, Shipp \& van Houten (1997) found that at temperatures $\geq 25^{\circ} \mathrm{C}$ and VPDs of $1.00 \mathrm{kPa}$ or more, survival of the larva, protonymph and deutonymph stages decreased rapidly. The adult stage of the mite had a much greater survival rate, except when subjected to VPDs $>2.5 \mathrm{kPa}$. Based on these numbers and the results of this study, $A$. swirskii may be more tolerant of the extreme summer heat conditions often experienced in Ontario greenhouses than $N$. cucumeris. When their efficacy was compared in winter greenhouse conditions, there was no significant difference between $A$. swirskii and $N$. cucumeris in WFT control. In addition, 
there was no significant difference in number of mites present each week in winter. Ultimately, it may be that $A$. swirskii have an advantage in summer seasonal conditions because of their tropical origin.

When Messelink et al. (2006) conducted a greenhouse study that compared efficacy of $N$. cucumeris and A. swirskii preying on WFT in greenhouse cucumber crops, they found $A$. swirskii to be the more effective predator. Their study was conducted during April-May in the Netherlands. The mites used for this study were reared under LD conditions. Although the months of April and May are within the spring season, $A$. swirskii population numbers increased to a higher level than those of $N$. cucumeris and were still recognized as the better predator.

Typically a greenhouse summer is characterized by a higher mean temperature, longer day length, and increased light intensity. In this study, mean temperature in commercial greenhouses while summer data were collected was $23.4 \pm 0.04^{\circ} \mathrm{C}$, maximum $31.3^{\circ} \mathrm{C}$, minimum $16.2^{\circ} \mathrm{C}$; while the mean winter temperature was $18.4 \pm 0.03^{\circ} \mathrm{C}$, max $/ \mathrm{min}: 21.3 / 16.4^{\circ} \mathrm{C}$. Data from the HOBO loggers inside the small cages used in the greenhouse trials indicated that mean temperature was $24.4 \pm 0.06^{\circ} \mathrm{C}$ in summer, and $18.3 \pm 0.03^{\circ} \mathrm{C}$ in winter. The summer max/min temperatures were $36.4 / 16.5^{\circ} \mathrm{C}$. Winter max $/$ min temperatures were $32.7 / 14.4^{\circ} \mathrm{C}$. These temperature data show that although greenhouse control systems are set to maintain a certain temperature within the greenhouse space, fluctuations at the plant level are common, and can impact the activities of both pests and predators. As expected, average temperatures of the small cage trials are slightly higher than those of the commercial trials, primarily because the HOBO data loggers were hung inside the small cages, and air flow through the thrips-proof mesh siding was likely hindered. In addition, temperature fluctuation can cause VPD in a greenhouse to change. Vapor pressure deficit and temperature at the plant level play an important role in the survival of phytoseiid mites, especially in juvenile life stages. Shipp \& van Houten (1997) studied the effect of variable temperature and VPD levels on N. cucumeris survival, and found the probability of survival to be decreased in larval and nymphal stages of $N$. cucumeris at temperatures $\geq 25^{\circ} \mathrm{C}$, and VPDs $\geq 1.00 \mathrm{kPa}$. In comparison, the adult life stage had a $>90 \%$ survival rate, except when VPDs climbed above $2.5 \mathrm{kPa}$. 
Despite WFT numbers being much greater in the summer trials than in winter, the overall week-to-week trends in leaf damage control are very similar. In both summer and winter, the amount of leaves with light feeding damage remained relatively stable, while leaves with heavy and no visible damage fluctuated over the trial duration. The increase in heavily damaged leaves and decrease in non-damaged leaves was expected, as given more time to feed and oviposit, WFT should scar more leaves in total. Both mite species were able to keep heavy feeding damage significantly lower on chrysanthemum leaves than those of the control plants in both summer and winter. Fitting with the pattern of better $A$. swirskii performance in summer, heavy feeding damage was lowest on the $A$. swirskii-treated plants in the summer small cage trials. Although both mite species reduced heavy feeding damage to the same level during the winter, $A$. swirskii had a higher proportion of leaves with no visible damage. This result may influence a grower's decision when choosing a predatory mite for their IPM program. Feeding damage is the major impact of WFT, because potted plants with heavily damaged leaves are unacceptable to the consumer. In a study of consumer tolerance to defoliation and flower damage, Sadof \& Sclar (2002) report that the maximum amount of damage that is tolerable to a consumer is $\leq 25 \%$ of a total chrysanthemum plant. Based on this information, a damage threshold for the marketability of plants was set at no more than $25 \%$ of the leaves containing light feeding damage, or no more than $10 \%$ of the leaves with heavy damage.

Depending on where the damaged leaves are found on a plant (i.e. top vs. bottom, outer leaves vs. inner) this threshold for marketability could fluctuate. During the last week of the cage trials in both summer and winter, the proportion of leaves that were heavily damaged exceeded the $10 \%$ threshold, and thus, plants from all treatments would not be marketable. Mites were only applied once at the beginning of the trial, but did not sufficiently control feeding damage to the end of the four weeks. This result highlights the importance of regular mite application to a crop.

As a result of WFT numbers remaining low in the commercial greenhouse trials, no heavy feeding damage was observed on the plants and consequently no crop losses were sustained. 


\subsection{Summary}

These results clearly indicate that seasonality within a greenhouse greatly affects performance of predatory mites used for WFT mitigation. In greenhouse cage trials conducted during the winter, no difference was found in WFT control efficacy of both mite species. However, during the summer trials, A. swirskii was a more efficient BCA, exhibiting numbers that were sustained at levels significantly higher than $N$. cucumeris. In commercial greenhouses during the summer, $A$. swirskii adult numbers were significantly higher that $N$. cucumeris, while no difference between the two was detected in the winter. Although light feeding damage by WFT may be tolerated, potted plants containing even a few heavily damaged leaves may result in reduced crop production. In both summer and winter, heavy feeding damage was significantly reduced by $A$. swirskii.

Based on the findings of this study, it is advisable that growers or crop advisors consider the time of year when planning an IPM strategy that involves the use of predatory mites for WFT control. During winter production of chrysanthemum in greenhouses, $N$. cucumeris would provide WFT control equivalent to $A$. swirskii, more economically. In Canada, $N$. cucumeris cost approx. $\$ 40.00$ for 50,000 bulk mites, while $A$. swirskii are roughly three times the price at $\$ 115.00$ for a similar quantity. However, during the summer, WFT populations tend to increase exponentially at the beginning of the season, and if a grower is not prepared for this, large economic losses may occur. As a result of $A$. swirskii numbers increasing to a higher level, initiating an innundative release of $A$. swirskii in the summer may ensure that there are enough predators present to mitigate WFT infestations if they reach outbreak levels. In addition, A. swirskii reduced heavy feeding damage during the summer and winter, which may impact grower's decision for mite selection. Therefore, $A$. swirskii would be worth the investment in the summer, but during northern temperate winters $N$. cucumeris is the recommended BCA option. To avoid the higher costs of $A$. swirskii in the summer, a grower may also consider applying $N$. cucumeris to a crop at an increased frequency or rate. One option for application would be to hang one mini CRS sachet of $N$. cucumeris on each pot. By applying mites more frequently, there will be mites present in the crop 
to quickly respond to pest pressure. On the other hand, a grower may decide to apply mites at an increased rate while maintaining the same application frequency. This practice is likely a waste of money, because there may not be enough food available for a larger number of mites, and therefore many will starve and die before they are able to find prey. Mite treatments were applied once during the small cage trials of this study, and biweekly in the commercial greenhouse trials. In the cage trials, N. cucumeris was not as effective at controlling WFT as $A$. swirskii in summer; however, there was no difference in WFT control by either species in the summer commercial greenhouse trials. Thrips pressure in the commercial greenhouse was low however, and results might have been different if there was a thrips outbreak. Applying N. cucumeris more frequently means the grower does not need to rely on their population stability and increase, but instead just their predation capacity. Increased labour for greenhouse workers may quell this option. In addition, depending on application method (i.e. bulk mites in bran vs. controlled slow-release system (CRS) sachets), there may be more bran and debris left behind on plants leading to a less cosmetically appealing plant.

Neoseiulus cucumeris was the first predatory mite to be used in greenhouse IPM and thus, is the most widely used predatory mite for WFT control. However, as new BCAs are discovered, the greenhouse industry needs to consider adoption of new recommendations once they are scientifically confirmed. Messelink et al. (2006) studied 10 species of predatory mites currently available for WFT control. They found that the species that performed the best were all sub-tropical in origin; with Typhlodromalus limonicus (Garman \& McGregor), A. swirskii and Euseius scutalis (Athias-Henriot) all reaching higher numbers than $N$. cucumeris, and subsequently providing better WFT control as a result.

To achieve the most success in controlling WFT in a greenhouse crop, combininations of BCAs often provide a superior result in terms of the speed at which the pest is controlled. Neoseiulus cucumeris and $A$. swirskii feed primarily on the first larval instar, thus by combining their efforts with other compatible BCAs that control other life stages of thrips, the pest population can be more rapidly controlled. Biocontrol agents belonging to Orius spp. are another popular option for thrips control. They feed on multiple life stages of WFT, and will often prey on thrips even after they are satiated. 
However, intraguild predation between predatory mites and Orius spp. has been reported on many occasions (Cloutier \& Johnson, 1993; Colfer et al., 2003; Gillespie \& Quiring, 1992; Madadi et al., 2009; Sanderson et al., 2005). When given the choice between WFT and $A$. swirskii on cut roses, Orius insidiosus consumed whatever arthropod was highest in abundance (Chow et al., 2010). Thus, predatory mites and bugs are not a complementary biocontrol option for WFT. The compatibility of the entomopathogenic fungus - Beauveria bassiana, with $N$. cucumeris also has been tested. In both laboratory and greenhouse trials, $B$. bassiana had no detrimental effect on $N$. cucumeris, and WFT control by the fungus was not hindered by the presence of the mite (Jacobson et al., 2001). In a greenhouse trial investigating the effect of beevectored $B$. bassiana on several BCAs, mortality of $A$. swirskii was not different between the control and $B$. bassiana-treated cages (Shipp et al., 2012), suggesting the fungus is a compatible option for use with predatory mites. Entomopathogenic nemotades such as Steinernema feltiae (Nematoda: Steinernematidae) are a compatible and effective option for use with predatory mites to control WFT. Nematodes are a good option in a biological control strategy involving predatory mites, because they primarily attack the soil-dwelling pupal stage of WFT (Buitenhuis \& Shipp, 2005; Ebssa et al., 2004; 2006), leaving the larval stages for predatory mites. Emergence of adult WFT was significantly reduced when the predatory mite $G$. aculeifer was added to bean seedlings along with two species of entomopathogenic nematodes, than either mite or nematode treatment alone (Premachandra et al., 2003). In addition, an $83 \%$ reduction of thrips numbers was observed compared to a control when $N$. cucumeris and two nematode species were applied to beans (Ebssa et al., 2006). Similar to predatory mites, nematodes are also highly affected by temperature, and are more effective at temperatures similar to those of their origin (Ebssa et al., 2004). The optimal temperature for $S$. feltiae is $20^{\circ} \mathrm{C}$ (Cuthbertson et al., 2005). Temperatures inside the greenhouse of my summer trials were often much higher than $20^{\circ} \mathrm{C}$, thus making $\mathrm{S}$. feltiae a more suitable option for winter biocontrol programs. In addition, nematodes are not very effective when used as the only BCA (Ebssa et al., 2004), and should therefore be combined with at least one other form of control to ensure adequate pest reduction. 


\section{CHAPTER 5}

\section{GENERAL CONCLUSIONS}

\subsection{IPM in Ontario Greenhouse Floriculture}

Ontario's greenhouse floricultural sector has grown into an important component of agricultural income, with a total farm gate value of $\$ 571$ mill in 2011 (Statistics Canada, 2011). In light of changes in federal pesticide registration and provincial regulation, concern for human health and environmental safety, and increasing insecticide resistance issues, IPM programs are now focusing on biological control as the primary tactic in ornamental greenhouse operations. WFT is one of the most ubiquitous pests of greenhouse crops. Research and development in the area of biological control continues to provide the most accurate knowledge of pest management strategies involving BCA for the greenhouse industry. Unlike pesticide use which is relatively straight-forward to implement, biological control of pests requires attention to detail and willingness to commit to a prescribed program and trust in its' ability to reduce pests over the long term. Compared to greenhouse vegetable growers, where more than $90 \%$ are using biological control, ornamental greenhouse producers are much more concerned with damage that affects the overall cosmetic appearance of the product. Heavy consumer scrutiny means that plants with even minor amounts of damage or pests present on the plant are unmarketable, causing economic losses to the greenhouse operation. To keep damage to the lowest level possible, greenhouse growers prefer BCAs to act in the same manner as pesticides, bringing about rapid pest population knock-down (Gerson \& Weintraub, 2007). In a survey of greenhouse growers across the United States, $42 \%$ of the respondents agreed or strongly agreed that the cost of biological controls are too high; while $67 \%$ said they would prefer biological control methods as long as profits remained the same (Schumacher, 2002). Continued research and grower education will aid in increasing adoption and success of biological control.

In the northern temperate climate where these greenhouse trials were conducted, light intensity and day length, as well as temperature, are all reduced during the winter months. Unlike specialty ornamental crops such as poinsettias, there is year- 
round demand for chrysanthemums, and thus, a need for pest control on this crop during all seasonal climates. Western flower thrips is a major pest of chrysanthemums throughout the year in Ontario. Predatory mites are one of the primary BCA options for thrips control on chrysanthemum. Therefore, choosing a mite species that is best suited for greenhouse conditions in every season will aid in maximizing pest reduction.

\subsection{Recommendations for Summer}

In laboratory bioassays, increased temperature, long daylength and high light intensity conditions that are characteristic of summer, yielded results that favour the selection of Amblyseius swirskii for biological control of WFT. Amblyseius swirskii predation rates were significantly increased over those of Neoseiulus cucumeris at the increased light levels and temperatures, while there was no difference in oviposition rate between the mites. In the summer small cage and commercial trials, number of recovered $A$. swirskii adults was often higher than that of $N$. cucumeris. Western flower thrips reduction was similar in both mite species; however, $A$. swirskii did reduce WFT to lower numbers than $N$. cucumeris during week 2 in the summer. The number of leaves classified as heavily damaged was significantly reduced compared to the control on N. cucumeris-treated plants at the end of the trial. Amblyseius swirskii reduced heavy feeding damage to lower levels in weeks 3 and 4 . In addition, the number of leaves with no visible feeding damage was significantly higher for $A$. swirskii at the end of the trial than those of $N$. cucumeris or the control.

Based on these findings, $A$. swirskii is a better BCA than N. cucumeris for summer greenhouse pest management. Western flower thrips numbers are often elevated in summer greenhouses, and if left unchecked, the pest numbers may increase to a point in which they are too high to be controlled. If pest numbers remain high for too long, feeding damage may cause large crop losses. In the summer small cage trials, $A$. swirskii reduced WFT numbers to significantly lower levels than those of N. cucumeris-treated plants in week 2 . During week 2, WFT on the no-mite control plants were at the highest numbers for the whole trial. It is important for a BCA to bring about rapid pest reduction after application, which $A$. swirskii did. In addition, $A$. swirskii did a better job of controlling WFT feeding damage after four weeks. Regular 
applications of $A$. swirskii throughout the summer growing season is a good option for controlling WFT in the hot, sunny weather.

\subsection{Recommendations for Winter}

When $N$. cucumeris and $A$. swirskii were subjected to conditions typical of winter in laboratory bioassays, predation rate on Day 1 was often higher for $A$. swirskii, while

predation rates did not differ for $N$. cucumeris and A. swirskii on Day 2 and 3. Oviposition rates were not different between species at lower light levels and temperatures. There was no overall difference between the mite species in the winter small cage or commercial trials. Western flower thrips numbers were equally reduced by both mite species, and there was no difference in the number of recovered mite adults in the cage trials. In the commercial greenhouses, WFT numbers were very low during the winter and thus no difference in WFT reduction was observed between the control and mite treatments. The number of mite adults recovered from the treated plants was the same overall for both mite species. As a result of these findings, there is no advantage to using $A$. swirskii over $N$. cucumeris in winter greenhouse production systems. Neoseiulus cucumeris are a more cost-effective BCA, and thus there is nothing to be gained by using $A$. swirskii in the winter. Lower numbers of WFT present in winter may hinder the ability of a mite population to establish within a crop during the winter. A high frequency of mite application will ensure that predators are present at a consistent level throughout the winter growing season.

\subsection{Future Considerations}

Pest management is a rapidly evolving industry within the greenhouse sector. New pests and natural enemies to combat them are constantly discovered; and with them, recommendations for application and use must be updated as well. To expand upon this research, it is recommended that studies similar to this one be conducted for new BCAs becoming available, such as Typhlodromalus limonicus. I have shown that climatic differences can greatly impact the efficacy of predatory mites, and this may be the case for other BCAs as well. 
In order to more accurately simulate actual greenhouse biological control situations, future study should be conducted in the summer and winter small cage trials in which the trial length is extended to six weeks, with mite applications occurring on a biweekly basis.

Results of the present study (differences between Day 1, 2 and 3, Chapter 3), suggest that insect rearing conditions such as light levels and temperatures, may impact their efficacy as a BCA when applied to a crop. Future research involving impacts of rearing practices may enhance the quality of BCAs supplied to the market. Future research in greenhouses may also include the effects of altered environments (i.e. supplemental lighting and altered leaf structures), or fluctuating daily temperature on the survival and efficacy of BCAs. Ornamental plants usually lack leaf trichomes, which often serve as a refuge for phytoseiids and can mediate climate effects at the leaf level (O'Dowd \& Willson, 1991). When Loughner et al. (2009) studied the interaction of leaf trichome density on mite dispersal, they found a linear response between Typhlodromus pyri Scheuten dispersal and the density of fiber meant to mimic leaf trichomes present; with less dispersal at higher amounts of fiber on the leaf. In future laboratory study, placing a fiber or alternate substrate on the leaf square may enhance the oviposition rates of predators.

This research focused on the pest WFT; however, there are often multiple insect pests present at any one time in a greenhouse. Growers may consider choosing BCAs that are generalist predators to control pests more efficiently. Amblyseius swirskii, for example, is a BCA of WFT and whiteflies and will also prey on spider mites and broad mites. Finally, some plants react differently in various climatic conditions, with respect to volatile production or leaf transpiration rates. Research comparing BCA efficacies among seasonal climates should also be conducted in other crops.

Biological control can be an effective pest reduction strategy in greenhouses; but only if carefully planned and managed. As more knowledge is gained on the biology and activity of predators, more accurate recommendations can be made to growers as a result. From this research it is clear that seasonal climatic conditions in a greenhouse need to be considered when deciding the best biological control tactics for an overall IPM strategy. Neoseiulus cucumeris are the most cost-efficient and effective predatory 
mite during winter. However, in the summer, A. swirskii maintain higher populations on crop plants and reduce WFT populations and feeding damage to a lower number.

The efficacy of an IPM program can be increased by combining two or more BCAs for control of WFT at all life stages. One must be mindful of interactions between predators when taking this approach so as to not decrease efficacy of either BCA. The predatory bug Orius insidiosus is another commonly used BCA for WFT control. However, Orius will also kill predatory mites when given the choice, and therefore may not be a viable option for use with $N$. cucumeris or $A$. swirskii in a greenhouse. On the other hand, S. feltiae (nematodes) attack mainly the soil-dwelling life stages of WFT and are a compatible option for use with predatory mites. Entomopathogenic fungi such as Beauveria bassiana are also compatible with phytoseiids and provide another layer of WFT control when used in combination (Jacobson et al., 2001; Shipp et al., 2012). As another method of increasing the efficacy of BCAs, Chow et al. (2012) studied the effect of reducing the prescribed amount of fertilizer for rose production in combination with the application of $A$. swirskii to achieve optimal pest number reduction. Reducing the fertilizer level to $33 \%$ of the recommended rate aided in WFT control and did not affect rose flowering. When A. swirskii was added to these plants, WFT control was improved.

Biological control is a large component of greenhouse IPM. However, IPM is an all-encompassing approach to pest management; and other pest reduction strategies such as cultural and physical control should not be overlooked. Pest and predator monitoring via sticky cards, screening, trap plants and sanitation measures can all help to reduce pest outbreak occurrence. Research findings such as those herein, are only truly useful if adopted by commercial greenhouse operators. In order to share knowledge and increase adoption rates; social media, greenhouse publications and educational workshops should all be utilized by government and industry experts to convey information to greenhouse horticultural producers. 


\section{CHAPTER 6 \\ REFERENCES CITED}

Agriculture and Agri-Food Canada (AAFC) (2012) Statistical Overview of Canadian Horticulture. http://www4.agr.gc.ca/AAFC-AAC/displayafficher.do?id=1184692853496\&lang=eng. Accessed: December 6, 2012.

Anderson DB (1936) Relative humidity or vapor pressure deficit. Ecology 17: 277-282.

Auger P, Tixier M-Sp, Kreiter S \& Fauvel G (1999) Factors affecting ambulatory dispersal in the predaceous mite Neoseiulus californicus (Acari: Phytoseiidae). Experimental \& Applied Acarology 23: 235-250.

Bakker FM \& Sabelis MW (1989) How larvae of Thrips tabaci reduce the attack success of phytoseiid predators. Entomologia Experimentalis et Applicata 50: 47-51.

Birken EM \& Cloyd RA (2007) Food preference of the rove beetle, Atheta coriaria Kraatz (Coleoptera: Staphylinidae) under laboratory conditions. Insect Science 14: 53-56.

Blumthal MR, Cloyd RA, Spomer LA \& Warnock DF (2005) Flower color preferences of western flower thrips. HortTechnology 15: 846-853.

Brown W \& Murphy G (2010) A Profile- The Ontario Greenhouse Floriculture Industry. Ontario Ministry of Agriculture Food \& Rural Affairs (OMAFRA). http://www.omafra.gov.on.ca/english/crops/facts/greenflor.htm\#Industry. Accessed: October 29, 2010.

Buitenhuis R, Shipp J, Jandricic S, Murphy G \& Short M (2007) Effectiveness of Insecticide-Treated and Non-Treated Trap Plants for the Management of Frankliniella occidentalis (Thysanoptera: Thripidae) in Greenhouse Ornamentals. Pest Management Science 63: 910-917.

Buitenhuis R \& Shipp JL (2005) Efficacy of entomopathogenic nematode Steinernema feltiae (Rhabditida: Steinernematidae) as influenced by Frankliniella occidentalis (Thysanoptera: Thripidae) developmental stage and host plant stage. Journal of Economic Entomology 98: 1480-1485.

Buitenhuis R, Shipp L \& Scott-Dupree C (2010a) Dispersal of Amblyseius swirskii Athias-Henriot (Acari: Phytoseiidae) on potted greenhouse chrysanthemum. Biological Control 52: 110-114. 
Buitenhuis R, Shipp L \& Scott-Dupree C (2010b) Intra-guild vs extra-guild prey: effect on predator fitness and preference of Amblyseius swirskii (Athias-Henriot) and Neoseiulus cucumeris (Oudemans) (Acari: Phytoseiidae). Bulletin of Entomological Research 100: 167-173.

Chow A, Chau A \& Heinz KM (2010) Compatibility of Amblyseius (Typhlodromips) swirskii (Athias-Henriot) (Acari: Phytoseiidae) and Orius insidiosus (Hemiptera: Anthocoridae) for biological control of Frankliniella occidentalis (Thysanoptera: Thripidae) on roses. Biological Control 53: 188-196.

Chow A, Chau A \& Heinz KM (2012) Reducing fertilization: a management tactic against western flower thrips on roses. Journal of Applied Entomology 136: 520529.

Cloutier C, Arodokoun D, Johnson SG \& Gelinas L (1995) Thermal dependence of Amblyseius cucumeris (Acarina: Phytoseiidae) and Orius insidiosus (Heteroptera: Anthocoridae) in greenhouses. Thrips Biology and Management 231-235.

Cloutier C \& Johnson SG (1993) Predation by Orius tristicolor (Hemiptera: Anthocoridae) on Phytoseiulus persimilis (Acarina: Phytoseiidae): testing for compatibility between biocontrol agents. Environmental Entomology 22: 477-482.

Colfer RG, Rosenheim JA, Godfrey LD \& Hsu CL (2003) Interactions between the augmentatively released predaceous mite Galendromus occidentalis (Acari: Phytoseiidae) and naturally occurring generalist predators. Environmental Entomology 32: 840-852.

Costa HS, Robb KL \& Wilen CA (2002) Field Trials Measuring the Effects of UltravioletAbsorbing Greenhouse Plastic Films on Insect Populations. Journal of Economic Entomology 95: 113-120.

Cuthbertson AGS, North JP \& Walters KFA (2005) Effect of temperature and host plant leaf morphology on the efficacy of two entomopathogenic biocontrol agents of Thrips palmi (Thysanoptera: Thripidae). Bulletin of Entomological Research 95: 321-327.

de Moraes GJ, McMurtry JA, Denmark HA \& Campos CB (2004) A revised catalog of the mite family Phytoseiidae. Zootaxa 434: 1-494.

Doukas D \& Payne CC (2007) The use of ultraviolet-blocking films in insect pest management in the UK; effects on naturally occurring arthropod pest and natural enemy populations in a protected cucumber crop. Annals of Applied Biology 151: 221-231. 
Ebssa L, Borgemeister C, Berndt O \& Poehling H-M (2001) Efficacy of entomopathogenic nematodes against soil-dwelling life stages of western flower thrips, Frankliniella occidentalis (Thysanoptera: Thripidae). Journal of Invertebrate Pathology 78: 119-127.

Ebssa L, Borgemeister C \& Poehling H-M (2004) Effectiveness of different species/strains of entomopathogenic nematodes for control of western flower thrips (Frankliniella occidentalis) at various concentrations, host densities, and temperatures. Biological Control 29: 145-154.

Ebssa L, Borgemeister C \& Poehling H-M (2006) Simultaneous application of entomopathogenic nematodes and predatory mites to control western flower thrips Frankliniella occidentalis. Biological Control 39: 66-74.

El-Laithy AYM \& Fouly AH (1992) Life table parameters of the two phytoseiid predators Amblyseius scutalis (Athias-Henriot) and A. swirskii A.-H. (Acari Phytoseiidae) in Egypt. Journal of Applied Entomology 8: 8-12.

El-Tawab AY, El-Keifl AH \& Metwally AM (1982) Effect of temperature and photoperiod on the development, fecundity and longevity of Amblyseius swirskii Ath.-Henr. (Acari, Gamasida, Phytoseiidae). Anz Schadlingskunde Plfanzensch Umweltschutz 55: 107-109.

Ferrero M, Gigot C, Tixier MS, van Houten YM \& Kreiter S (2010) Egg hatching response to a range of air humidities for six species of predatory mites. Entomologia Experimentalis et Applicata 135: 237-244.

Gerson U \& Smiley RL (1990) Acarine Biocontrol Agents. Chapman and Hall, Suffolk.

Gerson U, Smiley RL \& Ochoa R (2003) Mites (Acari) for Pest Control. Blackwell Science Ltd., Oxford.

Gerson U \& Weintraub PG (2007) Review: mites for the control of pests in protected cultivation. Pest Management Science 63: 658-676.

Gerson U \& Weintraub PG (2012) Mites (Acari) as a factor in greenhouse management. Annual Review of Entomology 57: 229-247.

Gillespie DR \& Quiring DJM (1992) Competition between Orius tristicolor (White) (Hemiptera: Anthocoridae) and Amblyseius cucumeris (Oudemans) (Acari: Phytoseiidae) feeding on Frankliniella occidentalis (Pergande) (Thysanoptera: Thripidae). Canadian Entomologist 124: 1123-1128. 
Hajek A (2004) Natural Enemies: An Introduction to Biological Control. Cambridge University Press, New York. ISBN:0521652952.

Heinz KM, Van Driesche RG \& Parrella MP (2004) Biocontrol in Protected Culture. Ball Publishing, Batavia, NY. ISBN:1883052394.

Hoddle M (1994) Encarsia formosa: A parasitic wasp that attacks whiteflies. University of Massachusetts Floral Notes 6: 5-7.

Jacobson RJ, Chandler D, Fenlon J \& Russell KM (2001) Compatibility of Beauveria bassiana (Balsamo) Vuillemin with Amblyseius cucumeris Oudemans (Acarina: PHytoseiidae) to control Franklinilella occidentalis Pergande (Thysanoptera: Thripidae) on cucumber plants. Biocontrol Science and Technology 11: 391-400.

Johansen NS, Vanninen I, Pinto DM, Nissinen AI \& Shipp L (2011) In the light of new greenhouse technologies: 2. Direct effects of artificial lighting on arthropods and integrated pest management in greenhouse crops. Annals of Applied Biology 159: 1-27.

Jones T, Shipp JL, Scott-Dupree CD \& Harris CR (2005) Influence of greenhouse microclimate on Neoseiulus (Amblyseius) cucumeris (Acari: Phytoseiidae) predation on Frankliniella occidentalis (Thysanoptera: Thripidae) and oviposition on greenhouse cucumber. Journal of the Entomological Society of Ontario 136: 71-83.

Karnkowski W \& Trdan S (2002) Diagnostic protocols for regulated pests- Frankliniella occidentalis. OEPP/EPPO Bulletin 32: 281-292.

Kazak C, Cone WW \& Wright LC (2004) Influence of variable photoperiods on the feeding activity and fecundity of Galendromus occidentalis (Nesbitt) (Acari : Phytoseiidae) under laboratory conditions. Journal of Pest Science 77: 131-135.

Kogan M (1998) Integrated Pest Management: Historical Perspectives and Contemporary Developments. Annual Review of Entomology 43: 243-270.

Lee H-S \& Gillespie DR (2011) Life tables and development of Amblyseius swirskii (Acari: Phytoseiidae) at different temperatures. Experimental \& Applied Acarology 53: 17-27.

Lee JH \& Ahn JJ (2000) Temperature Effects on Development, Fecundity, and Life Table Parameters of Amblyseius womersleyi (Acari: Phytoseiidae). Environmental Entomology 29: 265-271. 
Loomans AJM, Tolsma, J., Fransen, J.J., van Lenteren, J. C. (2006) Releases of parasitoids (Ceranisus spp.) as biological control agents of western flower thrips (Frankliniella occidentalis) in experimental glasshouses. Bulletin of Insectology 59: 85-97.

Loughner R, Wentworth K, Loeb G \& Nyrop J (2009) Leaf trichomes influence predatory mite densities through dispersal behavior. Entomologia Experimentalis et Applicata 134: 78-88.

MacGill El (1939) A gamasid mite (Typhlodromus thripsi n.sp.), a predator of Thrips tabaci Lind. Annals of Applied Biology 26: 309-317.

Madadi H, Enkegaard A, Broedsgaard HF, Kharrazi-Pakdel A, Ashouri A \& MohagheghNeishabouri J (2009) Interactions between Orius albidipennis (Heteroptera: Anthocoridae) and Neoseiulus cucumeris (Acari: Phytoseiidae): Effects of host plants under microcosm condition. Biological Control 50: 137-142.

Messelink G, van Steenpaal S \& van Wensveen W (2005) Typhlodromips swirskii (Athias-Henriot) (Acari: Phytoseiidae): a new predator for thrips control in greenhouse cucumber. IOBC/WPRS Bulletin 28: 183-186.

Messelink GJ, van Maanen R \& Van Steenpaal SEF (2008) Biological control of thrips and whiteflies by a shared predator: two pests are better than one. Biological Control 44: 372-379.

Messelink GJ, Van Steenpaal SEF \& Ramakers PM (2006) Evaluation of phytoseiid predators for control of western flower thrips on greenhouse cucumber. Biocontrol 51: 753-768.

Mutwiwa UN, Borgemeister C, Von elsner B \& Tantau H (2005) Effects of UV-Absorbing Plastic Films on Greenhouse Whitefly (Homoptera: Aleyrodidae). Journal of Economic Entomology 98: 1221-1228.

Niagara Economic Development Corporation (2005) Ontario's Floriculture Industry. http://www.niagaracanada.com/uploads/Ontario_Greenhouse_Floral_profile_Rev ised.pdf. Accessed: October 29, 2010.

Nomikou M, Janssen A, Schraag R \& Sabelis MW (2001) Phytoseiid predators as potential biological control agents for Bemisia tabaci. Experimental \& Applied Acarology 25: 271-291.

O'Dowd DJ \& Willson MF (1991) Associations between mites and leaf domatia. Trends in Ecology and Evolution 6: 179-182. 
Ontario Greenhouse Vegetable Growers (OGVG) (2012) Ontario Greenhouse Vegetable Growers 2012 Fact Sheet. http://www.ontariogreenhouse.com/default/assets/File/2012\%20January\%20Fact \%20Sheet(1).pdf. Accessed: December 6, 2012.

Ontario Ministry of Agriculture Food and Rural Affairs (OMAFRA) (2012) Greenhouse Industry Statistics, Ontario and Canada, 2008 to 2011. http://www.omafra.gov.on.ca/english/stats/hort/greenhouse1.htm. Accessed: December 6, 2012.

Pedigo LP \& Rice ME (2009) Entomology and Pest Management. 6 Ed. Pearson Education Inc., Upper Saddle River.

Porath A \& Swirski E (1965) A survey of phytoseiid mites (Acarina:Phytoseiidae) on citrus, with a description of one new species. Israel Journal of Agricultural Research 15: 87-100.

Premachandra WTSD, Borgemeister C, Berndt O, Ehlers R-U \& Poehling H-M (2003) Combined releases of entomopathogenic nematodes and the predatory mite Hyoaspis aculeifer to control soil-dwelling stages of western flower thrips Frankliniella occidentalis. Biocontrol 48: 529-541.

Rechcigl JE \& Rechcigl NA (1998) Biological and Biotechnological Control of Insect Pests. Lewis Publishers, New York.

Reitz SR (2009) Biology and ecology of the western flower thrips (Thysanoptera: Thripidae): the making of a pest. The Florida Entomologist 92: 7-13.

Sabelis MW (1981) Biological control of two-spotted spider mites using phytoseiid predators. Part I, Vol. Ph.D. Thesis: Wageningen.

Sadof CS \& Sclar DC (2002) Public tolerance to defoliation and flower distortion in a public horticulture garden. Journal of Economic Entomology 95: 348-353.

Sanderson JP, Brodsgaard HF \& Enkegaard A (2005) Preference assessment of two Orius spp. for Neoseiulus cucumeris vs. Frankliniella occidentalis. IOBC/WPRS Bulletin 28: 221-224.

Schumacher SK (2002) Economic analysis of production and pest management decisions confronting greenhouse growers [PhD dissertation], Vol. PhD: Kansas State University, Manhattan. 
Shipp JL \& Gillespie TJ (1993) Influence of temperature and water vapor pressure deficit on survival of Frankliniella occidentalis (Thysanoptera: Thripidae). Environmental Entomology 22: 726-732.

Shipp JL \& Van Houten YM (1997) Influence of temperature and vapor pressure deficit on survival of the predatory mite Amblyseius cucumeris (Acari: Phytoseiidae). Environmental Entomology 26: 106-113.

Shipp JL, Ward KI \& Gillespie TJ (1996) Influence of temperature and vapor pressure deficit on the rate of predation by the predatory mite, Amblyseius cucumeris, on Frankliniella occidentalis. Entomologia Experimentalis et Applicata 78: 31-38.

Shipp L, Johansen N, Vanninen I \& Jocobson R (2009) Greenhouse climate: an important consideration when developing pest management programs for greenhouse crops. Acta Horticulturae (ISHS) 893: 133-143.

Shipp L, Kapongo JP, Park H-H \& Kevan P (2012) Effect of bee-vectored Beauveria bassiana on greenhouse beneficials under greenhouse cage conditions. Biological Control 63: 135-142.

Skirvin DJ, Kravar-garde L, Reynolds K, Jones J, Mead A \& Fenlon J (2007) Supplemental food affects thrips predation and movement of Orius laevigatus (Hemiptera: Anthocoridae) and Neoseiulus cucumeris (Acari: Phytoseiidae). Bulletin of Entomological Research 97: 309-315.

Smith JC \& Newsom LD (1970) Laboratory evaluation of Amblyseius fallacis as a predator of tetranychid mites. Journal of Economic Entomology 63: 1876-1878.

Statistics Canada (2011) Greenhouse, Sod and Nursery Industries. http://www.statcan.gc.ca/daily-quotidien/120503/dq120503a-eng.htm. Accessed: December 6, 2012.

Symondson WOC, Sunderland KD \& Greenstone MH (2002) Can generalist predators be effective biocontrol agents? Annual Review of Entomology 47: 561-594.

The Ontario Growers Association (TOGA) (2009) Greenhouses Grow Ontario: The Greenhouse Sector in Ontario 2009 Update. http://www.theontariogreenhousealliance.com/files/TOGA_Greenhouse_Sector_ 2009_Update.pdf. Accessed: October 13, 2010.

Trudgill DL, Honek A, Li D \& van Straalen NM (2005) Thermal time-concepts and utility. Annals of Applied Biology 146: 1-14. 
Van Driesche RG \& Hoddle M (1998) Western flower thrips in greenhouses: a review of its biological control and other methods. University of California Riverside Department of Entomology, http://www.biocontrol.ucr.edu/WFT.html\#Monitoring. Accessed: October 13, 2010.

van Houten Y, Ostlie ML, Hoogerbrugge H \& Bolckmans K (2005) Biological control of western flower thrips in sweet pepper using the predatory mites Amblyseius cucumeris, Iphiseius degenerans, A. andersoni and A. swirskii. IOBC Bulletin 28: 283-286.

van Houten YM \& van Lier AMM (1995) Influence of temperature and humidity on the survival of eggs of the thrips predator Amblyseius cucumeris. Mededelingen van de Faculteit Landbouwwetenschappen Rijksuniversiteit Gent 60: 879-884.

van Houten YM \& van Lier T (1996) Effect of temperature and humidity on survival of the thrips predators Amblyseius cucumeris and A. limonicus in a cucumber crop. 7. Meeting of Experimental and Applied Entomologists in The Netherlands, Utrecht (The Netherlands), 15 Dec 1995 7: 95-100.

van Houten YM, van Rijn PC, Tanigoshi LK, van Stratum P \& Bruin J (1995a) Preselection of predatory mites to improve year-round biological control of western flower thrips in greenhouse crops. Entomologia Experimentalis et Applicata 74: 225-234.

van Houten YM, van Stratum P, Bruin J \& Veerman A (1995b) Selection for nondiapause in Amblyseius cucumeris and Amblyseius barkeri and exploration of the effectiveness of selected strains for thrips control. Entomologia Experimentalis et Applicata 77: 289-295.

van Rijn PCJ, Bakker FM, van der Hoeven WAD \& Sabelis MW (2005) Is arthropod predation exclusively satiation-driven? Oikos 109: 101-116.

Vanninen I, Pinto DM, Nissinen AI, Johansen NS \& Shipp L (2010) In the light of new greenhouse technologies: 1. Plant-mediated effects of artificial lighting on arthropods and tritrophic interactions. Annals of Applied Biology 157: 393-414.

Weintraub PG, Kleitman S, Mori R, Shapira N \& Palevsky E (2003) Control of broad mites (Polyphagotarsonemus latus (Banks)) on organic greenhouse sweet peppers (Capsicum annuum L.) with the predatory mites, Neoseiulus cucumeris (Oudemans). Biological Control 26: 300-309.

Weintraub PG, Kleitman S \& Palevsky E (2005) Diel movement of predatory mites (Neoseiulus cucumeris), reared in light or dark, on greenhouse sweet pepper. 
IOBC/wprs Bulletin: Ingegrated Control in Protected Crops, Temperate Climate 28(1): 313-316.

Whittaker MS \& Kirk WDJ (2004) The effect of photoperiod on walking, feeding and oviposition in the western flower thrips. Entomologia Experimentalis et Applicata 111: 209-214.

Wiethoff J, Poehling H-M \& Meyhofer R (2004) Combining plant- and soil-dwelling predatory mites to optimise biological control of thrips. Experimental \& Applied Acarology 34: 239-261.

Yano E (2006) Ecological considerdations for biological control of aphids in protected culture. Population Ecology 48: 333-339.

Zhang Z-Q (2003) Mites of Greenhouses: Identification, Biology and Control. CABI International Publishing, Wallingford, UK.

Zilahi-Balogh G, Shipp JL, Cloutier C \& Brodeur J (2006) Influence of Light Intensity, Photoperiod, and Temperature on the Efficacy of Two Aphelinid Parasitoids of the Greenhouse Whitefly. Environmental Entomology 35: 581-589.

Zilahi-Balogh GMG, Shipp JL, Cloutier C \& Brodeur J (2007) Predation by Neoseiulus cucumeris on western flower thrips, and its oviposition on greenhouse cucumber under winter vs. summer conditions in a temperate climate. Biological Control 40: 160-167. 


\section{APPENDIX I}

\section{ANOVA Tables Associated with Chapter 4 Statistical Analysis}

\section{Summer Cage Trial}

Appendix Table 1. Analysis of variance for number of WFT found on plants in a summer greenhouse under two mite treatments and a no-mite control.

\begin{tabular}{ccccrr}
\hline Source & df & $\begin{array}{c}\text { Sum of } \\
\text { Squares }\end{array}$ & MS & F & P>F \\
\hline week & 3 & 34.2 & 11.4 & 6.00 & 0.0010 \\
mite treatment & 2 & 54.5 & 27.3 & 43.16 & $<0.0001$ \\
week*mite & 6 & 65.4 & 10.9 & 1.30 & 0.2661 \\
treatment & & & & & \\
\hline
\end{tabular}

Appendix Table 2. Analysis of variance for number of adult mites found on plants in a summer greenhouse.

\begin{tabular}{ccccrc}
\hline Source & df & $\begin{array}{c}\text { Sum of } \\
\text { Squares }\end{array}$ & MS & $\mathbf{F}$ & P>F \\
\hline Week & 3 & 43.7 & 14.6 & 5.55 & 0.0021 \\
Mite treatment & 1 & 45.3 & 45.3 & 10.92 & 0.0017 \\
Week*mite & 3 & 56.5 & 18.8 & 1.27 & 0.2944 \\
treatment & & & & & \\
\hline
\end{tabular}

\section{Winter Cage Trial}

Appendix Table 3. Analysis of variance for number of WFT found on plants in a winter greenhouse under two mite treatments and a no-mite control.

\begin{tabular}{ccccrr}
\hline Source & df & $\begin{array}{c}\text { Sum of } \\
\text { Squares }\end{array}$ & MS & $\mathbf{F}$ & P $>\mathbf{F}$ \\
\hline Week & 3 & 45.3 & 15.1 & 12.72 & $<0.0001$ \\
Mite treatment & 2 & 23.6 & 11.8 & 46.70 & $<0.0001$ \\
Week ${ }^{*}$ mite & 6 & 24.6 & 4.1 & 1.17 & 0.3334 \\
treatment & & & & & \\
\hline
\end{tabular}

Appendix Table 4. Analysis of variance for number of adult mites found on plants in a winter greenhouse.

\begin{tabular}{cccccc}
\hline Source & df & $\begin{array}{c}\text { Sum of } \\
\text { Squares }\end{array}$ & MS & F & P>F \\
\hline Week & 3 & 32.4 & 10.8 & 6.49 & 0.0008 \\
Mite treatment & 1 & 26.4 & 26.4 & 1.05 & 0.3098 \\
$\begin{array}{c}\text { Week } \\
\text { treatmite }\end{array}$ & 3 & 76.4 & 25.5 & 0.36 & 0.7824 \\
\hline
\end{tabular}




\section{Summer Leaf Damage}

Appendix Table 5. Analysis of variance for number of heavily damaged leaves found on plants in a summer greenhouse under two mite treatments and a no-mite control.

\begin{tabular}{ccccrc}
\hline Source & df & $\begin{array}{c}\text { Sum of } \\
\text { Squares }\end{array}$ & MS & F-value & P>F \\
\hline Week & 3 & 35.7 & 11.9 & 33.85 & $<0.0001$ \\
Mite treatment & 2 & 82.6 & 41.3 & 79.53 & $<0.0001$ \\
Week ${ }^{\star}$ mite & 6 & 72.5 & 12.1 & 9.84 & $<0.0001$ \\
treatment & & & & & \\
\hline
\end{tabular}

Appendix Table 6. Analysis of variance for number of lightly damaged leaves found on plants in a summer greenhouse under two mite treatments and a no-mite control.

\begin{tabular}{cccrrr}
\hline Source & df & $\begin{array}{c}\text { Sum of } \\
\text { Squares }\end{array}$ & \multicolumn{1}{c}{ MS } & F-value & P>F \\
\hline Week & 3 & 26.4 & 8.8 & 2.86 & 0.0501 \\
Mite treatment & 2 & 27.5 & 13.8 & 2.53 & 0.0941 \\
Week ${ }^{\star}$ mite & 6 & 75.4 & 12.6 & 3.33 & 0.0103 \\
treatment & & & & & \\
\hline
\end{tabular}

Appendix Table 7. Analysis of variance for number of leaves with no visible damage found on plants in a summer greenhouse under two mite treatments and a nomite control.

\begin{tabular}{ccccrr}
\hline Source & df & $\begin{array}{c}\text { Sum of } \\
\text { Squares }\end{array}$ & MS & F-value & P >F \\
\hline Week & 3 & 37.5 & 12.5 & 21.16 & $<0.0001$ \\
Mite treatment & 2 & 87.2 & 43.6 & 42.24 & $<0.0001$ \\
Week ${ }^{*}$ mite & 6 & 85.2 & 14.2 & 5.17 & 0.0006 \\
treatment & & & & & \\
\hline
\end{tabular}

\section{Winter Leaf Damage}

Appendix Table 8. Analysis of variance for number of heavily damaged leaves found on plants in a winter greenhouse under two mite treatments and a no-mite control.

\begin{tabular}{cccccr}
\hline Source & df & $\begin{array}{c}\text { Sum of } \\
\text { Squares }\end{array}$ & MS & F & P>F \\
\hline Week & 3 & 37.6 & 12.5 & 8.70 & $<0.0001$ \\
Mite treatment & 2 & 76.4 & 38.2 & 9.23 & 0.0002 \\
Week*mite & 6 & 87.4 & 14.6 & 1.33 & 0.2515 \\
treatment & & & & & \\
\hline
\end{tabular}


Appendix Table 9. Analysis of variance for number of lightly damaged leaves found on plants in a winter greenhouse under two mite treatments and a no-mite control.

\begin{tabular}{cccccr}
\hline Source & df & $\begin{array}{c}\text { Sum of } \\
\text { Squares }\end{array}$ & MS & F & P>F \\
\hline Week & 3 & 76.3 & 25.4 & 7.67 & 0.0001 \\
Mite treatment & 2 & 76.2 & 38.1 & 6.28 & 0.0029 \\
Week*mite & 6 & 23.6 & 3.9 & 6.21 & $<0.0001$ \\
treatment & & & & & \\
\hline
\end{tabular}

Appendix Table 10. Analysis of variance for number of leaves with no visible damage on leaves found on plants in a winter greenhouse under two mite treatments and a no-mite control.

\begin{tabular}{cccrrr}
\hline Source & df & $\begin{array}{c}\text { Sum of } \\
\text { Squares }\end{array}$ & MS & F & P>F \\
\hline Week & 3 & 87.3 & 29.1 & 17.79 & $<0.0001$ \\
Mite treatment & 2 & 47.3 & 23.7 & 15.69 & $<0.0001$ \\
Week*mite & 6 & 57.3 & 9.6 & 5.60 & $<0.0001$ \\
treatment & & & & & \\
\hline
\end{tabular}

\section{Summer Commercial Greenhouse Trials}

Appendix Table 11. Analysis of variance for number of WFT found on plants in a summer commercial greenhouse under two mite treatments and a no-mite control.

\begin{tabular}{cccrrr}
\hline Source & df & $\begin{array}{c}\text { Sum of } \\
\text { Squares }\end{array}$ & MS & F & P>F \\
\hline Week & 5 & 473.4 & 94.7 & 21.58 & $<0.0001$ \\
Mite treatment & 2 & 276.6 & 138.3 & 28.61 & $<0.0001$ \\
Repetition & 3 & 784.3 & 261.4 & 0.00 & \\
Week*mite & 10 & 473.6 & 47.4 & 13.15 & $<0.0001$ \\
treatment & & & & & \\
\hline
\end{tabular}

Appendix Table 12. Analysis of variance for number of adult mites found on plants in a summer commercial greenhouse under two mite treatments and a no-mite control.

\begin{tabular}{cccrrr}
\hline Source & df & $\begin{array}{c}\text { Sum of } \\
\text { Squares }\end{array}$ & MS & $\mathbf{F}$ & P $>\mathbf{F}$ \\
\hline Week & 5 & 435.7 & 87.1 & 26.89 & $<0.0001$ \\
Mite treatment & 1 & 549.8 & 549.8 & 41.08 & $<0.0001$ \\
Repetition & 3 & 478.3 & 159.4 & 0.00 & \\
Week ${ }^{*}$ mite & 5 & 589.4 & 11.7 & 3.52 & 0.0051 \\
treatment & & & & & \\
\hline
\end{tabular}




\section{Winter Commercial Greenhouse Trials}

Appendix Table 13. Analysis of variance for number of WFT found on plants in a winter commercial greenhouse under two mite treatments and a no-mite control.

\begin{tabular}{cccrrr}
\hline Source & df & $\begin{array}{c}\text { Sum of } \\
\text { Squares }\end{array}$ & MS & $\mathbf{F}$ & P>F \\
\hline Week & 5 & 384.7 & 76.9 & 2.80 & 0.0186 \\
Mite treatment & 2 & 587.5 & 293.8 & 0.30 & 0.7431 \\
Repetition & 3 & 374.4 & 124.8 & 1.80 & \\
Week ${ }^{*}$ mite & 10 & 587.4 & 58.7 & 0.82 & 0.6090 \\
treatment & & & & & \\
\hline
\end{tabular}

Appendix Table 14. Analysis of variance for number of adult mites found on plants in a winter commercial greenhouse under two mite treatments and a no-mite control.

\begin{tabular}{|c|c|c|c|c|c|}
\hline Source & df & $\begin{array}{c}\text { Sum of } \\
\text { Squares }\end{array}$ & MS & $F$ & $\mathrm{P}>\mathrm{F}$ \\
\hline Week & 5 & 373.6 & 74.7 & 11.83 & $<0.0001$ \\
\hline Mite treatment & 1 & 487.3 & 487.3 & 3.81 & 0.0533 \\
\hline Repetition & 3 & 784.7 & 261.6 & 1.38 & \\
\hline $\begin{array}{c}\text { Week*mite } \\
\text { treatment }\end{array}$ & 5 & 584.7 & 116.9 & 12.22 & $<0.0001$ \\
\hline
\end{tabular}

